University of South Florida

DIGITAL COMMONS

@ UNIVERSITY OF SOUTH FLORIDA
Digital Commons @ University of South Florida

$12-1-2001$

\title{
Pedestrian Mid-block Crossing Difficulty
}

CUTR

Follow this and additional works at: https://digitalcommons.usf.edu/cutr_nctr

\section{Scholar Commons Citation}

CUTR, "Pedestrian Mid-block Crossing Difficulty" (2001). Research Reports. 192.

https://digitalcommons.usf.edu/cutr_nctr/192

This Technical Report is brought to you for free and open access by the National Center for Transit Research (NCTR) Archive (2000-2020) at Digital Commons @ University of South Florida. It has been accepted for inclusion in Research Reports by an authorized administrator of Digital Commons @ University of South Florida. For more information, please contact digitalcommons@usf.edu. 
Pedestrian Mid-block Crossing Difficulty

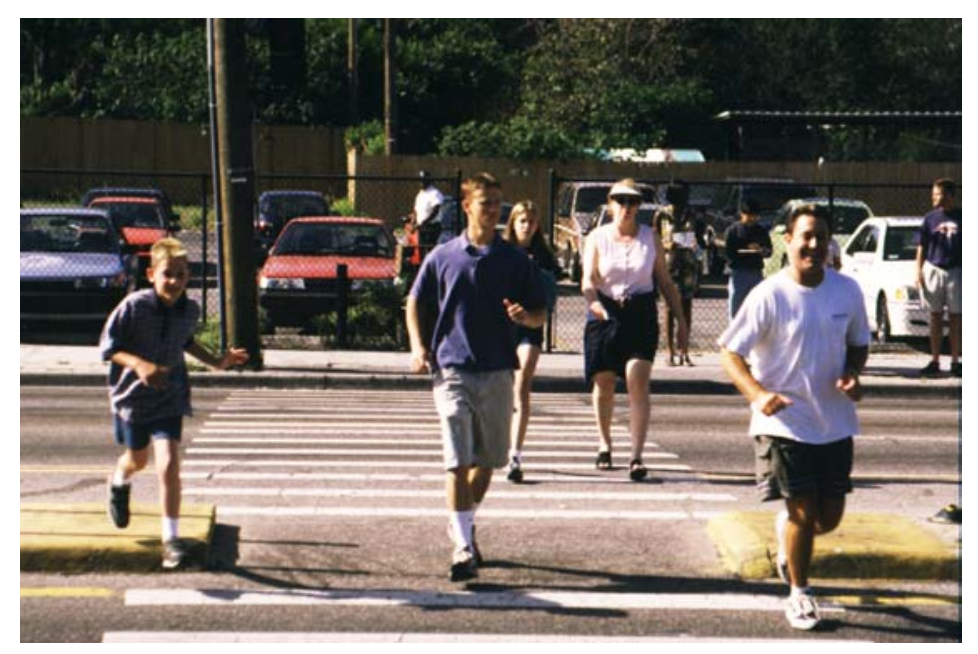

Final Report 
TECHNICAL REPORT STANDARD TITLE PAGE

\begin{tabular}{|c|c|c|c|}
\hline $\begin{array}{l}\text { 1. Report No. } \\
\text { NCTR-392-09 }\end{array}$ & 2. Government Accession No. & \multicolumn{2}{|c|}{ 3. Recipient's Catalog No. } \\
\hline \multirow{2}{*}{\multicolumn{2}{|c|}{$\begin{array}{l}\text { 4. Title and Subtitle } \\
\text { Pedestrian Mid-block Crossing Difficulty }\end{array}$}} & \multicolumn{2}{|c|}{$\begin{array}{l}\text { 5. Report Date } \\
\text { December } 2001\end{array}$} \\
\hline & & \multicolumn{2}{|c|}{ 6. Performing Organization Code } \\
\hline \multicolumn{2}{|l|}{$\begin{array}{l}\text { 7. Author(s) } \\
\text { Xuehao Chu and Michael R. Baltes }\end{array}$} & \multicolumn{2}{|c|}{ 8. Performing Organization Report No. } \\
\hline \multirow{2}{*}{\multicolumn{2}{|c|}{$\begin{array}{l}\text { 9. Performing Organization Name and Address } \\
\text { National Center for Transit Research (NCTR) } \\
\text { University of South Florida } \\
4202 \text { E Fowler Av, CUT 100, Tampa, FL 33620-5375 }\end{array}$}} & \multicolumn{2}{|l|}{ 10. Work Unit No. } \\
\hline & & \multicolumn{2}{|c|}{$\begin{array}{l}\text { 11. Contract or Grant No. } \\
\text { DTRS98-G-0032 }\end{array}$} \\
\hline \multicolumn{2}{|c|}{$\begin{array}{l}\text { 12. Sponsoring Agency Name and Address } \\
\text { Office of Research and Special Programs } \\
\text { U.S. Department of Transportation, Washington, D.C. } 20590\end{array}$} & \multicolumn{2}{|c|}{ 13. Type of Report and Period Covered } \\
\hline \multicolumn{2}{|c|}{$\begin{array}{l}\text { Florida Department of Transportation } \\
605 \text { Suwannee Street, MS 26, Tallahassee, FL } 32399\end{array}$} & \multicolumn{2}{|c|}{ 14. Sponsoring Agency Code } \\
\hline \multicolumn{4}{|c|}{$\begin{array}{l}\text { 15. Supplementary Notes } \\
\text { Supported by a grant from the Florida Department of Transportation and the U.S. Department of Transportation }\end{array}$} \\
\hline \multicolumn{4}{|c|}{$\begin{array}{l}\text { 16. Abstract } \\
\text { This report documents a research project that developed a model of mid-block crossing difficulty as perceived by } \\
\text { pedestrians. Four aspects of the research are reported: research design issues, selection of potential determinants, } \\
\text { data collection, and statistical analysis. This model was done through a statistical calibration and validation process } \\
\text { involving collecting actual site characteristics and stated levels of crossing difficulty by a sample of persons at a sample } \\
\text { of sites from Hillsborough and Pinellas Counties in Florida. } \\
\text { For traffic operations applications, this model may be used as a screening tool to determine whether pedestrian mid- } \\
\text { block crossing facilities, such as crosswalks or pedestrian signals, may be needed at particular locations. For planning } \\
\text { purposes, this model has a number of applications: 1) It can be used as a measure of effectiveness for determining } \\
\text { pedestrian level of service for mid-block crossing; } 2 \text { ) It could potentially be combined with those for pedestrian level of } \\
\text { service for walking along a roadway segment and for crossing at intersections to determine the overall pedestrian level } \\
\text { of service for an entire roadway segment; and 3) This overall level of service at the segment-level could then be used } \\
\text { as a direct input into transit level of service methodologies that take into account pedestrian street-crossing difficulty. }\end{array}$} \\
\hline $\begin{array}{l}\text { 17. Key Words } \\
\text { Pedestrian, street crossing, mid-block, } \\
\text { crossing difficulty, level of service, } \\
\text { measure of effectiveness, transit }\end{array}$ & $\begin{array}{l}\text { 18. Distribution Statement } \\
\text { Available to the public } \\
\text { (NTIS), } 5285 \text { Port Ro } \\
\text { through the NCTR we }\end{array}$ & $\begin{array}{l}\text { lational Techn } \\
\text { igfield, VA } 22 \\
\text { ww.nctr.usf.e }\end{array}$ & $\begin{array}{l}\text { nation Service } \\
487-465, \text { and }\end{array}$ \\
\hline $\begin{array}{l}\text { 19. Security Classif. (of this report) } \\
\text { Unclassified }\end{array}$ & $\begin{array}{l}\text { 20. Security Classif. (of this page) } \\
\text { Unclassified }\end{array}$ & $\begin{array}{l}\text { 21. No. of pages } \\
79 \text { (without } \\
\text { appendices) }\end{array}$ & 22. Price \\
\hline
\end{tabular}




\title{
RESEARCH TEAM
}

Principal Investigators:

Xuehao Chu

Michael R. Baltes

Reviewers:

Francis Cleland

Chris Hagelin

Ed Mierzejewski

Steve Polzin

\section{Bus Transportation:}

Rob Gregg

\author{
Video Equipment: \\ Dennis Hinebaugh \\ Laurel Land \\ Steve Polzin \\ Joel Rey \\ Brenda Thompson \\ Surveys: \\ Brandi Bartolomeo \\ Martin Catala \\ Francis Cleland \\ David King \\ Mark Mistretta \\ Bill Williams
}




\section{ACKNOWLEDGEMENT}

Many people and organizations provided assistance to the research team. This research project would not have been successfully completed without their assistance.

City of St. Pete: We thank Michael Fredrick for providing information on street blocks with mid-block crosswalks or pedestrian signals and for providing traffic counter services.

Committees: We thank members of the project Advisory Committee for guidance throughout the research. We also thank members of the Department's Multimodal LOS Steering Committee for comments on the research during two presentations made to the Committee.

Florida Department of Transportation: We want to thank Martin Guttenplan, the FDOT Project Manager, for his continuing support. We also thank Dave Blodgett, Doug McLeod, and Theo Petritsch for comments on different versions of the issue paper. We also thank Dwight Danley and his staff of the Department's District Seven for providing the traffic counter services. We also would like to thank the Planning Office of District Seven for providing RCI files.

HARTLine: We thank Ronald Beavers, Greg Brigham, Sharon Dent, Dennis Lisiak, Aldo Marisco, Ralph Lavado, Shirley Odenweller, Toni Short, and Phyllis Turner for assistance in providing bus transportation.

PSTA: We thank Bruce Gralow, Crystal Roundtree, Denise Skinner, Harold Spring, and Roger Sweeney for assistance in providing bus transportation.

University of Florida: We want to thank Dr. Crider for comments on the various versions of the issue paper and for direct assistance in conducting the field surveys.

This report was prepared in cooperation with the State of Florida Department of Transportation and the U.S. Department of Transportation. The opinions, findings and conclusions expressed in this publication are those of the authors and not necessarily those of the Department of Transportation or the U.S. Department of Transportation. 


\section{TABLE OF CONTENTS}

RESEARCH TEAM

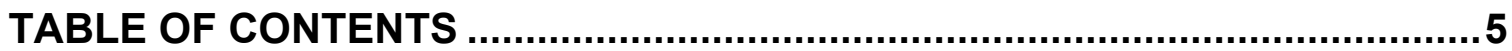

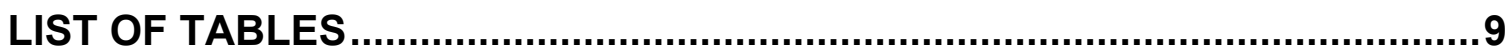

LIST OF FIGURES

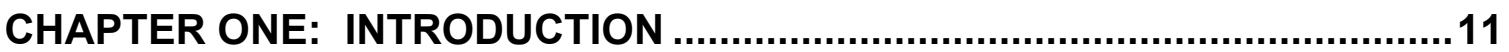

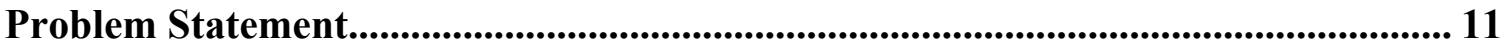

Project Objectives ............................................................................................................................. 11

Project Approach ........................................................................................................................ 12

Report Organization .................................................................................................................... 12

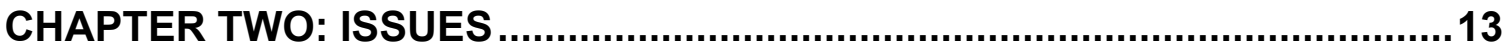

Basic Concepts....................................................................................................................... 13

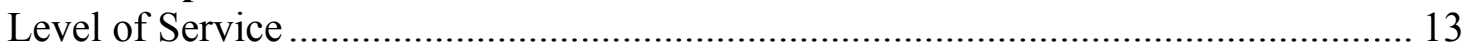

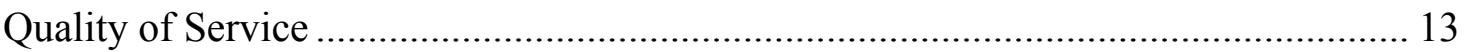

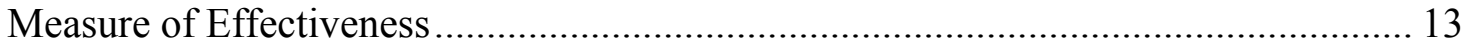

Legal Issues ........................................................................................................................... 14

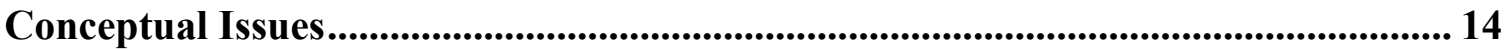

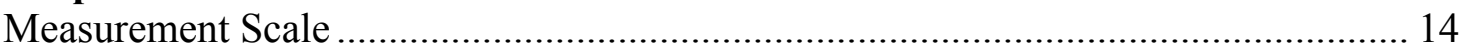

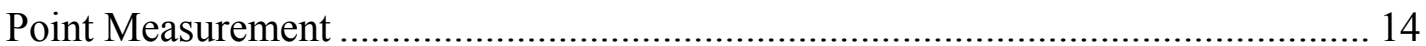

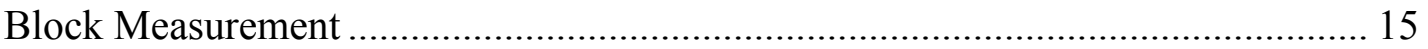

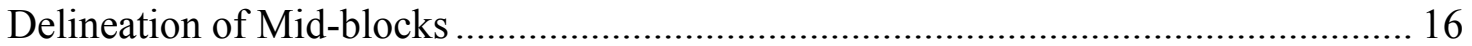

Subjective versus Objective Measures of Effectiveness............................................... 16

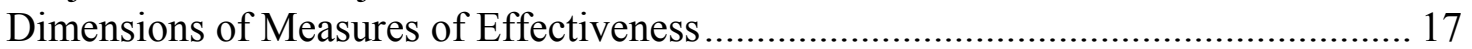

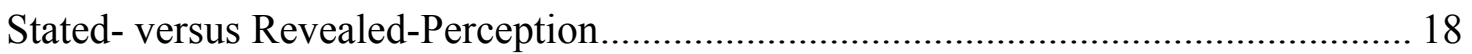

Perceived Quality of Service vs. Perceived Level of Service...................................... 18

Data-Collection Issues .............................................................................................................. 19

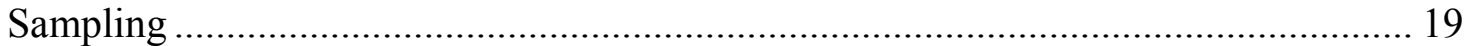

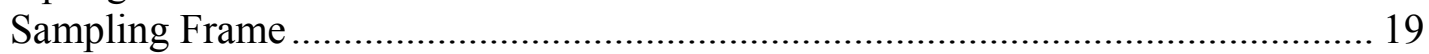




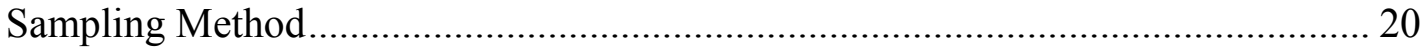

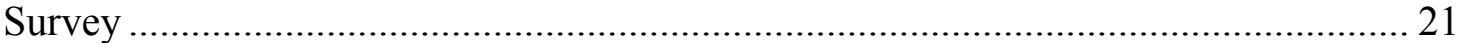

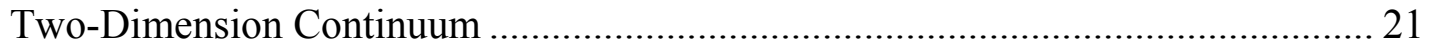

Mail-back Survey with Real Pedestrians ............................................................ 21

Field Observation with Real Pedestrians ......................................................... 22

Field Survey with General Public ........................................................................ 22

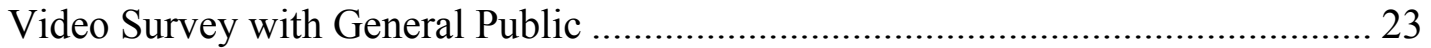

Observational Duration................................................................................ 23

Collecting Site Characteristics .......................................................................... 24

Calibration Issues.............................................................................................................. 24

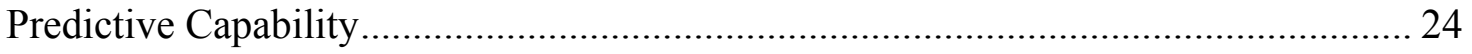

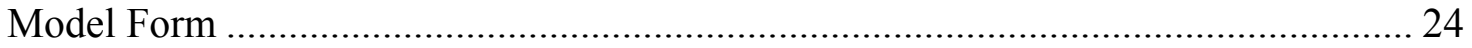

Approach to Relationship Establishment .................................................................. 25

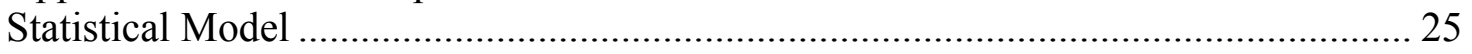

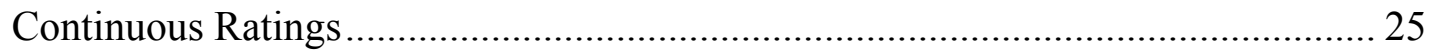

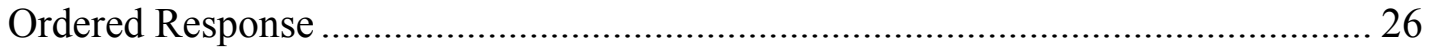

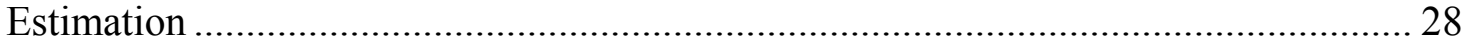

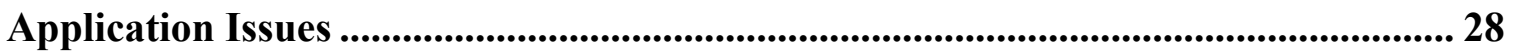

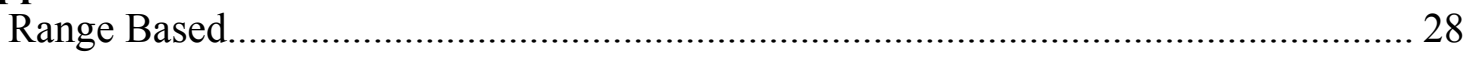

Distribution Based .................................................................................................. 29

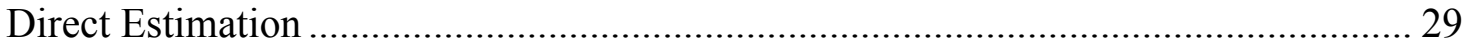

CHAPTER THREE: SELECTION OF DETERMINANTS ................................30

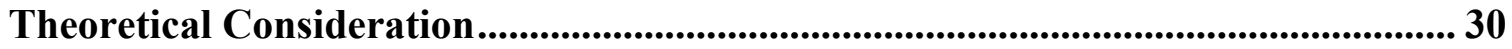

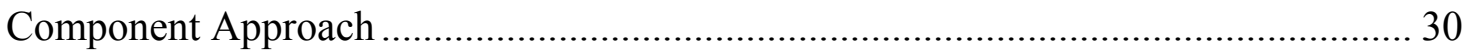

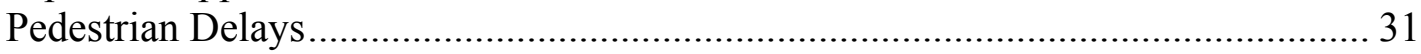

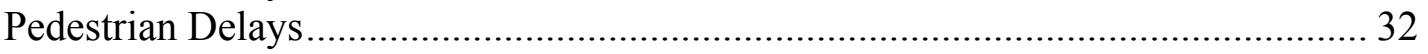

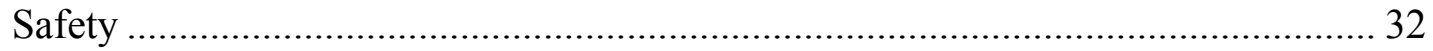

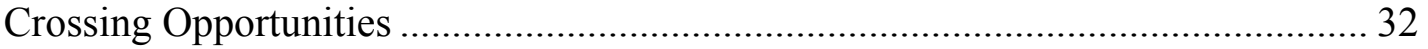

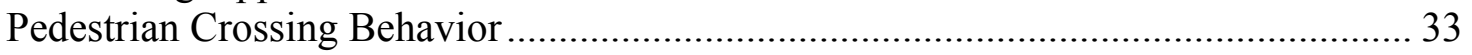

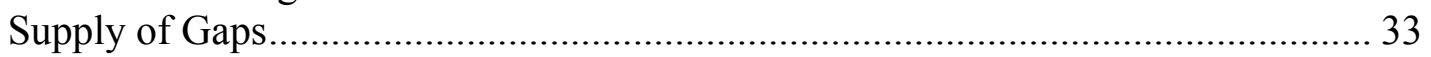

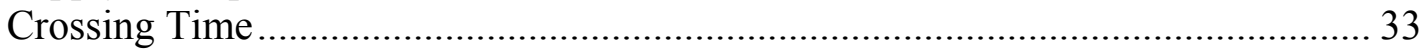

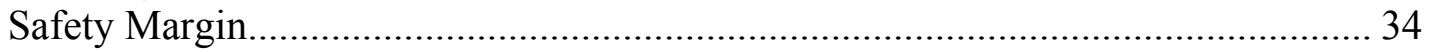

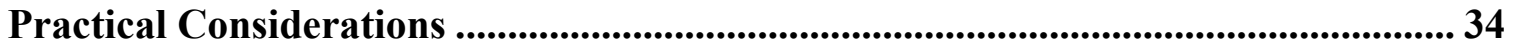

CHAPTER FOUR: DATA COLLECTION ....................................................36

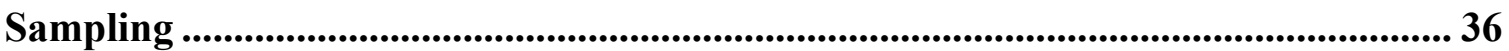

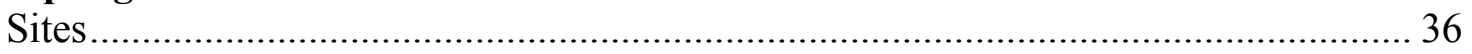

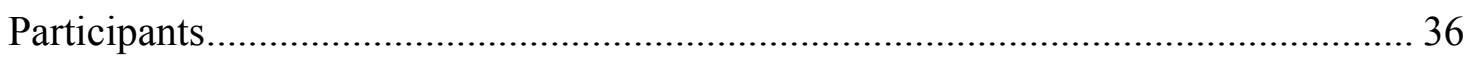

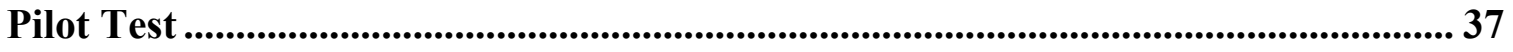




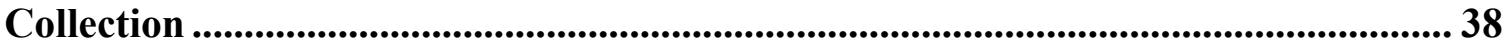

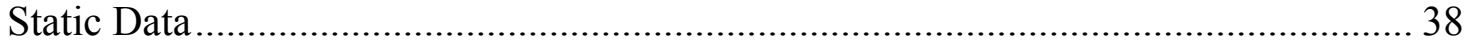

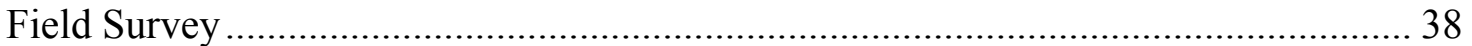

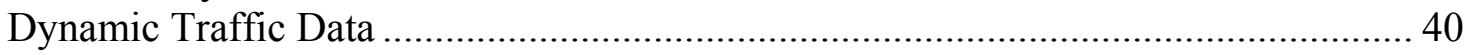

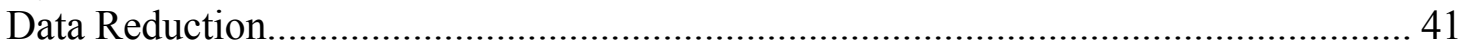

CHAPTER FIVE: STATISTICAL ANALYSIS ..............................................43

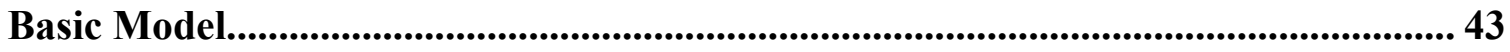

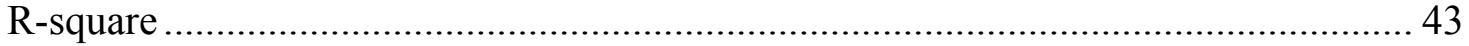

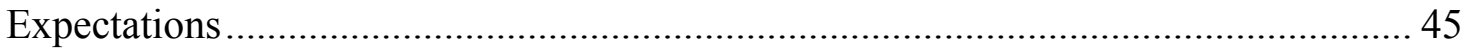

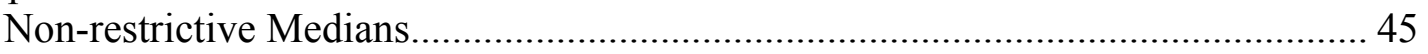

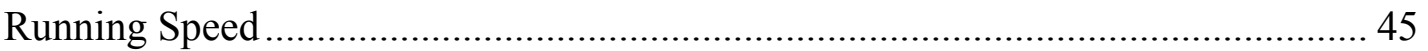

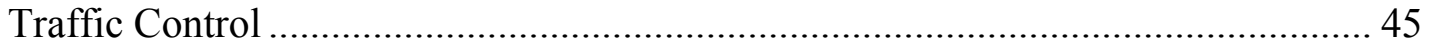

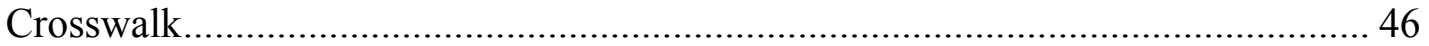

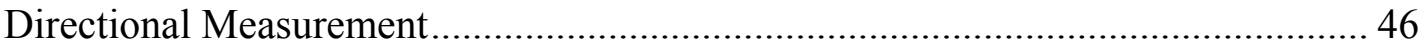

Ambiguous Variables...................................................................................... 46

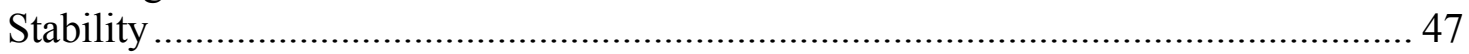

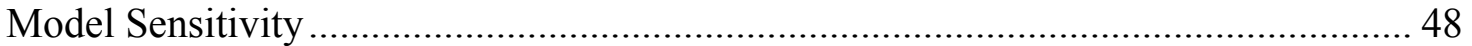

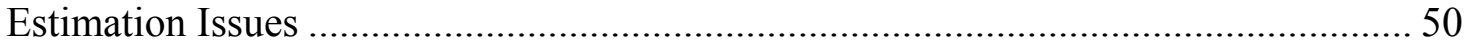

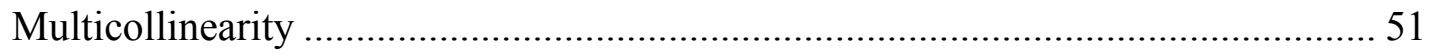

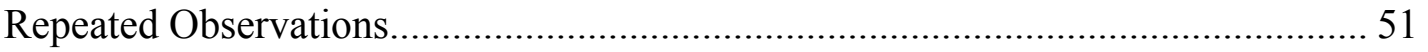

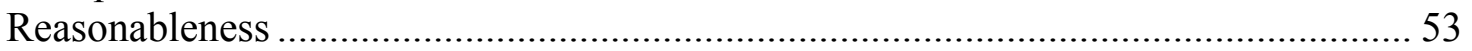

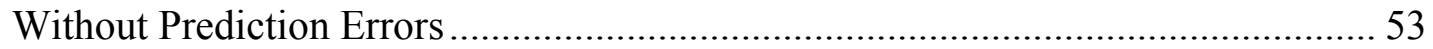

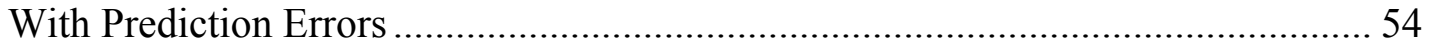

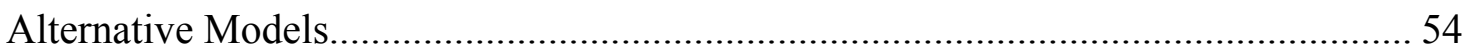

Non-linear Form............................................................................................ 54

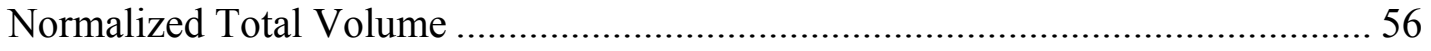

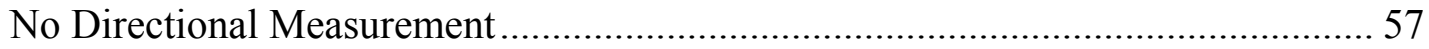

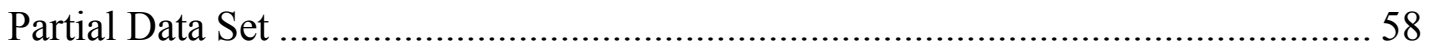

CHAPTER SIX: LESSONS LEARNED ....................................................60

What Worked Well ........................................................................................................6 60

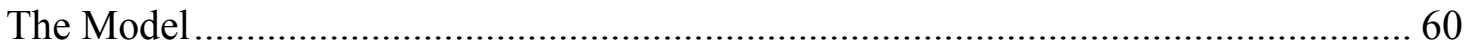

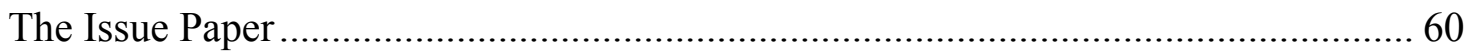

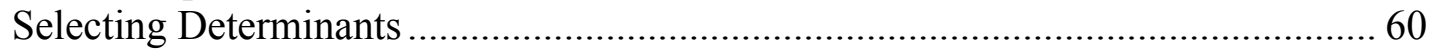

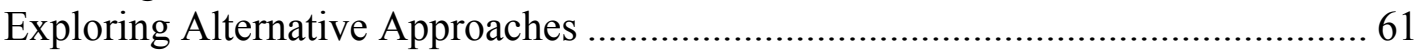

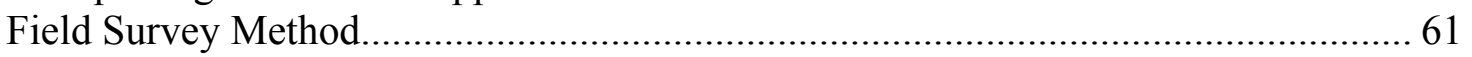

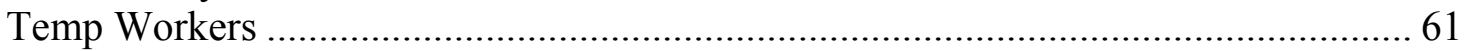

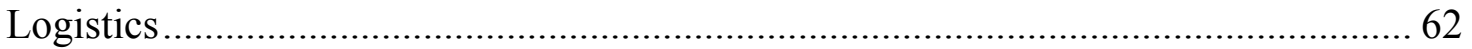

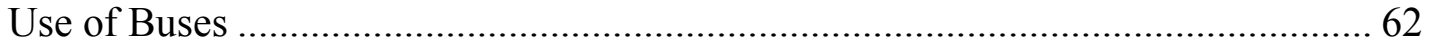

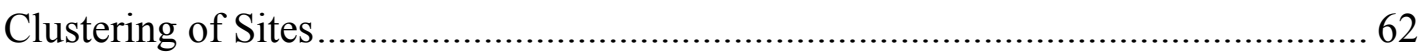

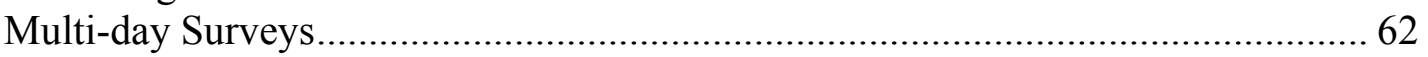

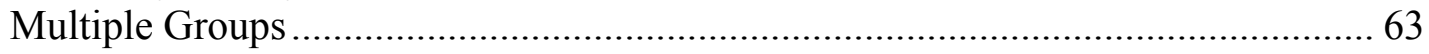




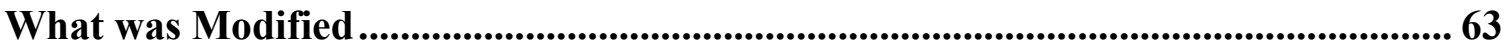

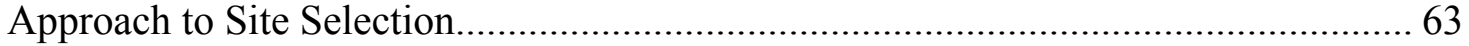

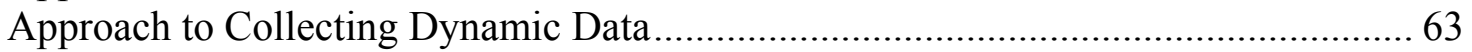

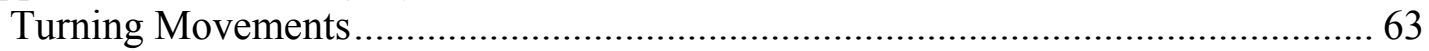

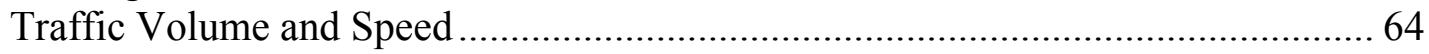

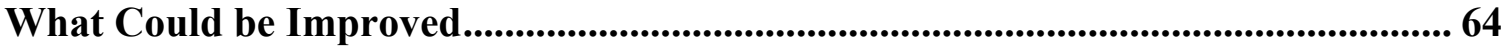

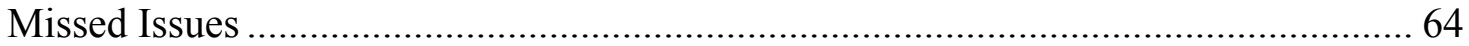

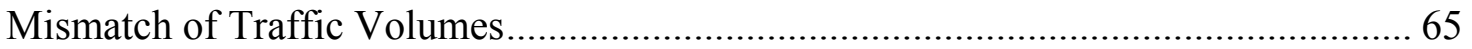

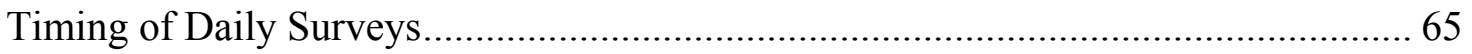

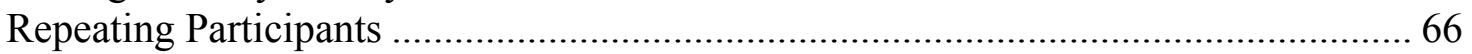

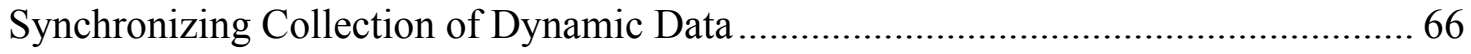

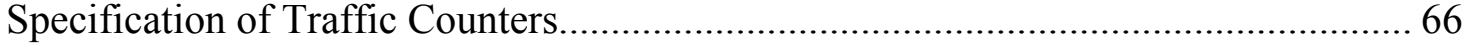

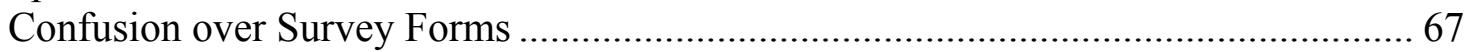

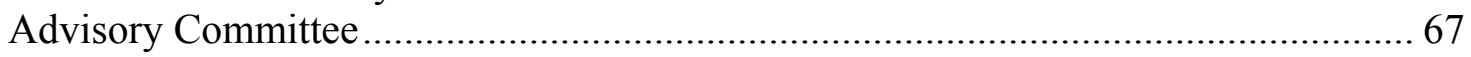

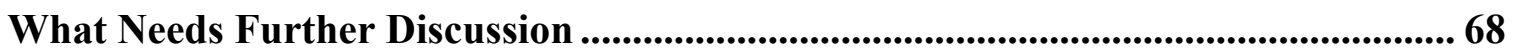

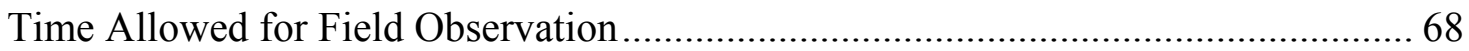

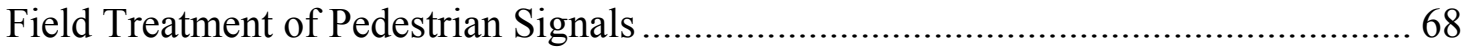

What Needs Further Research .............................................................................68

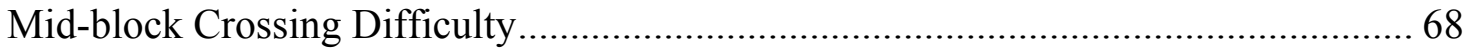

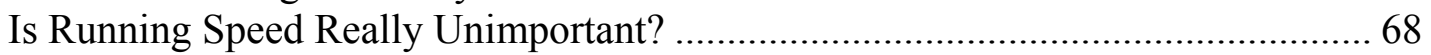

Do Wider Painted Medians Make Crossing More Difficult? .................................. 69

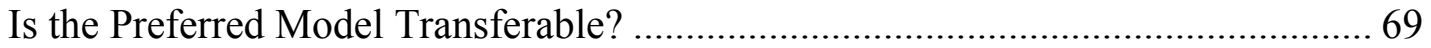

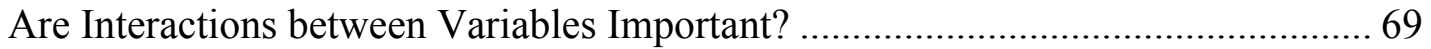

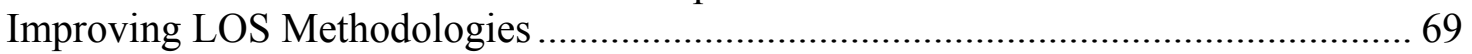

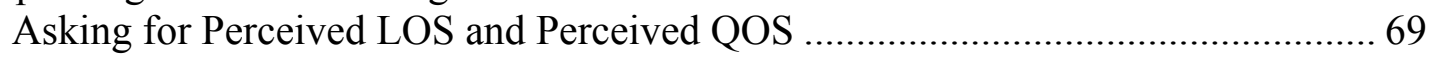

Differences Between Stated and Revealed Perception ....................................... 70

Continuous and Ordered-Response Modeling ................................................... 70

LOS Conversion With Arbitrary Versus Estimated Ranges.................................... 70

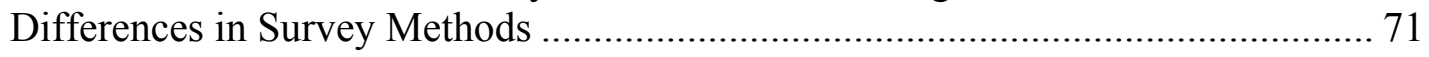

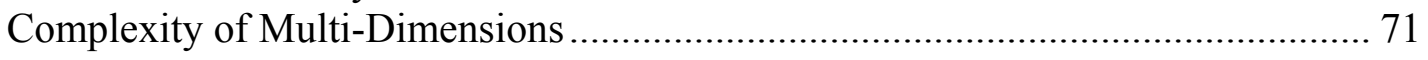

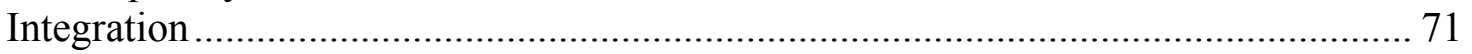

CHAPTER SEVEN: MODEL APPLICATION ................................................72

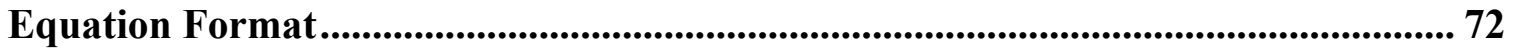

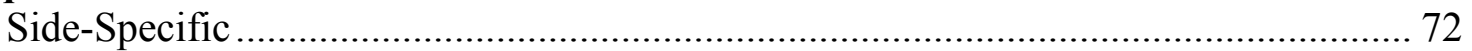

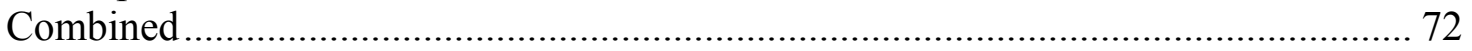

Example Calculations ................................................................................................. 73

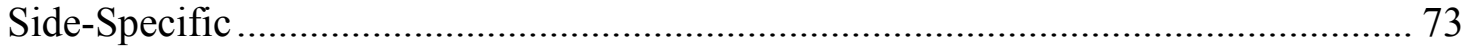

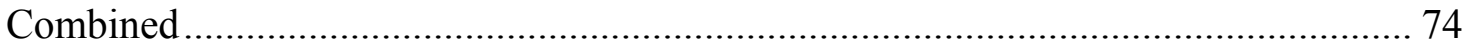

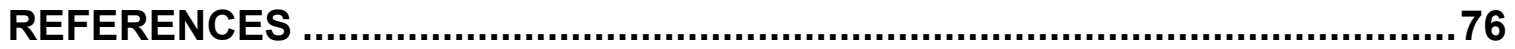




\section{LIST OF TABLES}

Table 1. Two-Dimension Continuum of Survey Methods........................................... 21

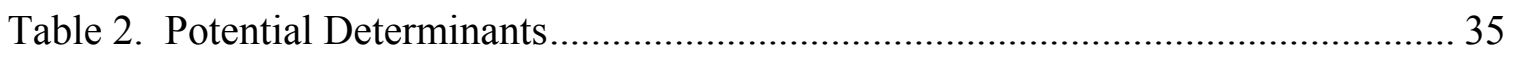

Table 3. Stated Difficulty Levels by Age and Gender of the Full Sample ..................... 42

Table 4. Selected Statistics of Explanatory Variables for the Full Sample .................... 42

Table 5. Basic Model with Full Sample........................................................................ 44

Table 6. Models Including One Characteristic Group ................................................. 47

Table 7. Models Excluding One Characteristic Group................................................ 48

Table 8. Adjustment of t-statistics for Repeated Observations.................................... 52

Table 9. Comparing Predicted and Observed Difficulty and LOS .............................. 53

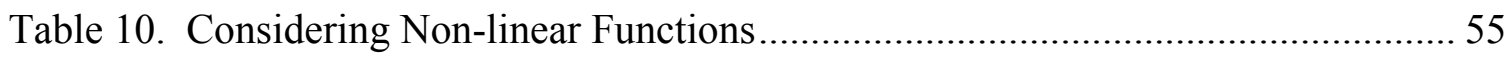

Table 11. Non-Linear Effects of Selected Explanatory Variables on Crossing

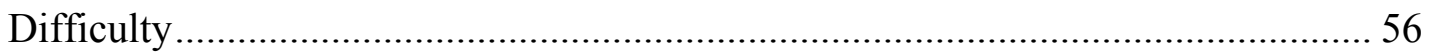

Table 12. Considering Normalized Total Volume.................................................... 57

Table 13. Considering Non-Directional Measurement ............................................. 58

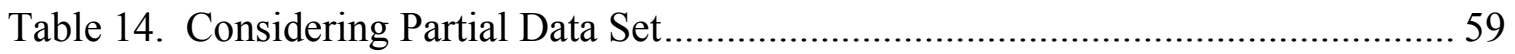

Table 15. Illustration of Side-Specific Model............................................................ 74

Table 16. Illustration of Combined Model ............................................................... 75 


\section{LIST OF FIGURES}

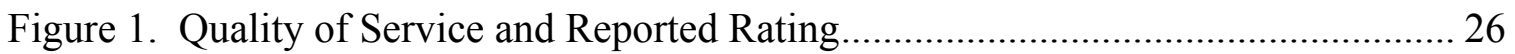

Figure 2. Calibrating Pedestrian Quality of Service Model............................................ 27

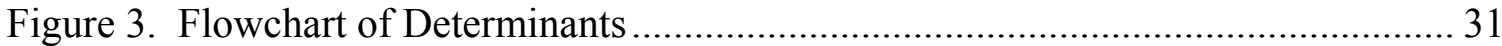

Figure 4. Form for Collecting Roadway and Control Characteristics ............................. 37

Figure 5. Field-Survey Form.................................................................................... 39

Figure 6. Data Form for Turning Movements ………….............................................. 41

Figure 7. Spreadsheet on Sensitivity of Basic Model ..................................................... 49 


\section{Chapter One: INTRODUCTION}

\section{Problem Statement}

As part of the State match to the Second and Third Year Programs of the National Center for Transit Research (NCTR) at the Center for Urban Transportation Research (CUTR), the Systems Planning Office of the Florida Department of Transportation (FDOT) initiated a research project to develop a pedestrian level of service methodology for midblock crossings.

This project is part of the Department's Multimodal Quality of Service Program. The purpose of this program is to improve the methodologies contained in ART_PLAN so that they can be used to evaluate arterial level of service from a multi-modal perspective. This program was motivated by two factors. At the national level, the Transportation Equity Act for the $21^{\text {st }}$ Century (TEA-21) and the Inter-modal Surface Transportation Efficiency Act of 1991 (ISTEA) have led to a national desire to know the levels of service for automobile users as well as for transit users, pedestrians, and bicyclists. At the state level, the Florida legislature passed the Urban Infill and Redevelopment Act, requiring the local governments use professionally accepted methodologies for measuring Multi-modal level of service and that FDOT develop these methodologies and provide technical assistance in their applications.

The FDOT has already developed or adopted methodologies for evaluating transit level of service, bicycle level of service for riding along roadways, pedestrian level of service for walking along roadways. Currently, there are no known methodologies for evaluating pedestrian level of service for street crossing at either mid-block locations or intersections.

\section{Project Objectives}

The research project is aimed at developing a pedestrian level of service methodology for street crossing at mid-block locations. This methodology is capable of providing a measure of effectiveness that indicates pedestrians' perceived quality of service in crossing roads at mid-block locations. This measure of effectiveness can then be converted to a level of service designation. This methodology should be generally consistent with other level of service methodologies being developing as part of the FDOT's Multimodal Quality of Service Program. The study will attempt to determine what variables are correlated with pedestrians' perceived quality of service for mid-block crossing. This will be done through a statistical calibration and validation process involving collecting actual site characteristics and stated levels of quality of service by a sample of persons at a sample of sites. These variables will include those that are most important to the FDOT and local governments for the purpose of improving pedestrian mobility, safety, and livability. 


\section{Project Approach}

The overall project was carried out in two phases with an iterative approach.

The first phase had two major objectives: 1) to explore the alternative approaches to dealing with various issues involved in developing such a model and 2) to form an initial research design for model development. The result of the first phase is documented in an issue paper (CUTR, 2001). The objective of the second phase was to carry out the research design, including data collection and model estimation.

The final research design was refined over several iterative steps. In step one, a preliminary research design was first formed by the research team and reported in a draft version of the issue paper in September 2000. In step two, the draft issue paper was then sent to an Advisory Committee of the project for review and comments. These comments were used in revising the preliminary research design and forming an initial research design. This initial research design was reported in the final version of the issue paper in February 2001 (CUTR, 2001). As noted above, this is a major outcome of the first phase. This initial research design was further refined in two additional steps in the second phase. In step three, a pilot field survey was carried out in March 2001. The initial research design was revised with the lessons learned from this pilot. In step four, further refinements were made to the revised research design after the first field survey of a total of three surveys. These refinements over several iterations were necessary because several issues were left out of the issue paper from the first phase.

It is important to point out that one guiding principal of this iterative process of research design was to maintain consistency, whenever possible, with the approaches that were taken for the already developed pedestrian and bicyclist level of service measures. Among the various issues explored in the first phase, some of them are unique to this particular project, while others are common to research efforts in developing other level of service methodologies that are based on user perception. This guiding principal applied mainly to the common issues.

\section{Report Organization}

This final report documents the overall research project. The rest of the report is organized as follows. Chapters Two and Three cover the first phase, including the issues explored and the determinants selected. Chapters Four and Five cover the second phase, including data collection and statistical analysis. Chapter Six draws lessons learned from both phases of the research project. The last chapter gives model formats for applications. 


\section{Chapter Two: ISSUES}

This chapter describes approaches to dealing with issues in developing a pedestrian level of service methodology for mid-block street crossing. This potential methodology contains two components. One is a relationship between pedestrian quality of service for mid-block street crossing and a set of geometric and operational conditions as its determinants. This relationship can be used to determine the pedestrian quality of service for any particular roadway block. The other component is a mechanism to convert the determined quality of service to a particular level of service designation. The issues examined here are related to a variety of steps in developing the methodology. These include the legality of mid-block crossing, conceptual issues, issues about the collection of data, model-calibration issues, and issues related to the conversion mechanism. Much of the discussion is based on the issue paper from the first phase (CUTR, 2001).

\section{Basic Concepts}

Several concepts are fundamental to this overall research projects. These include level of service, quality of service, and measure of effectiveness.

\section{Level of Service}

Following the 1997 update of the Highway Capacity Manual (TRB, 1998), levels of service are qualitative indicators that characterize operational conditions of a facility or service, and users' perception of these conditions. The descriptions of individual levels of service characterize these conditions in terms of several aspects. For the automobile mode, for example, these aspects include speed and travel time, freedom to maneuver, traffic interruptions, comfort and convenience, and safety.

\section{Quality of Service}

Quality of service is seen as a quantitative indicator of the operational conditions of a facility or service, and users' perception of these conditions. In contrast, levels of service are qualitative indicators of such conditions and perceptions. Levels of service are defined on the basis of a quality of service indicator that best describe the operating conditions of a facility or service.

\section{Measure of Effectiveness}

Qualities of service are represented by one or more measures of effectiveness. The selected measures of effectiveness represent available measures best describing qualities of service for each facility or service. Levels of service are determined by breaking down the quality of service as quantified by a selected measure of effectiveness into six letter designations, with A describing the highest range of quality and F describing the lowest range of quality. Each level of service represents a range of operational conditions, as defined by a range in the measure of effectiveness selected. 


\section{Legal Issues}

As pointed out earlier in the background chapter, whether mid-block crossing is legal depends on the presence of mid-block crosswalks and whether the mid-block is signalized at both intersections. If both intersections are signalized, mid-block crossing is legal within a crosswalk but illegal outside a crosswalk, regardless of how long this midblock is. On the other hand, if one or neither intersection is signalized, mid-block crossing is legal, with or without a crosswalk, as long as one crosses the street at right angles and yields to motor vehicles.

This project was not limited to legal mid-block crossings. Limiting to legal mid-block crossings will significantly reduce the universe of sites for inclusion in this project. From a research point of view, not limiting to legal mid-block crossings does not create any problem if project participants do not actually cross any streets as part of the project.

\section{Conceptual Issues}

Six conceptual issues are discussed here, including:

- Measurement scale

- Delineation of mid-blocks

- Subjective versus objective measures of effectiveness

- Dimension of measures of effectiveness

- Stated- versus revealed-perception

- Perceived quality of service versus perceived level of service

\section{Measurement Scale}

Pedestrian quality of service for mid-block crossing may be measured for a particular point in a mid-block or for the entire mid-block.

\section{Point Measurement}

The point measurement focuses on the quality of service for crossing at an isolated midblock point, regardless of whether alternative mid-block points may offer different levels of quality of service. With the point measurement it is relatively easier for a pedestrian to perceive the quality of service because they do not need to consider variations in quality of service across mid-block locations.

The point measurement may be a better reflection of pedestrian behavior. It is true that some people will look for the best crossing point on a block, including crossing at the two intersections. Most people, however, choose their crossing point under one of two scenarios. Under one scenario, the pedestrian reaches a mid-block location and just wants to go to the other side of the street. As a result, the pedestrian may cross the street where he or she is. Under another scenario, the pedestrian reaches a mid-block location 
and has to go to some place on the other side of the street. In that case, the pedestrian may start to walk in the direction of his or her destination and look for a crossing opportunity. As a result, the pedestrian may cross the street whenever such an opportunity exists. Under either scenario, they cross the street not by searching for the best point in terms of facility alone, rather they cross the street at the most convenient location.

One issue of concern with the point measurement is how the variation in cross-sectional characteristics in a given mid-block should be treated in applying the point measurement. Will a given mid-block have a single level of service for pedestrian crossing or multiple levels of service at its different locations of different cross-sectional characteristics? If a given mid-block is to have a single level of service, will that level of service be measured for any single point in the given mid-block? Or will that level of service be based on some weighted average of the predicted quality of service at its different locations with the cross-sectional characteristics used as the weights?

\section{Block Measurement}

The point measurement, on the other hand, takes into account all potential crossing points in a mid-block. The point measurement better fits the FDOT's Multi-modal Quality of Service Program. In this program, there is already a measure of pedestrian quality of service for walking along a particular roadway block. In addition, a measure of pedestrian quality of service in terms of crossing at intersections is being developed. A point measurement for street crossing completes the puzzle perfectly. With the point measurement, on the other hand, a block measurement will have to be developed first by applying the point-measurement to multiple mid-block locations in order to complete the same puzzle.

Using traffic barriers against pedestrians as a measure of effectiveness for pedestrian crossing quality of service at mid-block locations, Russell and Hine discuss several issues in measuring traffic barriers (1996). In their words, traffic barriers are "the sum of inhibiting effects upon pedestrian behavior resulting from the impact of traffic conditions, including physical (observable) and psychological (unobservable) impediments to pedestrian movements." On the issue of measurement scale, they have the following arguments:

"Measures of traffic barrier effects should be defined over well-defined sections of roads. Coverage of a section reduces the problems resulting from the flexibility of pedestrians' crossing strategies and crossing points, which makes measures at any individual point of limited value. An ideal section should be bounded by formal crossing facilities."

To understand the relevance of the flexibility of pedestrians' crossing strategies and crossing points, one may ask these questions: Will a pedestrian who is close to a signalized intersection with a walk-cycle not go to this facility for crossing? Will mid- 
block street crossing be more likely chosen by a pedestrian who is far away from a signalized intersection?

One issue of concern with the point measurement is how the variation of cross-sectional characteristics in a given mid-block be treated in developing the point measurement. This issue comes up in applications with respect to the point measurement but in the development of the methodology with respect to the point measurement.

This project took the point measurement approach in order to reduce the burden that would be placed on the participants with a block measurement.

\section{Delineation of Mid-blocks}

In order to measure pedestrian level of service for mid-block crossing, blocks may be defined in one of two ways. A block may be narrowly seen as the roadway section between two consecutive intersections, regardless of whether they are signalized or not. This view is in line with the traditional definition of a street block. Alternatively, a block may be broadly seen as the roadway section between two consecutive signalized intersections. This view is in line with what constitutes a highway segment for multimodal quality of service analysis by McLeod (1999).

The narrow view of a block was taken for the overall research project involved because quality of service is separately measured for intersections in the FDOT Multi-modal Quality of Service Program. The result of pedestrian quality of service for mid-block street crossing can then be combined with those of other components of pedestrian quality of service measures to form an overall pedestrian quality of service for roadway segments.

With the block-measurement approach, one may define a mid-block as the entire block, excluding its two intersections. This definition is theoretically sound with the current project. However, there is the possibility that potential pedestrians may unconsciously take into account intersection characteristics when asked for their perception of the quality of service for crossing a street near an intersection. To avoid such a concern, an alternative definition of a mid-block may be the middle portion of a block. If this definition is adopted, one then needs to set a cutoff distance from intersections to define mid-blocks.

\section{Subjective versus Objective Measures of Effectiveness}

The interpretation of "perception" in the definition of level of service is debatable. Most seem to see it as a requirement to measure levels of service as qualitative indicators of perceived operational conditions by users (Harkey et al., 1998). Examples of subjective measures include the perceived level of safety and comfort in FDOT's bicycle level of service methodology and the pedestrian level of service methodology for walking along roadway segments. This result of this interpretation would be subjective measures of effectiveness. 
There is some evidence that the presence of "perception" in the definition is just a requirement for using measures of effectiveness that can be easily perceived by users. The 1965 HCM never used the word "perception" in defining level of service (HRB, 1965). As a result, the $1965 \mathrm{HCM}$ uses both traffic volume and volume/capacity ratio as measures of effectiveness for determining automobile level of service. However, traffic volume later was dropped a measure of effectiveness in the later versions of HCM largely because drivers cannot adequately perceive traffic volumes (Roess and McShane, 1987; and Kittleson, 2000). If this second interpretation is taken, we do not need to come up with measures of effectiveness that indicate user-perceived operating conditions of a facility or service. Rather we just need to come up with measures of effectiveness that users can easily perceive. The result of this interpretation would be objective measures of effectiveness.

The Department appears to take the first interpretation on the role of perception in defining level of service. Consequently, the rest of the report is based on the first interpretation.

\section{Dimensions of Measures of Effectiveness}

A good starting point in developing a methodology for evaluation the level of service of a facility or service is to select a measure of effectiveness most appropriate for this facility or service. One aspect of this selection involves determining what operation conditions are important to users for a particular situation. For some facilities or services, the most appropriate measure of effectiveness is one that characterizes the operational conditions in multiple dimensions, including some or all of the following: speed and travel time, freedom to maneuver, traffic interruptions, comfort and convenience, and safety. For some other facilities or services, only one of these dimensions may be determined to be important. With objective measurement, single dimensions have typically been used as in the case of automobile levels of service. With subjective measurement, multiple dimensions could be incorporated into a measure of effectiveness.

One difficulty with this multiple dimension approach in a subjective measure is communication about these multiple conditions with the participants from whom data would be collected. In the case of pedestrians crossing streets at mid-block locations, for example, it was decided to include every aspect of the operation conditions. The participants were asked to consider all of these operational conditions and provide their perception of these conditions in terms of the level of "difficulty." It is unclear how many of these operational conditions were being considered by the participants and how "difficulty" was being interpreted differently by them. Both of these unknowns can significantly affect the data collected and ultimately the level of service methodology developed. 


\section{Stated- versus Revealed-Perception}

To get an objective measure of quality of service is one thing, to estimate a perceived measure of quality of service is a different thing. Typically, a stated-perception approach is taken to get a perceived measure. Under this approach, one derives the perceived quality of service by directly asking the participants of a research project about how they perceive the quality of service as a pedestrian or a bicyclist for a particular site. The studies by Landis and associates (Landis et al., 1997; Landis et al., 1999; and Landis et al., 2001) are examples of this approach.

An alternative would take a revealed-perception approach, under which one would derive the perceived quality of service from estimating a behavioral model that is based on pedestrian choices of some kind. One example of such choices is whether a pedestrian would cross a street at certain locations under certain conditions. Variables used to characterize these conditions will be part of the behavioral model. The estimated utility functions from the model would be used as a measure of effectiveness. Such a measure of effectiveness would reflect the perceived quality of service for street crossing for two reasons. The estimation results in parameters of the variables that reflect how important each variable is to the pedestrians. In addition, the measure of effectiveness captures the overall quality of service a pedestrian would experience from crossing a street. By basing the model on hypothetical pedestrian choices rather than actually observed ones, this alternative approach would also take into account potential latent demand for street crossing. This approach is similar to the utility-theoretical approach in the literature on measuring pedestrian level of service for airport facilities (Momer and Khan, 1988) and automobile driver level of service for highways (Kita, 2000).

The choice between these two approaches affects the complexity of the task given to the participants. With the stated-perception approach, a participant typically is asked to pick a rating out of a scale from 1 to 6 for any given situation. With the revealed-perception approach, a participant faces a much simpler task of making a choice between two options (cross or not to cross). The choice between the approaches also affects whether the estimated quality of service model is based on a behavioral foundation. A model that has a behavioral foundation is more desirable.

The approach with stated perception was taken for this project, following previous studies in the Department's Multi-modal Quality of Service Program.

\section{Perceived Quality of Service vs. Perceived Level of Service}

Even under the stated-perception approach, what is being asked of the participants may conceptually differ.

In several studies, participants were directly asked for their perceived level of service (Landis et al., 1997; Landis et al., 1999; and Landis et al., 2001). This perceived level of service is conceptually qualitative but was used as quantitative in correlating it with a set 
of the determinants of quality of service. The predicted quantitative level of service value was finally be used in designating qualitative levels of service.

To be consistent with the level of service concept described earlier, however, the participants should be asked for their perceived quality of service for mid-block street crossing. This perceived quality of service is a quantitative measure of the operational conditions for mid-block street crossing as perceived by pedestrians. Data collected on this perceived quality of service are used to develop a model relating perceived quality of service to a set of its determinants. The determined value of perceived quality of service from this model is viewed as the measure of effectiveness and can be used in designating qualitative levels of service.

Following previous studies in the Department's Multi-modal Quality of Service Program, the participants were asked for their perceived level of service.

\section{Data-Collection Issues}

Several data-collection issues are discussed here. These are grouped into sampling and survey issues.

\section{Sampling}

Sampling refers to the selection of sites and participants from which data will be collected for developing the pedestrian quality of service model. Sampling involves a number of choices with respect to sampling frames, sampling methods, and sample sizes. A sampling frame is made up of sampling units and represents the population. An example of the population is all households in Hillsborough County, Florida, while a sampling frame is the listed residential phone numbers in the telephone directory for the county. A sampling method is a way to draw a sample from a given sampling frame.

\section{Sampling Frame}

The issue is where the sites and participants should come from.

Sites. One potential sampling frame is a computerized database of all roadway blocks in the study area with information on key characteristics such as the number of lanes and AADT. Alternatively, sites may be selected subjectively through visiting a large number of roadway blocks in the study area. The second approach was taken for this project because of a lack of a complete computerized database.

Participants. Two options are available: sampling from the general public or sampling from sites with relatively high pedestrian volumes for street crossing. Either choice has significant implications to site selection and data collection. Sampling from the general public offers flexibility in site selection and its inclusion of potential latent demand for street crossing at mid-block locations. On the other hand, using real pedestrians at the 
sampled sites allows the responses to be based on real crossing behavior and the use of any day of the week for data collection. The major shortcomings of using real pedestrians are the inflexibility of site selection and the lack of control over site characteristics. This project selected the participants from the general public to increase the flexibility in site selection.

Sampling Method

The issue is how sites and participants are selected for a given sampling frame. Standard methods include simple random sampling and stratified simple random sampling. With simple random sampling, each sampling unit in a frame has an equal probability to be sampled. With stratification, the frame is divided into sub-frames and simple random sampling is done within each sub-frame.

Participants. Ad hoc methods, however, are frequently used in selecting participants. Participants, for example, may be solicited as volunteers through media campaigns. This sampling method was used in developing the pedestrian level of service for walking along roadways and the bicyclist level of service for riding along roadways (Landis et al., 1997; Landis et al., 1999; and Landis et al., 2001). Another ad hoc method of sampling is to solicit volunteers through sponsor organizations. Ad hoc methods potentially have serious consequences to the research results. There are at least two sources for such consequences. One relates to the sampling frame from which ad hoc methods draw samples. In the case of soliciting volunteers through media campaigns, for example, the sampling frame is limited to the population that has exposure to the median campaign. In the case of sampling through organizations, the sampling frame would be limited to people within these sponsors, which potentially are not representative of the general population. Another source relates to the potential bias in the responses of participants sampled through ad hoc methods, especially volunteers. Volunteers are likely to be more passionate about pedestrian issues. Consequently, a policy-response bias is likely: They may believe that responding negatively might induce improvements in favor of pedestrians.

This project used neither of these approaches for selecting participants. Instead, the participants were recruited through a temporary employment agency. The research team reasoned that any bias from using temp workers is unlikely to be larger than that from using volunteers, for example. The research team really liked the certainty in the number of participants that a temp agency would bring.

Sites. With a computerized database, blocks may be sampled within individual strata defined by different combinations of key characteristics contained in the database. With the ad hoc method of visiting a large number of sites, the selection would be largely subjective. Under either approach, sites may be clustered by geography to facilitate the logistics of carrying out the field survey.

The research team used the subjective approach of visiting individual locations within three clusters. 


\section{Survey}

The issue is how data on the perceptions of individual participants about mid-block street crossing are to be collected. This section shows a two-dimension continuum for comparing alternative survey methods and describes four particular methods.

Two-Dimension Continuum

In exploring the alternative approaches, the research team found a great way to compare alternative survey methods that may be used for collecting user perception of transportation quality of service. The trick is that all potential survey methods are more or less defined by two attributes. One is how the operational conditions, which are the basis of user perception, are presented to the participants. Potential methods include conventional presentations, computer simulation, video, or field. Conventional presentations include paper format, in-person interviews, telephone interviews, or computer-assisted format. The other attribute is the behavioral roles of the participants before they respond to survey questions. Potential behavioral roles include no role at all, scripted behavior, or actual behavior. The result is a two-direction continuum as shown in Table 1 with some of the commonly used methods shown in the appropriate cells. Some of these are described further below.

\section{Table 1. Two-Dimension Continuum of Survey Methods}

\begin{tabular}{|c|c|c|c|}
\hline \multirow{2}{*}{$\begin{array}{l}\text { Presentation of } \\
\text { Operational Conditions }\end{array}$} & \multicolumn{3}{|c|}{ Behavioral Role of Participants } \\
\hline & None & Scripted & Actual \\
\hline Conventional & $\begin{array}{l}\text { Paper survey with } \\
\text { general public } \\
\text { (Hensher, 1991) }\end{array}$ & & $\begin{array}{l}\text { Mail-back survey with } \\
\text { real users }\end{array}$ \\
\hline \multicolumn{4}{|l|}{ Computer Simulation } \\
\hline Video & $\begin{array}{l}\text { Video survey with } \\
\text { general public }\end{array}$ & & \\
\hline Field & $\begin{array}{l}\text { Field survey with } \\
\text { general public and no } \\
\text { behavior (this project) }\end{array}$ & $\begin{array}{c}\text { Field survey with } \\
\text { general public and } \\
\text { scripted behavior (SCI } \\
\text { efforts) }\end{array}$ & $\begin{array}{l}\text { Field observation with } \\
\text { real users }\end{array}$ \\
\hline
\end{tabular}

Mail-back Survey with Real Pedestrians

The mail-back survey would solicit information from people who recently crossed a midblock on foot in a study area. A random sample of the households would be selected. Multiple survey forms would be mailed to each of these households. Any household member with a recent crossing would be eligible to participate. In addition to their perceived quality of service of the most recent crossing, the respondents would also be asked to identify the mid-block, day of week, and time of day. Such identification information would then be used to collect site characteristics after the mail-back surveys 
are received. The advantages include that nighttime could be covered and that random sampling or some other form of systematic sampling is possible because mail-back surveys require far less effort from the participants than approaches involving field surveys. One cannot over-empathize the importance of random sampling or some other form of systematic sampling to the validity of the research results. One major disadvantage is that site characteristics and perception are not concurrent. Other disadvantages include the uncertainty in response rates and loss of control over site selection.

\section{Field Observation with Real Pedestrians}

A field survey of real pedestrians would solicit information from people who just crossed a mid-block on foot in a study area. Sites with relatively high volumes of street crossing would need to be identified and selected first. People who just crossed a street at the sites are asked to participate. One advantage of this approach is that field surveys may be carried out on any day of the week. Another potential advantage is that perceptions are based on crossing experiences in real-life situations. The major disadvantage is that people who just crossed a street at a mid-block location illegally are unlikely to cooperate with the research staff.

\section{Field Survey with General Public}

This approach would select participants from the general public and bring them to preselected sites for the survey. Its advantage over the approach of field surveys with real pedestrians is its relative flexibility in selecting sites. Its advantage over the mail-back approach is its use of real-time perception, the possibility of concurrent data collection of perception and traffic conditions, and its inclusion of potential latent demand for street crossing at mid-block locations. One serious disadvantage of this approach is the amount of time and effort required on the part of the participants. While this requirement in itself is not a disadvantage, it would mean that some form of ad hoc sampling is necessary. Another potential disadvantage is that times for the field survey are limited to when traffic volumes are low because it almost requires all participants be surveyed at the same time, which is likely the weekends. This may not be a serious problem for roadways of higher functional classification or roadways in tourist attraction areas. It could potentially prevent the project from including local streets as part of the study because of low volumes.

This survey method can be applied in one of two forms. One form would place the participants in the field for observation without actually asking them to cross the street. The alternative form would place the participants in the field and ask them to actually cross the street and respond after the crossing action. Some, including researchers at SCI, feel strongly about having the participants actually involved in behavioral activities before responding to survey questions. Arguments can be made, however, for not placing the participants in actual behavioral activities. Not having the participants involved in actual behavioral activities improves participant safety and reduces researcher liability. More importantly, what really matters is the pre-action perception rather than post-action 
perception. That is, it is the perception formed before a person crosses a street not the perception formed after the crossing that influences the crossing behavior.

The research team chose to not ask the participants to actually cross the streets to avoid liability issues. The research team believes that the University of South Florida would not approve the use of the other approach.

Video Survey with General Public

This approach would sample participants from the general public and bring them to a central location for the survey. Videos of selected sites would be prerecorded. The participants would base their responses on their perception of the operational conditions as shown in the videos. The main disadvantage of this approach is the uncertainty in how accurately the participants can perceive the traffic conditions from the tapes. However, this uncertainty may be resolved to a large extent by conducting a limited experiment. A small number of volunteers would be randomly assigned to two groups: one will be subject to the approach of field surveys with participants from the general public while the other will be subject to this approach. The results from these two groups can then be compared. In fact, Harkey et al. (1998) conducted such a limited experiment and found the results to be favorable to this video survey approach. This approach has several advantages, including: 1) Specific variables can be presented to the participants in a controlled environment (For example, two participants asked to rate the same site at different times may be exposed to different conditions. Bias will result if these conditions are not measured in the study.); 2) Sites from a larger geography can be selected; and 3) It saves time and effort on the part of the participants (Harkey et al., 1998). As a result of the third advantage, it is possible to select participants through random sampling from the general public.

\section{Observational Duration}

With both the survey approaches using participants sampled from the general public, there is the issue of how much time the participants should be given for observation before a response. There are potentially three options: 1) The participants are asked to respond at the instant they are placed at the site; 2) They are given the average amount of delay a pedestrian would tolerate before crossing a street; 3) They are given enough time so that their responses reflect the operation conditions in a full traffic cycle. The observation duration matters because the operational conditions of a roadway segment on an urban arterial are subject to both the cycles from the traffic lights and the randomness in traffic. Behaviorally, option 2 would be the most appropriate because most people would not wait any longer to observe the operational conditions. Methodologically, however, option 3 would be more appropriate because these operational conditions could be far better controlled under this option. The third option was chosen for this project. 


\section{Collecting Site Characteristics}

It is convenient to separate the site characteristics into dynamic and static characteristics. Dynamic characteristics tend to change with traffic conditions, while static characteristics are relatively stable. Examples of dynamic characteristics include traffic volume and speed. Examples of static characteristics include roadway width and the presence of a median. Static site characteristics would be collected either before or after the survey. It is highly desirable that dynamic characteristics are to be collected concurrently with what is being observed by the participants.

\section{Calibration Issues}

For future application, each of the site characteristics need to have a weight attached that reflects its relative importance in influencing pedestrian quality of service for mid-block street crossing. To accomplish this, one needs a mathematical framework to connect these site characteristics to pedestrian quality of service and a separate approach to determine the relative weights within that mathematical framework. The choice of the mathematical framework should have a behavioral foundation. The statistical approach allows the weights for the site characteristics to be estimated. Such a statistical approach should be chosen with care so that the weights are estimated with precision and accuracy.

\section{Predictive Capability}

The issue is whether a level of service methodology provides an instrument that can be repeatedly used. Alternatively, level of service methodologies may be developed for monitoring purposes (Ndoh and Ashford, 1994). Such a methodology really only offers a procedure that needs to be repeated every time it is used.

This project chose to develop a method that can be easily applied to other situations. The FDOT wanted a relationship between the pedestrian level of service and its determinants that can be used by practitioners in the state to determine levels of service for roadway segments in their own jurisdictions without re-conducting a customized survey.

\section{Model Form}

As mentioned earlier, the methodology would include a relationship that relates pedestrian quality of service with a set of determinants. However, different formats have been used in presenting this relationship: tabular and equation.

With the tabular form, each determinant is entered as a dummy variable. That is, it takes 1 if a condition is satisfied and zero otherwise. Each determinant is assigned a score (or weight). Typically, this assignment is somewhat arbitrary. The quality of service of a particular site is given by summing the scores across all determinants that meet the conditions. Levels of service are determined by comparing the actually total score with preset level of service designations. The tabular format is likely to be perceived to be 
mathematically simpler than the equation form. This format has been adopted in many communities, including Gainesville, Florida (Dixon, 1996), Winter Park, Florida (Jaskiewicz, 2000), and Auburn, Alabama (City Auburn, 2000).

Alternatively, a mathematical equation is used to express pedestrian quality of service for mid-block street crossing as a single mathematical function of its determinants. The function itself may be determined in different ways. See more discussion on this issue below. Similar to the tabular format, levels of service are determined by comparing the predicted quality of service with pre-set level of service designations. The advantages of the equation format are its compactness, its flexibility in terms of the number of variables included, and the potential responsiveness to change in continuous variables. Note that the tabular form is a special case of the equation form when all the determinants enter the function as dummies in a linear form. The equation format has been used for the Bicycle Compatibility Index (Harkey et al, 1998), the Walk Security Index (Wellar, 1998), and the Bicycle Level of Service and Pedestrian Level of Service Models (Guttenplan et al., 2001).

The equation format was chosen for this project because of the Department's preference.

\section{Approach to Relationship Establishment}

The issue is how the relationship between the pedestrian level of service and its determinants should be established. One approach combines the set of determinants arithmetically into an index as Wellar has done (1998). Unless there is theoretical guidance, how these determinants are combined seems to be arbitrary. Alternatively, this relationship is to be statistically calibrated with data collected on both the perceived pedestrian quality of service and its determinants. Statistical calibration was used in developing the Bicycle Compatibility Index (Harkey et al., 1998) and the Bicycle and Pedestrian Level of Service Models (Guttenplan et al., 2001).

The approach of statistical calibration was chosen for this project.

\section{Statistical Model}

When equations are used, there is the issue of selecting a statistical model that is most appropriate for the nature of the data collected. Data collected on perceived pedestrian quality of service are typically ratings on a scale from 1 through 6 , for example. Such ratings are not continuous but discrete and ordinal.

\section{Continuous Ratings}

One modeling approach has been to treat the reported ratings as continuous. That is, the reported ratings are directly used to correlate with a set of potential determinants of pedestrian quality of service for mid-block street crossing. The advantage of the continuous-rating approach is that it is the conventional approach and its relative 
mathematical simplicity. The main disadvantage is that it is inappropriate for the nature of data. It implicitly treats the discrete and ordinal dependent variable as a continuous and cardinal one. As a result, for example, they treat the difference between ratings of 1 and 2 the same as the difference between 4 and 5. The straight line in Figure 1 illustrates this. In reality, however, one is likely to be preferable the increase in quality of service from 4 to 5 to increase from 1 to 2 (assuming higher ratings indicate higher quality of service). This is the case illustrated by the curved line in the same figure.

Figure 1. Quality of Service and Reported Rating

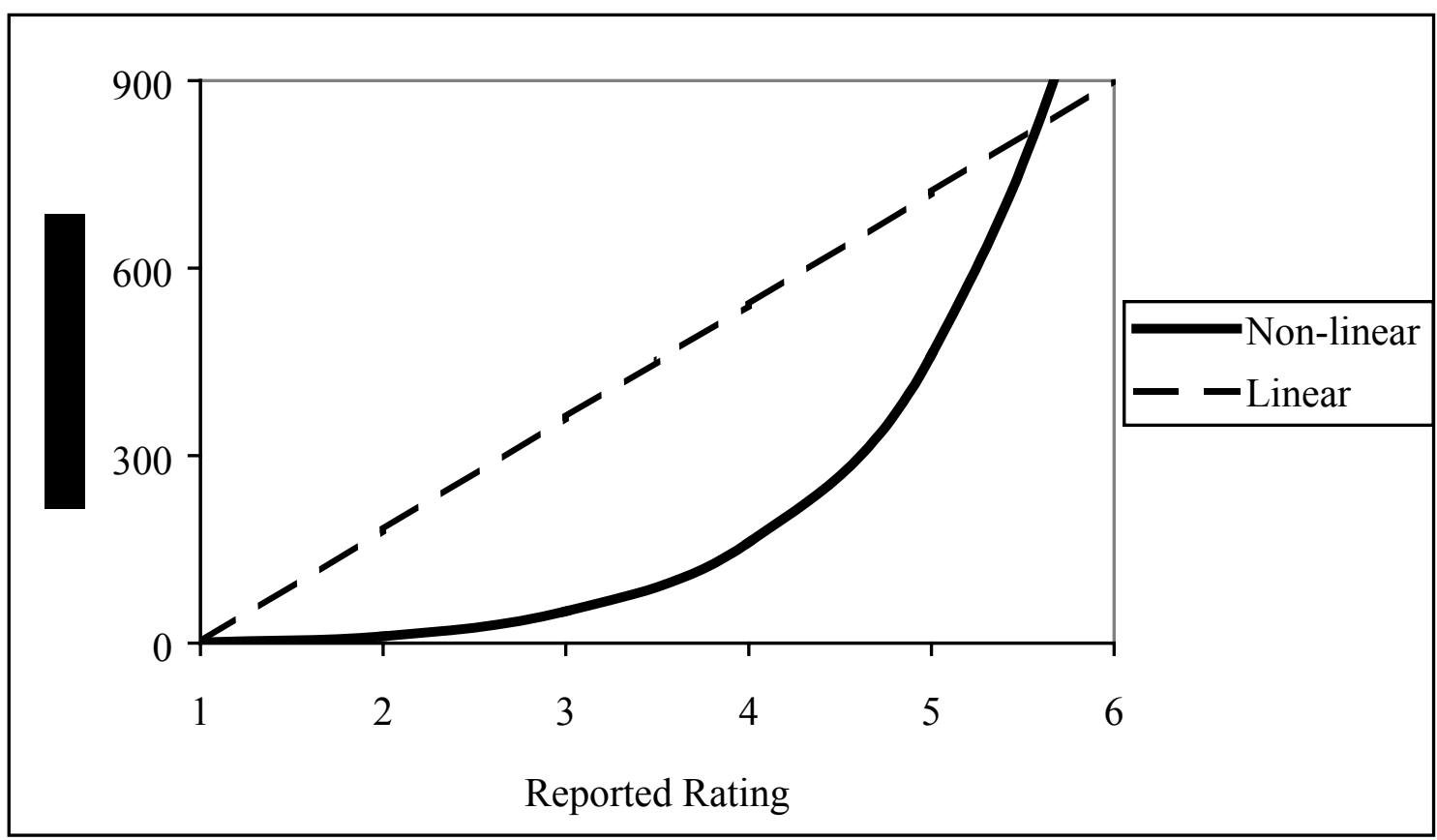

\section{Ordered Response}

An ordered response model takes advantage of the discrete and ordinal nature of the data on the reported quality of service. Common models for such data are the logit and probit models. While these models take advantage of the discrete nature of the data, they ignore the additional information on the ordinal nature of the data. The most commonly used model for ordered data is the ordered probit model (Greene, 1990). Along with the coefficients of variables included, the estimation of this model will also produce estimates of the thresholds of quality of service that define the six discrete ranges. These ranges may be used to directly define levels of service (see more discussion in the application section later). Figure 2 compares this ordered-response approach with the continuous-rating approach. In addition, the predicted quality of service from the ordered-response approach will actually be the underlying true quality of service $\mathrm{Y}^{*}$, rather than the rating, Y. Hensher (1991) uses this approach in the context of userperceived image of bus services in Australia. 
Following the previous studies in the Department's Multi-modal Quality of Service Program, this project treated the reported ratings as continuous.

Figure 2. Calibrating Pedestrian Quality of Service Model

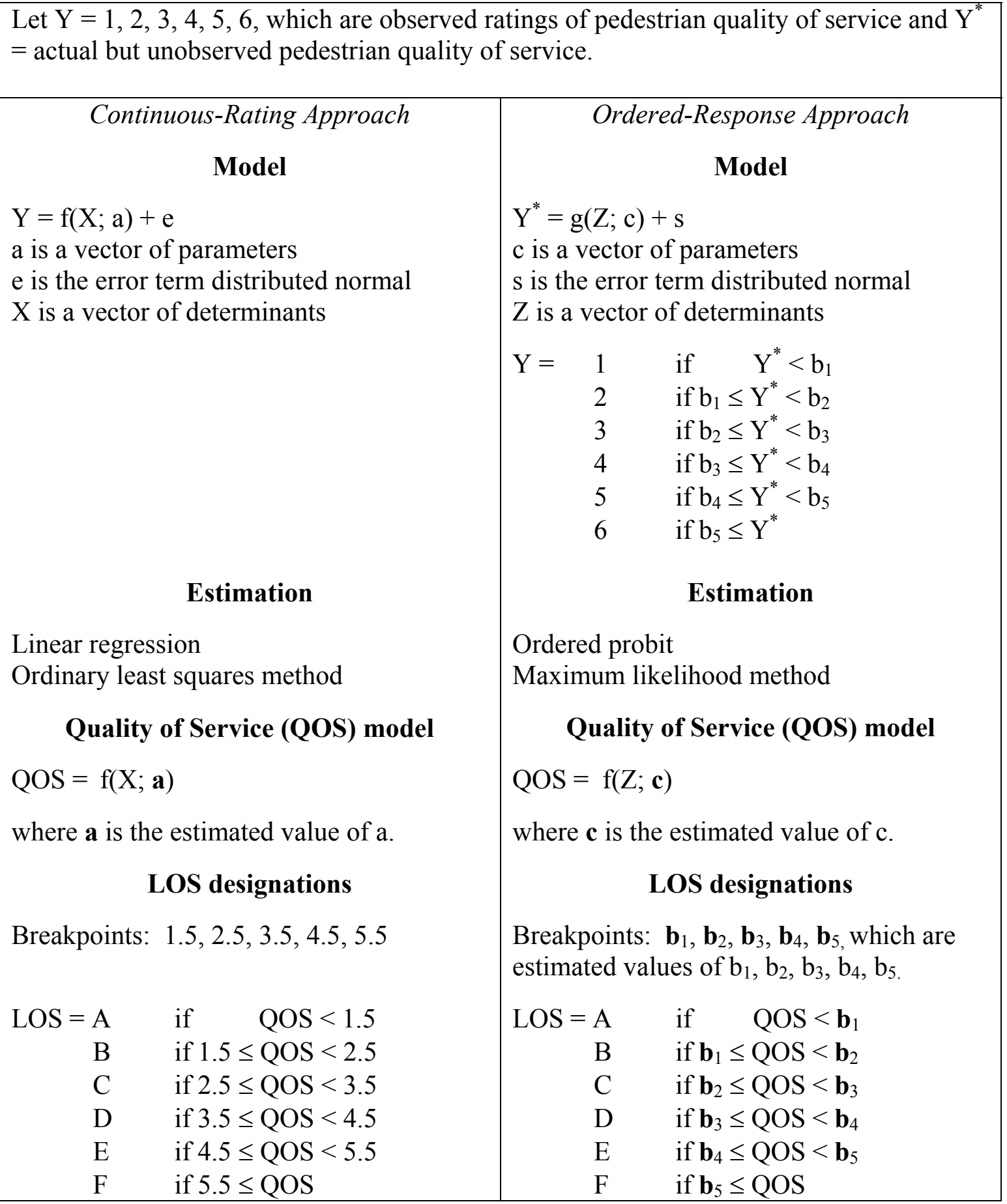




\section{Estimation}

Appropriate statistical methods would be used to calibrate the model with the data collected. The particular method used will depend on the framework selected, how quality of service is measured, and the type of data collected. In any case, alternative specifications of the model may be considered, including variations in the variables, the mathematical framework, and the statistical approaches. The results include the particular functional form, variables, and their parameters.

One issue of particular importance is the nature of the observations obtained through hypothetical questions. Typically, any participant is asked to provide his perception of a number of sites or facilities. These different perceptions from the same individual are typically used as independent observations in statistical estimation. For example, each participant provided 21 observations in a study of measuring pedestrian quality of service for walking along roadways (Landis et al., 2000) and 30 observations in a study of measuring bicyclist quality of service for cycling along roadways (Landis et al., 1997). Similarly, multiple roadway sections from the same facility are selected.

One problem is that the perceptions by the same individual on different roadway sections are not likely to be independent. By treating them as independent, previous estimations over-estimate the $\mathrm{R}^{2}$ but under-estimate the standard errors of coefficients. As a result, it is not uncommon to see claims that 90 percent of the variation is explained by the included variables. Also, variables that are not really significant at a given level of significance are claimed as significant. A similar problem arises from using roadway segments on a continuous route because the perceptions of even different participants on these segments are likely to be correlated.

This project examined this issue and used two methods to adjust the estimated t-statistics for potential correlation among the repeated observations.

\section{Application Issues}

Once a model is estimated, it can be used to estimate the quality of service of any site for which data are available for the variables included in the model. In order to determine the level of service for this site, however, one would need a conversion mechanism that translates the estimated quality of service to one of the level of service designations. Three approaches to conversion have appeared in the literature. Following the previous studies in the Department's Multi-modal Quality of Service Program, this project used the range-based approach.

\section{Range Based}

One approach is based on a set of pre-selected breakpoints within the range of possible quality of service values among a sample of sites. These breakpoints are used to define the various level-of-service designations. Landis et al. (1999) use this approach in 
determining pedestrian level of service for walking along roadway segments. In fact, 1.5, $2.5,3.5,4.5$, and 5.5 are suggested as the breakpoints on a rating range from 1 through 6 .

\section{Distribution Based}

The second approach is based on dividing the distribution of quality of service among a sample of sites into six segments. Under the distribution-based approach, a set of percentiles of the quality of service distribution among a sample of sites is selected and used to represent the breakpoints between the various level-of-service designations. The estimation sample typically is used for selecting the percentiles. Harkey et al. use this approach in developing the bicycle comparability index for bicycle riding along midblock locations of roadways (1998). Specifically, the $5^{\text {th }}, 25^{\text {th }}, 50^{\text {th }}, 75^{\text {th }}$, and $95^{\text {th }}$ percentiles are used as the breakpoints to designate six levels of service.

\section{Direct Estimation}

A third approach is to use an ordered probit model to directly estimate the breakpoints as illustrated in Figure 1 in comparison to the range-based approach. This approach was partially tested in the context of measuring bus level of service by Madanat et al. (1994). The main advantage of the direct-estimation approach over the other two is its objectivity. Another advantage of this direct approach is that the designation of level of service will be based on the true quality of service rather than ratings. A disadvantage is its relatively complexity. Once computerized, however, this complexity is not a real problem. 


\section{Chapter Three: SELECTION OF DETERMINANTS}

The literature on the measurement of pedestrian and bicyclist quality of service and level of service offers several alternative approaches to selecting such potential determinants. The data-mining approach starts with a large set of variables and narrows down to a smaller set as part of the statistical analysis through some form of data mining (Harkey et al., 1998; and Landis et al., 2001). The stakeholder approach starts with a huge set of variables and narrows down to a smaller set by the use of stakeholder opinions. A good example is the stakeholder approach used by Wellar in developing his walking security index (Wellar, 1998). He starts with a total of 212 candidate variables and ends up with only 7 of them. Gallin appears to use the same process (Gallin, 2001). The brainstorming approach relies on an expert panel to generate and finalize a set of potential determinants through some form of brainstorming (Landis et al., 1999). The theoretical approach generates a set of potential determinants through theoretical considerations of user behavior involved (Pecheux et al., 2000).

This project offers a balanced approach to the process of selecting potential determinants for level of service measurement. The process described in this paper makes both theoretical and practical considerations. It involved two steps. The first step selects a set of potential determinants through a theoretical analysis of pedestrian behavior for street crossing. The theoretical consideration ensures that these potential determinants have a sound behavioral foundation. The second step narrowed down this set through a practical consideration by an Advisory Committee. This practical analysis ensures that the final set of potential determinants meets planning needs and data availability.

\section{Theoretical Consideration}

One difficulty in understanding what determines perceived pedestrian quality of service for mid-block street crossing is the lack of a framework in the literature to guide the selection of there determinants. We started with a component approach, which turned out to be not fruitful. We then used a behavioral approach, which proved to be useful. Both are illustrated in Figure 3.

\section{Component Approach}

In terms of pedestrian quality of service for crossing streets at mid-block locations, three types of measures of effectiveness that have appeared in the literature could potentially be used. These include pedestrian delays, pedestrian safety, and crossing opportunities. These were treated as the three components. 
Figure 3. Flowchart of Determinants

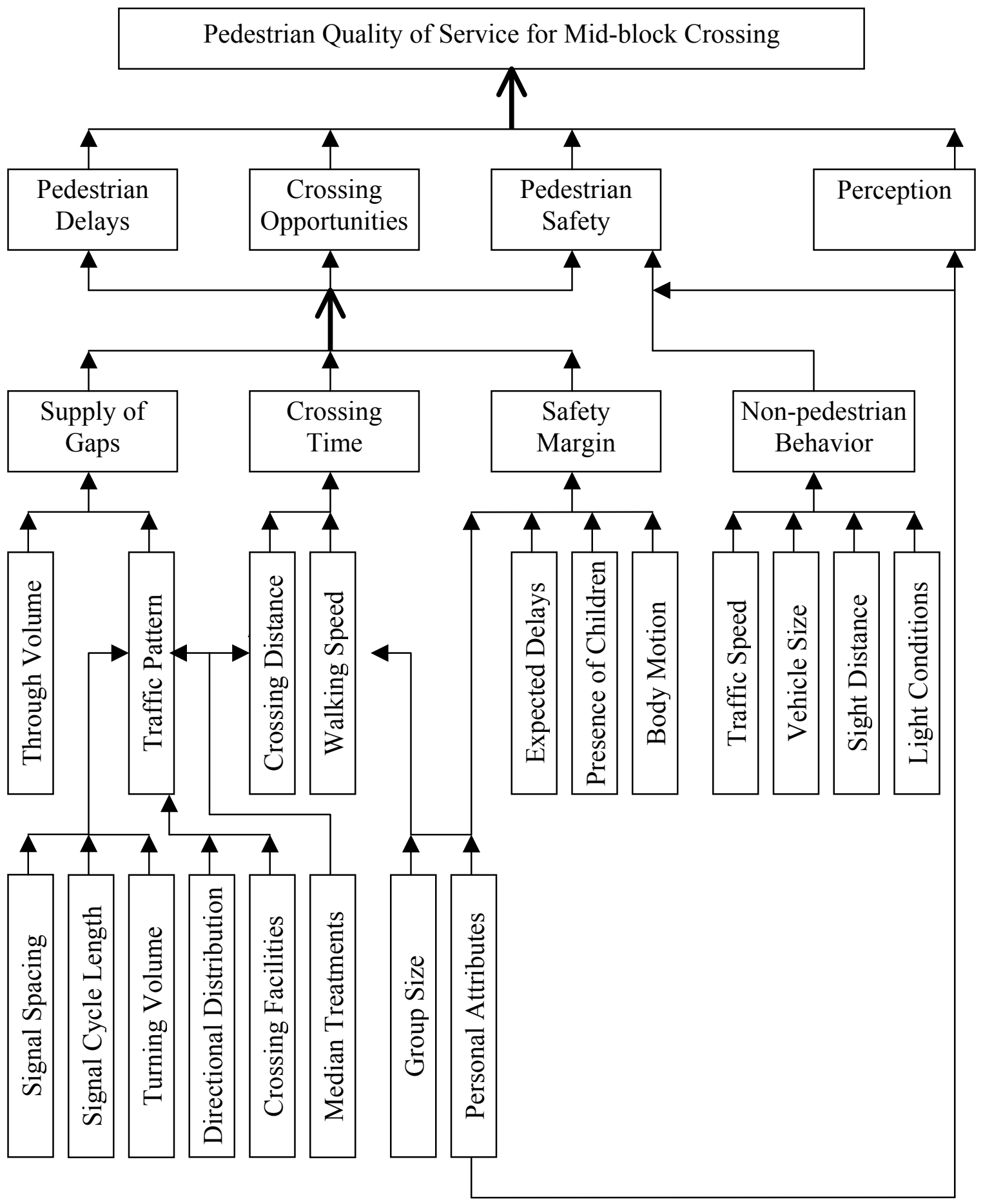


Pedestrian Delays

Pedestrian delays refer to any time spent waiting to cross, either at the curbside or at the middle of the road. It is natural to use pedestrian delays as a measure of pedestrian quality of service for mid-block street crossing. First, the amount of delay is typically used as the measure of effectiveness for intersections where conflicts frequently occur just as in the case with pedestrian mid-lock street crossings. Second, the amount of delay also reflects several aspects of the operational conditions faced by pedestrians crossing streets as mid-block locations. These include speed, travel time, and convenience.

Safety

Safety is one important aspect of the operational conditions that pedestrians face in the transportation system. Safety for pedestrian mid-block street crossings may be estimated in one of two ways. In one approach, pedestrian injuries and fatalities from crashes with motor vehicles or conflicts between pedestrians and motor vehicles are compiled for a mid-block segment. One problem with this approach of objective measurement is that crashes or conflicts between pedestrians and motor vehicles rarely occur at any single location in the state. This rare occurrence creates a problem for getting good data. If crash statistics are the basis, one may need these statistics over many years. If field observations are the basis for conflicts, a period of a few hours costs a lot to research projects but is not long enough to get good data. An alternative approach uses pedestrians' perception to measure safety. While safety has not been used as a measure of effectiveness for pedestrian mid-block street crossing, perceived safety and comfort is used by some (Landis et al., 1999) as a measure of effectiveness for pedestrians walking along roadway segments.

\section{Crossing Opportunities}

By basing a measure of pedestrian quality of service for mid-block street crossing on crossing opportunities, one assumes that what determines the quality of service is the number of time gaps in traffic that are long enough in time for pedestrians to safely cross the street. Some measure crossing opportunities by the proportion of time that an acceptable gap in the traffic is available (Hunt and Abduljabbar, 1993). This idea is used in establishing the maximal number of adequate gaps per hour in the Minimum Pedestrian Volume Warrant for pedestrian traffic control signals. An objective measure based on crossing opportunities has an advantage over an objective measure based on the other components. Both pedestrian delays and safety exclude suppressed demand for crossing. That is, those people who would have crossed the street at the mid-block locations may either have avoided the trip all together or have selected to cross the street at another location. The perceived quality of service is lowest for these people. As a result, average pedestrian delay or safety does not reflect the quality of service for crossing at this mid-block location and in fact overestimates the true level of quality of service. Measures based on crossing opportunities, on the other hand, do not suffer from this problem. 


\section{Pedestrian Crossing Behavior}

Pedestrian crossing behavior is largely governed by the gap-acceptance theory (Palamarthy et al., 1994). It states that each pedestrian has a critical gap. Upon arriving at the curb, the pedestrian would check if the current traffic gap is greater than the critical gap and decide whether to accept the traffic gap. If the current one is rejected, the next one is considered. This process continues until the pedestrian accepts a traffic gap or gives up. The critical gap consists of two parts. One part is the required crossing time and the other part is a safety margin. The safety margin is the difference between the time a pedestrian crosses the traffic and the time the next vehicle arrives at the crossing point. It is what is beyond the minimum crossing time for a traffic gap to be acceptable. The crossing time is what it takes a pedestrian to cross a particular street. This theory thus indicates that pedestrian crossing behavior is governed largely by three components: the supply of gaps, crossing time, and safety margin.

\section{Supply of Gaps}

There is no doubt that the supply of traffic gaps is the key determinant of pedestrian quality of service for street crossing at mid-block locations. There are two arguments, however, against using it as a variable for our research. Data for this variable will not be readily available or easily collected when the result of this project is applied. While data collection would not be a significant effort if the application is to a few blocks, it will be if an entire region is involved. In addition, the supply of traffic gaps is not a direct policy variable such as cycle length, crossing facilities, medians, or speed limit.

Instead of directly using it as a determinant, we may use the factors that influence the supply of traffic gaps as potential determinants of pedestrian quality of service for midblock street crossing. The supply of traffic gaps, including both the frequency and duration of gaps, is determined by traffic volume and its patterns. Traffic patterns indicate both the spatial and temporal distributions of traffic. Spatially, it indicates, for example, whether vehicles arriving at a given crossing point are evenly distributed across the traffic lanes and traffic directions. Temporally, it indicates how vehicles arriving at a given crossing point are distributed in time. In general, the more uniform the traffic pattern, the fewer the large gaps that allow people to safely cross a street.

\section{Crossing Time}

The time a pedestrian takes to cross a street is determined by the distance to be crossed, the walking speed of the pedestrian, and whether the median treatments allow the pedestrian to cross the street in two stages. Walking speed determines how much time a pedestrian takes to cover a given distance. It could be measured in the field if the participating pedestrians actually cross the street. One would need other variables in replacement to capture its effect if pedestrians do not do the crossing.

It appears that personal attributes such as age are good indicators for walking speeds on average (Coffin and Morrall, 1995; Hoxie and Rubenstein, 1994). The presence of 
disabilities certainly affects how fast one can walk. In addition, median treatments, crossing location, group size of pedestrians, and trip purpose appear to influence walking speed. The average walking speed is higher for roads with two-way-left-turn lanes than for undivided roads; and pedestrians tend to walk faster at mid-block locations than at signalized intersections (Bowman and Vecellio, 1994). Individual pedestrians crossed a street at mid-block locations at higher speeds than groups (Dipletro and King, 1970). Finally, commuters and students walk at higher speeds than shoppers (Puchkarev and Zupan, 1975).

\section{Safety Margin}

It appears that the size of the safety margin is largely determined by certain personal attributes such as age and gender (Dipletro and King, 1970; Harrell and Bereska, 1992). It may also depend on some other factors, including whether the pedestrian was walking or standing still before stepping into the street (Oudejans et al., 1996), the expected pedestrian delays before the next gap comes (Palamarthy et al., 1994), the relative supply of traffic gaps in the two directions of traffic (Hunt and Griffiths, 1991), the group size of pedestrians (Dipletro and King, 1970; Harrell and Bereska, 1992), and the presence of children (Harrell and Bereska, 1992). Finally, several other factors can also influence pedestrians' choice of safety margin and perception of crossing quality of service. These include traffic speed at mid-block locations, the presence of large vehicles in traffic, sight distance, and lighting conditions.

\section{Practical Considerations}

The potential determinants discussed in the previous section have been narrowed down to a smaller set for consideration in estimating the model of pedestrian quality of service for mid-block crossing. Once this process is described, the role and each of the final determinants is discussed by type: personal, traffic, roadway, and control characteristics.

A two-step process was used for this purpose. In the first step, the full set of potential determinants from the previous chapter was grouped into several categories: those directly observed, indirectly observed, and irrelevant. Those indirectly observed include traffic patterns and walking speed. They are difficult to be observed in the field and are determined by those directly observed. Those not directly relevant to this project include the number of pedestrians crossing as a group, light conditions, sight distance, the presence of young children, and body motion because it is expected the field survey will be done during day time, at sites with sufficient sight distance, and for individual persons without actually stepping into the street. This step was carried out largely by the project team without much involvement of FDOT staff or members of the Advisory Committee of this project. Those directly observed are candidates for further consideration in the second step.

In the second step, a large number of comments and suggestions were received on these directly observed variables from members of the Advisory Committee of this project. 
These comments and suggestions were then discussed and synthesized between the project team and FDOT staff. One outcome was to measure several roadway, traffic, and control characteristics by direction. Some observations of pedestrians suggest that pedestrians behave differently between crossing the near side and the far side of a street (Hine and Russell, 1993). Another outcome was the decision to further separate the directly observed variables into two groups: most important and less important. Those determined to be less important are crossing experience, and large-sized vehicles. Only the most important variables are to be included in the analysis.

Table 2 gives the final list of variables for statistical analysis. Also included in the table are how each variable will be measured both for calibration and application, the likely direction of effects, the form with which it will enter the model, and when the data will be collected. These variables are discussed below in terms of their measurement and expected effects.

Table 2. Potential Determinants

\begin{tabular}{|c|c|c|c|c|c|c|}
\hline Determinants & $\begin{array}{l}\text { Measurement for } \\
\text { Calibration }\end{array}$ & $\begin{array}{l}\text { Measurement } \\
\text { for Application }\end{array}$ & \begin{tabular}{c|} 
By \\
Direction
\end{tabular} & $\begin{array}{c}\text { Function } \\
\text { Form }\end{array}$ & $\begin{array}{c}\text { Data for } \\
\text { Calibration }\end{array}$ & $\begin{array}{c}\text { Data for } \\
\text { Application }\end{array}$ \\
\hline \multicolumn{7}{|c|}{ Personal Characteristics } \\
\hline Age 16-64 & $\begin{array}{l}1 \text { if age } 16-64 ; 0 \\
\text { otherwise }\end{array}$ & Share 16-64 & No & & $\begin{array}{l}\text { Concurrent } \\
\text { question }\end{array}$ & $\begin{array}{l}\text { Not in } \\
\text { ART_PLAN }\end{array}$ \\
\hline \multicolumn{7}{|c|}{ Traffic Characteristics } \\
\hline Traffic volume & $\begin{array}{l}\text { Vehicles per hour } \\
\text { per lane (VPH) }\end{array}$ & $\begin{array}{l}\text { VPH from } \\
\text { AADT }\end{array}$ & Yes & & $\begin{array}{l}\text { Concurrent } \\
\text { taping }\end{array}$ & $\begin{array}{l}\text { Available in } \\
\text { ART_PLAN }\end{array}$ \\
\hline $\begin{array}{l}\text { Turning } \\
\text { movements }\end{array}$ & $\begin{array}{l}\text { Vehicles per hour } \\
\text { from turning points }\end{array}$ & Same & Yes & & $\begin{array}{l}\text { Concurrent } \\
\text { taping }\end{array}$ & $\begin{array}{l}\text { Not in } \\
\text { ART_PLAN }\end{array}$ \\
\hline Traffic speed & $\begin{array}{l}\text { Midblock running } \\
\text { speed }\end{array}$ & Same & No & & $\begin{array}{l}\text { Concurrent } \\
\text { taping }\end{array}$ & $\begin{array}{l}\text { Available in } \\
\text { ART_PLAN }\end{array}$ \\
\hline \multicolumn{7}{|c|}{ Roadway Characteristics } \\
\hline $\begin{array}{l}\text { Crossing } \\
\text { distance }\end{array}$ & $\begin{array}{l}\text { Feet from curb } \\
\text { center }\end{array}$ & Same & Yes & & Pre-survey & $\begin{array}{l}\text { Not in } \\
\text { ART_PLAN }\end{array}$ \\
\hline $\begin{array}{l}\text { Restrictive } \\
\text { medians }\end{array}$ & Width in feet & Same & No & & Pre-survey & $\begin{array}{l}\text { Not in } \\
\text { ART_PLAN }\end{array}$ \\
\hline $\begin{array}{l}\text { Non-restrictive } \\
\text { medians }\end{array}$ & Width in feet & Same & No & & Pre-survey & $\begin{array}{l}\text { Not in } \\
\text { ART_PLAN }\end{array}$ \\
\hline Crosswalks & $\begin{array}{l}1 \text { if crosswalks } \\
\text { present; } 0 \text { otherwise }\end{array}$ & Same & No & & Pre-survey & $\begin{array}{l}\text { Not in } \\
\text { ART_PLAN }\end{array}$ \\
\hline $\begin{array}{l}\text { Pedestrian } \\
\text { signals } \\
\end{array}$ & $\begin{array}{l}1 \text { if signals present; } 0 \\
\text { otherwise }\end{array}$ & Same & No & & Pre-survey & $\begin{array}{l}\text { Not in } \\
\text { ART_PLAN }\end{array}$ \\
\hline \multicolumn{7}{|c|}{ Control Characteristics } \\
\hline Signal cycle & $\begin{array}{l}\text { Full cycle length in } \\
\text { seconds }\end{array}$ & Same & Yes & & Pre-survey & $\begin{array}{l}\text { Available in } \\
\text { ART_PLAN }\end{array}$ \\
\hline Signal spacing & $\begin{array}{l}\text { Feet between nearby } \\
\text { signalized } \\
\text { intersections }\end{array}$ & Same & No & & Pre-survey & $\begin{array}{l}\text { Available in } \\
\text { ART_PLAN }\end{array}$ \\
\hline
\end{tabular}




\section{Chapter Four: DATA COLLECTION}

\section{Sampling}

\section{Sites}

Databases of roadway facilities and roadway blocks for both Hillsborough and Pinellas Counties were obtained to assist in the selection of the sample of mid-lock crossing locations. These databases were extracted from the Roadway Characteristics Inventory database by District Seven of the FDOT. In addition, a list of signalized and unsignalized mid-block crosswalks was obtained from the Hillsborough County Transportation Department, City of Tampa Public Works Department, and City of Clearwater Public Works Department.

With the use of these databases during a three-week period in March 2001, the research team identified 20 mid-block locations in Hillsborough County and 13 mid-block locations in Pinellas County to be used as the sample of mid-block crossing locations during the data collection phase. Mid-blocks were defined on the basis of traditional blocks, i.e., roadway sections between two consecutive intersections regardless of signalization. It was important that the selected mid-block crossing locations have wide variation with regard to static characteristics. Selection of the 33 mid-block crossing locations was based on a thorough review of the static characteristics of nearly 100 possible mid-block crossing locations in the two counties. The static characteristics included pedestrian signals, distance between signalized intersections, crosswalks, signal cycle lengths, number of lanes, and median treatments.

\section{Participants}

A sample of participants from the general population was obtained by using a temporary staffing agency. Spherion staffing services was used to obtain the subjects for the field study. Spherion provided a total of 96 participants. The participants were diverse in nature ranging in age from 18 to 77 years and were composed of 68 percent females and 32 percent males. The average age of the participants was 42.7 years. Any person 13 years of age or older was eligible to participate.

Ideally, participants would have been recruited from the general population through random sampling so that they would be representative of the population as a whole. Another alternative would have been to recruit sponsors (employers) first and then select their employees or members as volunteers. Yet another alternative would be to recruit volunteers from the general population through some form of media campaign. It was determined that each of these alternatives for recruitment of participants would have been logistically impossible to accomplish in the timeframe allowed. 


\section{Pilot Test}

Approximately two weeks prior to the collection of data, a pretest was conducted to determine if the methods initially spelled out for collecting data at each of the locations were appropriate. In all, eight persons participated in the pretest. The pretest consisted of taking individuals out to several of the actual sites that were part of the final sample and have them review the way in which the research team planned to collect data. Video cameras were used during the pretest to determine best placement for collecting information about participants as well as for the collection of the turning movements.

During the pretest, several recommendations were made and ultimately incorporated into the final method for collecting data. Initially, the research team planned to have one person at a time approach the curb for 30 seconds then make an assessment of the site. However, it was suggested to the research team that groups of three participants evaluate at one time for three minutes instead of one at a time for 30 seconds. Also, difficulty with the placement of the video cameras for the collection of turning movements became apparent. It was recommended that turning movements be collected manually in addition to the use of video cameras.

Figure 4. Form for Collecting Roadway and Control Characteristics

Date: Site ID:

Street Name: Intersecting Streets: 1)

2)

\begin{tabular}{|c|c|c|c|c|}
\hline & Variables & Definition & Unit & Result \\
\hline \multirow{8}{*}{ 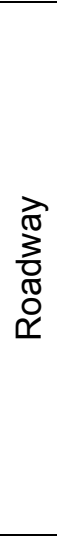 } & $\begin{array}{l}\text { Crossing distance } \\
\text { - near side }\end{array}$ & Curb to center distance & Feet & \\
\hline & $\begin{array}{l}\text { Crossing distance } \\
\text { - far side }\end{array}$ & Center to curb distance & Feet & \\
\hline & Raised median & Width & Feet & \\
\hline & Grassed median & Width & Feet & \\
\hline & Refuge island & Width & Feet & \\
\hline & Painted median & Width & Feet & \\
\hline & Crosswalks & $\begin{array}{l}\text { Whether a crosswalk is present: } 1 \text { if present; } \\
0 \text { otherwise }\end{array}$ & 0 or 1 & \\
\hline & Pedestrian signals & $\begin{array}{l}\text { Whether any pedestrian signal is present: } 1 \text { if } \\
\text { present; } 0 \text { otherwise }\end{array}$ & 0 or 1 & \\
\hline \multirow{3}{*}{$\begin{array}{l}\overline{0} \\
\text { 음 } \\
\bar{O}\end{array}$} & $\begin{array}{l}\text { Signal cycle - } \\
\text { near side }\end{array}$ & Full cycle length - near side & Seconds & \\
\hline & $\begin{array}{l}\text { Signal cycle - far } \\
\text { side }\end{array}$ & Full cycle length - far side & Seconds & \\
\hline & Signal spacing & $\begin{array}{l}\text { Block distance if both intersections are } \\
\text { signalized; } 1000 \text { feet otherwise }\end{array}$ & Feet & \\
\hline
\end{tabular}




\section{Collection}

\section{Static Data}

Static data, including both roadway and control characteristics, were collected before field surveys of crossing difficulty were carried out. A form like the one illustrated in Figure 4 was used for this purpose. The table lists all variables for which data are to be collected, a definition of the variables, and the unit of measurement. A measuring wheel was used to accurately determine distances such as crossing and median widths. The measured result for each variable was recorded in the last column.

One form was used for each site included in the study. The form identified a particular site both in terms of an ID that was pre-determined once the sites were selected, in terms of the name of the street the particular site was located, and in terms of the names of the intersecting streets. We separately determined whether each type of median treatment was present: raised, grassed, or painted medians. Raised and grassed medians are restrictive medians, while painted medians are non-restrictive. Painted medians included two-way-left-turn lanes. Refuge islands were treated as restrictive medians.

\section{Field Survey}

Prior to departing, the participants were read a set of briefing instructions that made it clear what was expected of them as well as some basic logistical issues such as the sites to be covered and other issues. It was also explained to participants what the research team meant by crossing difficulty. Crossing difficulty was explained as the risk of being hit by a car, the amount of time to wait for a suitable gap in traffic, presence of a median for refuge, lack of an acceptable (wide enough) traffic gap, or anything else that may affect crossing difficulty.

It was emphasized to participants that the research team is only interested in their perception of the level of difficulty of crossing the road. The research team, for instance, did not want their perception of the level of difficulty for other persons crossing the same road at the same point.

When it was their turn to evaluate any given site, three participants at a time were instructed to walk up to the curb and observe traffic conditions for three minutes. They were instructed not to enter or cross the street. In each case, a research team member kept the time for each group of participants. Based on research team member observations, three minutes was more than long enough for each group to observe any major changes in traffic conditions prior to making an assessment about the site. When observing, participants were instructed to continuously scan the roadway block by looking left, then right, then across the street as many times as they could during the three minutes. It was stressed to each participant that it was important for them to take into account all of the static and dynamic roadway characteristics that were present at each site prior to making an assessment or grading the site. Participants were told to be mindful that all of the dynamic characteristics are likely to continuously change during 
the three-minute observation window. They were also instructed that their perception of the level of crossing difficulty should not be based on the least favorable condition, the most favorable condition, or any single moment during the three-minute window of observation. Rather, they should base their perception on the summation of conditions, including any variations that they observe.

Once the three-minute observation window had closed, participants were asked to record their perception on a survey form before leaving the curb. The survey form contained either 5 or 6 rows of letters, with each row representing a mid-block crossing location. A copy of the survey form can be found in Figure 5. To simplify the matter of providing an assessment, the form was designed to parallel a grading system, ranging from A through F. An " $A$ " indicated no difficulty in crossing the road at a mid-block location and " $F$ " indicated extreme difficulty. Participants were instructed to think of the letter grades that they were to assign to the site as identical to those used in school. For each site, participants recorded their grade by simply circling the letter grade on the appropriate row.

Figure 5. Field-Survey Form

\begin{tabular}{|c|c|c|c|c|c|c|}
\hline \multirow{2}{*}{ Site ID } & \multicolumn{6}{|c|}{$\begin{array}{l}\text { Without actually crossing it, how do you perceive the } \\
\text { level of difficulty for you to cross this street at this point } \\
\text { under current conditions? }\end{array}$} \\
\hline & \multicolumn{2}{|c|}{ No Difficulty } & \multicolumn{2}{|c|}{$\begin{array}{l}\text { (Please circle only } \\
\text { one letter pr row) }\end{array}$} & & $\begin{array}{l}\text { Extreme } \\
\text { Difficulty }\end{array}$ \\
\hline 9 & A & B & C & D & $\mathbf{E}$ & $\mathbf{F}$ \\
\hline 2 & A & B & C & D & $\mathbf{E}$ & $\mathbf{F}$ \\
\hline 3 & A & B & C & D & $\mathbf{E}$ & $\mathbf{F}$ \\
\hline 4 & A & B & C & D & $\mathbf{E}$ & $\mathbf{F}$ \\
\hline 1 & $\mathbf{A}$ & B & C & D & $\mathbf{E}$ & $\mathbf{F}$ \\
\hline
\end{tabular}

Prior to leaving each day to collect data, participants were asked to keep several things in mind when observing and grading each mid-block location:

- Provide only your perception of crossing difficulty at the point of the mid-block where you will be standing.

- Do not consider any other sites that you have been asked to answer questions about today. Evaluate each site independently. 
- Do not consider your views on how important it is to improve conditions for pedestrians.

- Do not consider what you might do on the other side of the road. For example, if you are late for work and you have to make it across the street, you might grade the site less harshly than if you are in a more relaxed situation.

- Please don't compare or discuss your grades with any other evaluator at any time during the duration of the evaluation.

Participants were transported to the mid-block crossing locations with the use of full-size HARTline and PSTA motor coaches. Data collection took place on Tuesday, April 17, in Tampa, Thursday, April 19, in St. Petersburg, and Tuesday, April 24, in 2001 in Tampa from approximately 9 AM to 2:30 PM, depending on the day.

Once on the buses, participants were given a unique ID number on a 6-inch by 8-inch sheet of paper. They were asked to put their unique ID number on their survey form; a critical step in the data collection process since these ID numbers allowed the research team to match participant grades to the roadway characteristics and traffic conditions observed at each mid-block location. While at the curb observing traffic conditions, participants were instructed to hold up their ID numbers for a few seconds so that the video camera directly across the street could capture the unique number.

After grading a site, participants were asked to return to the bus or other designated area and wait to move on to another site. This process was repeated until all of the sites on a given day had been evaluated. The evaluation of all of the sites during the three days took between 5 and 6 hours each day.

\section{Dynamic Traffic Data}

Dynamic characteristics at each mid-block crossing location, such as traffic volume and speed and turning movements, were collected concurrently with the field survey. The sample of sites was separated into two groups for each of the days that data were collected. This resulted in a total of six groups of sites. The sample of mid-block locations contained within each of the six groups was grouped together in a logical fashion to make the collection of data easier.

In order to capture the dynamic characteristics, District Seven of the Florida Department of Transportation (FDOT) and the City of St. Petersburg provided traffic counters at each location during the field study.

In conjunction with the use of traffic counters, field researchers also manually cataloged turning movements. Figure 6 shows the alternative tool used for recording turning movements. Entries in italic are shown as examples of what the survey workers needed to record. 
Figure 6. Data Form for Turning Movements

\begin{tabular}{|c|c|c|c|c|c|}
\hline Site ID & 5 & Cluster & USF & Bus ID & One \\
\hline \multicolumn{2}{|c|}{ Nearside } & \multicolumn{4}{|c|}{ Eastbound } \\
\hline Group & Participant ID & Start Time & End Time & Turns & Misc. \\
\hline \multirow{3}{*}{1} & 1 & $9: 00$ & $9: 03$ & IIIIIIIIIIIIIIII & \\
\hline & 2 & & & & \\
\hline & 3 & & & & \\
\hline \multirow{3}{*}{2} & 4 & & & & \\
\hline & 5 & & & & \\
\hline & 6 & & & & \\
\hline \multirow{3}{*}{3} & 7 & & & & \\
\hline & 8 & & & & \\
\hline & 9 & & & & \\
\hline \multirow{3}{*}{4} & 10 & & & & \\
\hline & 11 & & & & \\
\hline & 12 & & & & \\
\hline \multirow{3}{*}{5} & 13 & & & & \\
\hline & 14 & & & & \\
\hline & 15 & & & & \\
\hline \multirow{3}{*}{6} & 16 & & & & \\
\hline & 17 & & & & \\
\hline & 18 & & & & \\
\hline \multirow{3}{*}{7} & 19 & & & & \\
\hline & 20 & & & & \\
\hline & 21 & & & & \\
\hline \multirow{3}{*}{8} & 22 & & & & \\
\hline & 23 & & & & \\
\hline & 24 & & & & \\
\hline \multirow{3}{*}{9} & 25 & & & & \\
\hline & 26 & & & & \\
\hline & 27 & & & & \\
\hline
\end{tabular}

\section{Data Reduction}

Once the data collection phase was complete, the collected data were entered into a spreadsheet for use later in building the pedestrian level of service model. In addition to entering the data from the survey forms, several videotapes were reviewed to obtain and verify information for traffic counts and turning movements at various sites for which information was incomplete. In all, 767 observations were recorded during the three days in which data were collected from 31 sites. Two of the original 33 sites selected were not used in the final field surveys. At one of the two sites, road construction started after the initial selection. The other site was skipped because of logistical problems. Among these observations, 48 were collected from two one-way streets. In addition, 26 observations were collected from a stop-controlled street. 
Table 3 shows the average and standard deviation of the stated perception on the level of crossing difficulty by participants' age and gender. The average is unusually low among those who were male and 65 years or old. The reason for this is unclear. It could have resulted from a relatively small sample of only 22 observations for this group.

Table 3. Stated Difficulty Levels by Age and Gender of the Full Sample

\begin{tabular}{|l|l|r|r|r|}
\hline Gender & Age & $\begin{array}{c}\text { Average Grade } \\
(1-6)\end{array}$ & Standard Deviation & \multicolumn{1}{c|}{$\begin{array}{c}\text { Number of } \\
\text { Observations }\end{array}$} \\
\hline \multirow{4}{*}{ Female } & $18-24$ & 2.66 & 1.463 & 119 \\
\cline { 2 - 5 } & $25-64$ & 2.92 & 1.736 & 345 \\
\cline { 2 - 5 } & $65+$ & 3.75 & 1.721 & 60 \\
\cline { 2 - 5 } & Total & 2.94 & 1.692 & 524 \\
\hline \multirow{5}{*}{ Male } & $18-24$ & 2.93 & 1.616 & 56 \\
\cline { 2 - 5 } & $25-64$ & 2.96 & 1.510 & 165 \\
\cline { 2 - 5 } & $65+$ & 2.55 & 1.262 & 243 \\
\cline { 2 - 5 } & Total & 2.92 & 1.514 & 175 \\
\hline \multirow{5}{*}{ Total } & $18-24$ & 2.75 & 1.514 & 510 \\
\cline { 2 - 5 } & $25-64$ & 2.94 & 1.665 & 82 \\
\cline { 2 - 5 } & $65+$ & 3.29 & 1.667 & 767 \\
\cline { 2 - 5 } & Total & 2.93 & 1.636 & \\
\hline
\end{tabular}

Table 4 shows the maximum, minimum, median, mean, and standard deviation of each explanatory variable to be used in the statistical analysis in the next chapter. For intersections without signals, the cycle length was set at zero. For blocks that were not signalized at both intersections, the signal spacing was set at 5000 feet. The statistics for cycle length and signal spacing reflect these assumptions.

Table 4. Selected Statistics of Explanatory Variables for the Full Sample

\begin{tabular}{|l|r|r|}
\hline Variables & Mean & Standard Deviation \\
\hline 65 Years Or Older Dummy (0-1) & 0.11 & 0.31 \\
\hline Nearside Total Volume (1000 vehicles / hour) & 4.43 & 3.79 \\
\hline Far-side Total Volume (1000 vehicles / hour) & 3.67 & 2.42 \\
\hline Nearside Turning Movements (vehicles / hour) & 137 & 183 \\
\hline Far-side Turning Movements (vehicles / hour) & 127 & 150 \\
\hline Average Speed (miles / hour) & 32.1 & 5.5 \\
\hline Nearside Crossing Width (feet) & 26.7 & 7.4 \\
\hline Far-side Crossing Width (feet) & 28.5 & 9.2 \\
\hline Width Of Restricted Median (feet) & 7.5 & 13.1 \\
\hline Width Of Painted Median (feet) & 3.5 & 5.8 \\
\hline Crosswalk Dummy (0-1) & 0.51 & 0.50 \\
\hline Pedestrian-Signal Dummy (0-1) & 0.23 & 0.42 \\
\hline Nearside Cycle Length (seconds) & 27.3 & 49.3 \\
\hline Far-side Cycle Length In (seconds) & 25.8 & 46.0 \\
\hline Signal Spacing (feet) & 4,075 & 1,614 \\
\hline
\end{tabular}




\section{Chapter Five: STATISTICAL ANALYSIS}

The statistical analysis of the data set started with a basic model as described earlier in Chapter Four. This basic model has several features: 1) it uses all characteristics that were hypothesized to be important in the research-design process; 2) it uses directional measures for four characteristics; 3) all variables are in linear form; and 4) the full data set was used for estimation.

Many alternative model forms were then considered, with four being reported here. The others are minor variations of these four. One set of alternatives uses one of the four groups of characteristics: personal, traffic, roadway, and control characteristics. These are discussed as part of the basic model. One alternative combines the two directional measures for each of the four directionally measured characteristics. Another alternative considers non-linear forms of the variables. The fourth alternative re-estimated the basic model with a part of the full data set that excludes observations from one site with stopsign control and two sites with one-way traffic.

Alternative model forms that include interactions between variables were considered but not estimated. It is reasonable to hypothesize that certain site characteristics become important only if some of the other site characteristics reach certain levels. For example, the presence of pedestrian signals may start to reduce the perceived difficulty for midblock crossing once traffic volume is very high. Such interactions are not included for several reasons. First, there are potentially a large number of interactions. Second, it is unknown where the breakpoints are for each interaction. Determining these breakpoints for the large number of potential interactions would mean almost endless mining of the data. Third, the range of variation, particularly traffic volume, is very limited in the sample due largely to the fact that the field surveys occurred mostly during the mid-day period.

\section{Basic Model}

Table 5 shows the results for the basic model. The discussion covers the overall fit of the model. Three aspects are covered, including the R-square, how well the results match the expectations discussed earlier, model stability, and model sensitivity.

\section{R-square}

The R-square reflects how well the model fits the data and measures the proportion of variation in the reported level of difficulty across the sample that is explained by the explanatory variables in the model. One property of the R-square is that it increases with the number of explanatory variables. It is customary to report the adjusted R-square that accounts for the number of explanatory variables.

The adjusted R-square of this model is 0.34 . While this value is reasonable for a crosssectional analysis of individual responses, it is low relative to several similar studies 
related to the Department's Multi-modal Quality of Service Program. For example, Landis et al. (2001) report an unadjusted R-square value of 0.85 . With adjustment, the $\mathrm{R}$-square value would be still more than double what is being reported from this analysis.

Table 5. Basic Model with Full Sample

\begin{tabular}{|l|r|r|r|}
\hline Variables & Coefficients & $\begin{array}{c}\text { Standardized } \\
\text { Coefficients }\end{array}$ & t-statistics \\
\hline Constant & -2.4778 & & -3.2120 \\
\hline$(+)$ 65 Years Or Older Dummy (0-1) & 0.4937 & 0.0933 & 3.1133 \\
\hline$(+)$ NS Total Volume (1000 vehicles / hour) & -0.1159 & -0.2682 & -4.1854 \\
\hline$(+)$ FS Total Volume (1000 vehicles / hour) & 0.2674 & 0.3957 & 6.8259 \\
\hline$(+)$ NS Turning Movements (vehicles / hour) & 0.0018 & 0.2033 & 3.5434 \\
\hline$(+)$ FS Turning Movements (vehicles / hour) & 0.0013 & 0.1224 & 2.5595 \\
\hline$(+)$ Average Speed (miles / hour) & 0.0107 & 0.0344 & 0.7618 \\
\hline$(+)$ NS Crossing Width (feet) & -0.0852 & -0.3846 & -4.3901 \\
\hline$(+)$ FS Crossing Width (feet) & 0.1241 & 0.7015 & 6.1663 \\
\hline$(-)$ Width Of Restricted Median (feet) & -0.0661 & -0.5300 & -5.5726 \\
\hline$(-)$ Width Of Painted Median (feet) & 0.0712 & 0.2531 & 7.2010 \\
\hline$(-)$ Crosswalk Dummy (0-1) & -0.2762 & -0.0844 & -1.5645 \\
\hline$( \pm)$ Pedestrian-Signal Dummy (0-1) & -0.4930 & -0.1265 & -3.1598 \\
\hline$( \pm)$ NS Cycle Length (seconds) & -0.0326 & -0.9823 & -3.3957 \\
\hline$( \pm)$ FS Cycle Length In (seconds) & 0.0610 & 1.7144 & 5.4797 \\
\hline$( \pm)$ Signal Spacing (feet) & 0.0007 & 0.6464 & 7.6269 \\
\hline $\begin{array}{l}\text { Adjusted R Square } \\
\text { Std. Error Of The Regression }\end{array}$ & & 0.34 & \\
Sample & & 1.328 & \\
\hline
\end{tabular}

Notes: "(+)" indicates that an increase in the explanatory variable would increase the level of difficulty. "(-)" indicates that an increase in the explanatory variable would decrease the level of difficulty. " $( \pm)$ " indicates that the direction of the net effect of the explanatory variable is analytically unknown and needs to be empirically determined. The abbreviations "NS" and "FS" represent nearside and far side, respectively. The dummy variables take one when the characteristic as described in the name of the variable is present and zero otherwise. The standardized coefficients represent the change in the level of difficulty from a change of one standard deviation in an explanatory variable. The t-statistics assumes that the repeated observations from the same participant were statistically independent.

One cannot pinpoint the exact reasons for this difference. Below are some of the most likely reasons in order of importance:

- All coefficients are estimated simultaneously in this analysis. In contrast, Landis et al. (2001) manually determined the three coefficients in the term called lateral separation elements to improve the model fit and thereby increased the R-square.

- The estimation is based on the individual responses in this study. In contrast, the estimation in Landis et al. (2001) appears to be based on directional segments with the individual observations on the same directional segment averaged. Instead of using the 1,315 actual observations, the estimation used 42 averaged 
observations corresponding to 42 directional segments. This high degree of aggregation may have increased the R-square significantly.

- Fewer repeated responses from the same participant were obtained in this study. In fact, the average number of repeated responses is about 7.5 in this study versus 21 in the study by Landis et al. (2001).

- Sites are unrelated to each other in this study. In contrast, the 21 segments used by Landis et al. (2001) were on a single loop.

\section{Expectations}

For each variable, the table shows its coefficient, standardized coefficient, t-statistic, and the expected sign of its coefficient in front of the variable name, and the unit of its measurement. Instead of discussing the results for individual variables, the following discussion is grouped by themes. With minimum exceptions (non-restrictive medians and running speed), all characteristics are statistically significant and show coefficients of expected signs.

\section{Non-restrictive Medians}

Although the magnitude of effects of non-restrictive medians was expected to be smaller than that of restrictive medians, the width of a non-restrictive median was expected to reduce the level of difficulty for mid-block street crossing. The estimated magnitude is slightly smaller for non-restrictive medians than restrictive medians. The estimated sign, however, is positive for non-restrictive medians, indicating that wider non-restrictive medians would be perceived to make crossing at mid-block locations more difficult for pedestrians. In comparison to restrictive medians, pedestrians in non-restrictive medians face a larger risk of being hit by motor vehicles in both directions. It is possible that people may think that wider non-restrictive medians would increase the likelihood of motor vehicles using the medians and, hence, the risk of being hit by such vehicles.

\section{Running Speed}

Speed is statistically insignificant in this sample and model specification. It is possible that people may have difficulty in perceiving speed. Evidence from Scotland shows that real pedestrians have difficulty in indicating the effects of speed on their street crossing behavior (Hine and Russell, 1993).

\section{Traffic Control}

Based on the standardized coefficients, the most influential variables are signal cycle and signal spacing, both of which measure traffic control. This is what one would expect because they are key determinants of traffic patterns and gap availability on urban arterials. Gap availability is intuitively the most important factor in determining midblock crossing difficulty. 


\section{Crosswalk}

The presence of crosswalks is marginally significant. The variable is statistically insignificant at the 95 percent confidence level under a two-tailed test but marginally significant under a one-tailed test. Typically, whether a variable is statistically significant is determined with the so-called two-tailed test. This should be done when one does not have a specific expectation on the sign of the coefficient. When one does have a specific expectation on the sign of the coefficient, a one-tailed test is more appropriate.

\section{Directional Measurement}

The coefficients for the directional measures of traffic volume, crossing width, and signal cycle are negative for the nearside but positive for the far side. Given other characteristics and their values for the far side, this result says that people tend to perceive mid-block street crossing less difficult with heavier traffic, wider crossing distance, or longer signal cycle on the nearside but more difficult with heavier traffic, wider crossing distance, or longer signal cycle on the far-side. Other than some evidence that people have different views and different crossing behaviors between the two sides of a street (Hunt and Russell, 1993), there is no explanation for such differential effects by direction.

However, the combined effect of both directions for either traffic volume or crossing width has the expected sign. This is true when the two sides are symmetric in these characteristics. This is also true when the nearside is not significantly wider or has no significantly heavier traffic than the far side. More specifically, the combined effect of both directions for traffic volume would be positive as long as the nearside traffic volume does not reach 230 percent of the far-side volume. Similarly, the combined effect of both directions for crossing width would be positive as long as the nearside width does not reach 145 percent of the far-side width.

\section{Ambiguous Variables}

As pointed out earlier, the expected effects of the presence of mid-block pedestrian signals and the length of signal cycles are ambiguous. The presence of a mid-block pedestrian signal tends to increase both gap availability and pedestrian delays for street crossing. Similarly, longer signal cycles tend to increase gap size at mid-block locations but reduce gap frequency (and increase pedestrian delays). In both cases, the net effect depends on which of the two opposing factors dominates the other. The empirical results show that the estimated coefficient is negative for pedestrian signal, indicating that the gap-availability effect appears to dominate the delay effect. The estimated overall coefficient is positive for signal cycle, indicating that the frequency effect appears to dominate the gap-size effect. 


\section{Stability}

One indicator of the quality of a model is whether it is stable when certain explanatory variables are excluded or changed. Eight alternative sets of variables are first reported in Tables 6 and 7. Table 6 shows four models that included only one of the four characteristic groups at a time: personal, traffic, roadway, and control characteristics. Reported for each model are the individual coefficients and whether they are statistically significant at the 95 percent level. These models are reasonably stable compared to the full model reported in the last column. Stability here includes both the sign and the magnitude of a coefficient compared to the full model. In the two cases where the coefficients changed sign, both are statistically insignificant.

\section{Table 6. Models Including One Characteristic Group}

\begin{tabular}{|l|c|c|c|c|c|}
\hline \multirow{2}{*}{ Variables } & \multicolumn{5}{|c|}{ Characteristic Group Included } \\
\cline { 2 - 6 } & Personal & Traffic & Roadway & Control & All \\
\hline Constant & 2.8876 & 0.5535 & 1.9533 & 0.9812 & -2.4778 \\
\hline$(+)$ 65 Years Or Older (0-1) & 0.4051 & & & & 0.4937 \\
\hline$(+)$ NS Total Volume (1000 vehicles / hour) & & -0.0538 & & & -0.1159 \\
\hline$(+)$ FS Total Volume (1000 vehicles / hour) & & 0.2455 & & & 0.2674 \\
\hline$(+)$ NS Turning Movements (vehicles / hour) & & -0.0007 & & & 0.0018 \\
\hline$(+)$ FS Turning Movements (vehicles / hour) & & 0.0033 & & & 0.0013 \\
\hline$(+)$ Average Speed (miles / hour) & & 0.0434 & & & $0.0107 *$ \\
\hline$(+)$ NS Crossing Width (feet) & & & -0.0385 & & -0.0852 \\
\hline$(+)$ FS Crossing Width (feet) & & & 0.0684 & & 0.1241 \\
\hline$(-)$ Width Of Restricted Median (feet) & & & $0.0061 *$ & & -0.0661 \\
\hline$(-)$ Width Of Painted Median (feet) & & & 0.0961 & & 0.0712 \\
\hline$(-)$ Crosswalk Dummy (0-1) & & & -0.5450 & & -0.2762 \\
\hline$( \pm)$ Pedestrian-Signal Dummy (0-1) & & & -0.2168 & & -0.4930 \\
\hline$( \pm)$ NS Cycle Length (seconds) & & & & -0.0441 & -0.0326 \\
\hline$( \pm)$ FS Cycle Length In (seconds) & & & & 0.0624 & 0.0610 \\
\hline$( \pm)$ Signal Spacing (feet) & & & & 0.0004 & 0.0007 \\
\hline Adjusted R-Square & 0.005 & 0.176 & 0.239 & 0.061 & 0.341 \\
\hline Std. Error Of The Regression & 1.63 & 1.48 & 1.42 & 1.58 & 1.33 \\
\hline Sample & 767 & 767 & 767 & 767 & 767 \\
\hline
\end{tabular}

Notes: Coefficients with “*” are statistically insignificant at the 95 percent level.

Table 7 shows four models that exclude one of the four groups at a time. Reported for each model again are the individual coefficients and whether they were statistically significant at the 95 percent level. The magnitude of coefficients for a given variable was generally stable across the models for most variables. More important, the sign of coefficients is stable across all models for all variables. Taking into account the sign and magnitude of coefficients, the coefficients were extremely stable when one group of characteristics was excluded. 
Table 7. Models Excluding One Characteristic Group

\begin{tabular}{|l|c|c|c|c|c|}
\hline \multirow{2}{*}{ Variables } & \multicolumn{5}{|c|}{ Characteristic Group Excluded } \\
\cline { 2 - 6 } & Personal & Traffic & Roadway & Control & All \\
\hline Constant & -2.3389 & -1.2095 & -0.5651 & 1.7710 & -2.4778 \\
\hline$(+)$ 65 Years Or Older (0-1) & & 0.4689 & 0.4264 & 0.4729 & 0.4937 \\
\hline$(+)$ NS Total Volume (1000 vehicles / hour) & -0.1156 & & -0.0645 & -0.0555 & -0.1159 \\
\hline$(+)$ FS Total Volume (1000 vehicles / hour) & 0.2657 & & 0.2524 & 0.2307 & 0.2674 \\
\hline$(+)$ NS Turning Movements (vehicles / hour) & 0.0017 & & $0.0001^{*}$ & $0.0003^{*}$ & 0.0018 \\
\hline$(+)$ FS Turning Movements (vehicles / hour) & 0.0015 & & 0.0029 & 0.0020 & 0.0013 \\
\hline$(+)$ Average Speed (miles / hour) & $0.0104^{*}$ & & 0.0285 & $0.0053^{*}$ & $0.0107^{*}$ \\
\hline$(+)$ NS Crossing Width (feet) & -0.0871 & -0.0489 & & -0.0506 & -0.0852 \\
\hline$(+)$ FS Crossing Width (feet) & 0.1234 & 0.1128 & & 0.0473 & 0.1241 \\
\hline$(-)$ Width Of Restricted Median (feet) & -0.0634 & -0.0437 & & $-0.0013^{*}$ & -0.0661 \\
\hline$(-)$ Width Of Painted Median (feet) & 0.0721 & 0.0796 & & 0.0875 & 0.0712 \\
\hline$(-)$ Crosswalk Dummy (0-1) & $-0.2353^{*}$ & -0.6580 & & $-0.2488^{*}$ & -0.2762 \\
\hline$( \pm)$ Pedestrian-Signal Dummy (0-1) & -0.5142 & $-0.1841^{*}$ & & -0.5492 & -0.4930 \\
\hline$( \pm)$ NS Cycle Length (seconds) & -0.0341 & -0.0329 & -0.0349 & & -0.0326 \\
\hline$( \pm)$ FS Cycle Length In (seconds) & 0.0622 & 0.0570 & 0.0459 & & 0.0610 \\
\hline$( \pm)$ Signal Spacing (feet) & 0.0006 & 0.0005 & 0.0003 & & 0.0007 \\
\hline Adjusted R-Square & 0.334 & 0.291 & 0.210 & 0.288 & 0.341 \\
\hline Std. Error Of The Regression & 1.33 & 1.37 & 1.45 & 1.38 & 1.33 \\
\hline Sample & 767 & 767 & 767 & 767 & 767 \\
\hline Na Coeficients wit
\end{tabular}

Notes: Coefficients with “*” are statistically insignificant at the 95 percent level.

\section{Model Sensitivity}

One way to validate the basic model is to examine whether the derived level of service is reasonable and responsive to changes in individual or combination of explanatory variables in the model. To do this, a simple spreadsheet is created as shown in Figure 7.

The idea is to start with a set of base conditions under which the level of service is F. Two sets of scenario are then considered. Each scenario under the first set represents conditions that differ from the base conditions as a result of changes in one characteristic. When a characteristic is measured by direction, symmetrical changes are made in both directions. Each scenario under the second set represents conditions that differ from the base conditions as a result of changes in one or more of the four characteristic groups: personal, traffic, roadway, control characteristics.

The first column shows the scenarios. These scenarios are defined by the individual explanatory variables shown in the middle columns. The last two columns show the predicted level of difficulty and derived level of service.

For consistency, the same approach and the same ranges are used in converting predicted levels of difficulty into level of service categories as used by Landis et al. (2001). These ranges are also shown at the bottom of the spreadsheet. 


\section{Figure 7. Spreadsheet on Sensitivity of Basic Model}

\begin{tabular}{|c|c|c|c|c|c|c|c|c|c|c|c|c|c|c|c|c|c|}
\hline \multirow{4}{*}{$\begin{array}{l}\text { Variable Category } \\
\text { Variable name } \\
\text { Definition }\end{array}$} & \multirow{3}{*}{\begin{tabular}{|c|} 
Person \\
MA \\
Age
\end{tabular}} & \multicolumn{5}{|c|}{ Traffic } & \multicolumn{6}{|c|}{ Roadway } & \multicolumn{3}{|c|}{ Control } & \multirow{2}{*}{\multicolumn{2}{|c|}{$\begin{array}{l}\text { Crossing } \\
\text { Difficulty }\end{array}$}} \\
\hline & & \multirow{2}{*}{\begin{tabular}{|c|} 
NV \\
Near
\end{tabular}} & \multirow{2}{*}{$\begin{array}{l}\text { FV } \\
\text { Far }\end{array}$} & \multirow{2}{*}{$\begin{array}{c}\text { NT } \\
\text { Near }\end{array}$} & \multirow{2}{*}{$\begin{array}{l}\text { FT } \\
\text { Far }\end{array}$} & \multirow{2}{*}{$\begin{array}{c}\text { SP } \\
\text { Spd. }\end{array}$} & \multirow{2}{*}{$\frac{\text { NW }}{\text { Near }}$} & \multirow{2}{*}{$\begin{array}{l}\text { FW } \\
\text { Far }\end{array}$} & \multirow{2}{*}{$\begin{array}{c}\text { RM } \\
\text { Res. }\end{array}$} & \multirow{2}{*}{$\begin{array}{l}\text { NM } \\
\text { Non }\end{array}$} & \multirow{2}{*}{\begin{tabular}{|c|} 
CW \\
Cross
\end{tabular}} & \multirow{2}{*}{$\begin{array}{c}\text { PS } \\
\text { Ped. }\end{array}$} & \multirow{2}{*}{$\frac{\text { NC }}{\text { Near }}$} & \multirow{2}{*}{$\begin{array}{l}\text { FC } \\
\text { Far }\end{array}$} & \multirow{2}{*}{$\frac{\text { DS }}{\text { Signal }}$} & & \\
\hline & & & & & & & & & & & & & & & & \multirow{2}{*}{ Value } & \multirow{2}{*}{ LOS } \\
\hline & $65+$ & Vol & Vol & Turns & Turns & Limit & Width & Width & Med & Res. & Walk & Signal & Cycle & Cycle & Space & & \\
\hline Unit & $(\%)$ & (tvph) & (tvph) & (vph) & $(\mathrm{vph})$ & $(\mathrm{mph})$ & $(\mathrm{ft})$ & (ft) & (ft) & $(\mathrm{ft})$ & $0 / 1$ & $0 / 1$ & $(\mathrm{sn})$ & $(\mathrm{sn})$ & (ft) & $1-6$ & $A-F$ \\
\hline Base Condtitions & 25 & 4 & 4 & 180 & 180 & 55 & 36 & 36 & 0 & 0 & 0 & 0 & 150 & 150 & 1000 & 5.8 & $\mathbf{F}$ \\
\hline \multicolumn{18}{|c|}{ Scenarios Defined by Individual Characteristics } \\
\hline No older population (MA) & 0 & 4 & 4 & 180 & 180 & 55 & 36 & 36 & 0 & 0 & 0 & 0 & 150 & 150 & 1000 & 5.6 & $\mathbf{F}$ \\
\hline Half volume & 25 & 2 & 2 & 180 & 180 & 55 & 36 & 36 & 0 & 0 & 0 & 0 & 150 & 150 & 1000 & 5.5 & E \\
\hline Half turning movements & 25 & 4 & 4 & 90 & 90 & 55 & 36 & 36 & 0 & 0 & 0 & 0 & 150 & 150 & 1000 & 5.5 & E \\
\hline Half speed (SP) & 25 & 4 & 4 & 180 & 180 & 28 & 36 & 36 & 0 & 0 & 0 & 0 & 150 & 150 & 1000 & 5.5 & E \\
\hline Half road width & 25 & 4 & 4 & 180 & 180 & 55 & 18 & 18 & 0 & 0 & 0 & 0 & 150 & 150 & 1000 & 5.1 & E \\
\hline Res. median present (RM) & 25 & 4 & 4 & 180 & 180 & 55 & 36 & 36 & 5 & 0 & 0 & 0 & 150 & 150 & 1000 & 5.4 & E \\
\hline Non res. Median (NM) & 25 & 4 & 4 & 180 & 180 & 55 & 36 & 36 & 0 & 5 & 0 & 0 & 150 & 150 & 1000 & 6.1 & $F$ \\
\hline Crosswalk present (CW) & 25 & 4 & 4 & 180 & 180 & 55 & 36 & 36 & 0 & 0 & 1 & 0 & 150 & 150 & 1000 & 5.5 & E \\
\hline Pedestrian signal (PS) & 25 & 4 & 4 & 180 & 180 & 55 & 36 & 36 & 0 & 0 & 1 & 1 & 150 & 150 & 1000 & 5.0 & E \\
\hline Half signal cycle & 25 & 4 & 4 & 180 & 180 & 55 & 36 & 36 & 0 & 0 & 0 & 0 & 75 & 75 & 1000 & 3.6 & D \\
\hline Half signal spacing (DS) & 25 & 4 & 4 & 180 & 180 & 55 & 36 & 36 & 0 & 0 & 0 & 0 & 150 & 150 & 500 & 5.4 & E \\
\hline \multicolumn{18}{|c|}{ Scenarios Defined by Combination of Characteristics } \\
\hline Traffic charateristics & 25 & 2 & 2 & 90 & 90 & 28 & 36 & 36 & 0 & 0 & 0 & 0 & 150 & 150 & 1000 & 4.9 & E \\
\hline Roadway characteristics & 25 & 4 & 4 & 180 & 180 & 55 & 18 & 18 & 5 & 5 & 1 & 1 & 150 & 150 & 1000 & 4.3 & D \\
\hline Control characteristics & 25 & 4 & 4 & 180 & 180 & 55 & 36 & 36 & 0 & 0 & 0 & 0 & 75 & 75 & 500 & 3.3 & C \\
\hline Traffic and roadway char. & 25 & 2 & 2 & 90 & 90 & 28 & 18 & 18 & 5 & 5 & 1 & 1 & 150 & 150 & 1000 & 3.4 & C \\
\hline Traffic and control char. & 25 & 2 & 2 & 90 & 90 & 28 & 36 & 36 & 0 & 0 & 0 & 0 & 75 & 75 & 500 & 2.4 & B \\
\hline Roadway and control char. & 25 & 4 & 4 & 180 & 180 & 55 & 18 & 18 & 5 & 5 & 1 & 1 & 75 & 75 & 500 & 1.8 & B \\
\hline All characteristics & 0 & 2 & 2 & 90 & 90 & 28 & 18 & 18 & 5 & 5 & 1 & 1 & 75 & 75 & 500 & 0.8 & A \\
\hline
\end{tabular}

$\begin{array}{ll}\mathrm{MA}=\text { percentage of pedestrians } 65+ & \mathrm{DS}=\text { spacing of traffic signals } \\ \mathrm{NV}=\text { near-side volume } & \mathrm{RM}=\text { width restrictive medians } \\ \mathrm{FV}=\text { far-side volume } & \mathrm{NM}=\text { width of non-restrictive medians } \\ \mathrm{NT}=\text { near-side turning movements } & \mathrm{CW}=\text { crosswalks } \\ \mathrm{FT}=\text { far-side turning movements } & \mathrm{PS}=\text { pedestrian signals } \\ \mathrm{SP}=\text { midblock running speed } & \mathrm{tvph} / \mathrm{vph}=1000 \text { vehicles/vehicles per hour } \\ \mathrm{NW}=\text { near-side road width } & \mathrm{mph}=\text { miles per hour } \\ \mathrm{FW}=\text { far-side road width } & \mathrm{ft}=\text { feet } \\ \mathrm{NC}=\text { near-side signal cycle } & \mathrm{sn}=\text { seconds } \\ \mathrm{FC}=\text { far-side signal cycle } & \mathrm{O} / 1=0 \text { or } 1 \\ & \\ \text { LOS }=\text { A if Value }<=1.5 & \text { LOS }=\mathrm{D} \text { if Value }>3.5 \text { and }<=4.5 \\ \text { LOS }=\mathrm{B} \text { if Value }>1.5 \text { and }<=2.5 & \text { LOS }=\mathrm{E} \text { if Value }>4.5 \text { and }<=5.5 \\ \text { LOS }=\text { C if Value }>2.5 \text { and }<=3.5 & \text { LOS }=\mathrm{F} \text { if Value }>5.5\end{array}$

The specific changes for the individual characteristics depend on how they are to be measured in applications. For the percentage of pedestrians 65 years or older, the change is from 25 percent under base conditions to 0 percent. For crosswalks or pedestrian signals, the changes are from not being present under base conditions to being present. For all other variables, the changes are a reduction in their values by half. These changes 
are used in defining all scenarios. These changes are for illustration purposes and some of the scenarios may not be truly realistic as a result. However, most of the scenarios are reasonable. Also, the base conditions and the different scenarios do not necessarily represent variations of the same roadway segment, particularly when crossing width is cut in half.

The derived level of service ranges from $\mathrm{F}$ to $\mathrm{D}$ under the scenarios defined with individual characteristics and from $\mathrm{E}$ to $\mathrm{A}$ under the scenarios defined with one or more characteristic groups. The effect of changes in the individual characteristics is relatively minor. More dramatic effects result from changes in multiple characteristics. Among these scenarios, level of service A is achieved only under the scenario where all changes of the individual characteristics occur together. The derived level of service appears to be most responsive to changes in signal cycle. This is consistent with our earlier observation on what characteristics are most influential based on the standardized coefficients.

A note of caution is needed here. How the derived level of service changes in response to these scenarios depends very much on where the predicted level of difficulty under the base conditions is in the range that defines the base level of service. Under the base conditions in Figure 7, the predicted level of difficulty is 5.8, which is only slightly higher than the breakpoint, 5.5, for level of service F. Thus the derived level of difficulty is towards the lower end of the range for defining F. As a result, the derived level of service is relatively responsive to the stated scenarios. If the predicted level of difficulty under the base conditions happens to be toward the higher end of the range, however, the responsiveness would be much lower. This base-dependency of the derived level of service results from the fact the predicted level of difficulty is treated as quantitative but the derived level of service is qualitative. This base-dependency is also worsened by the fact that the predicted level of difficulty is not bounded upward. This lack of upward bound results from the modeling approach: the level of crossing difficulty is modeled directly as a function of various characteristics.

Another caution is related to the statistical uncertainty in the predicted difficulty levels. All predictions involve errors, including those that are based on statistically estimated models. We can only say that the predicted difficulty levels shown in Figure 7 fall into certain confidence intervals. Both the selected confidence level and the prediction errors determine the width of these intervals. For example, the width would be 0.74 with a confidence level of 95 percent and a standard error of 0.188 .

\section{Estimation Issues}

Two estimation issues are discussed here. One relates to the presence of multicollinearity across the explanatory variables. The other relates to the use of repeated observations from the same individuals. 


\section{Multicollinearity}

Some multicollinearity appears to be present in the data, particularly between each pair of directional measures of the same characteristic. Specifically, the correlation coefficients between the two directional measures are $0.77,0.71,0.82$, and 0.99 for traffic volume, turning movements, crossing width, and signal cycle, respectively. The correlation is particularly strong for signal cycle. However, correlation between different characteristics is relatively low and does not appear to be a concern.

The consequence of multicollinearity is that the coefficients of the highly correlated variables are not precisely estimated. This consequence becomes a serious problem if the objective of estimating a model is to test hypothesis on the individual variables. When the coefficients are not precisely estimated, any hypothesis testing based on these coefficients is unreliable. If, however, the model is estimated for predictive purposes, imprecision in the individual coefficients need not be a serious concern as long as two conditions are reasonably satisfied. One condition is that the correlated variables as a group are precisely estimated. The other condition that the correlation pattern is expected to prevail in the situations to be predicted (Kennedy, 1985). Because all these conditions are satisfied with this model, multicollinearity should not be the reason to reject this model.

\section{Repeated Observations}

Like previous modeling efforts of pedestrian or bicyclist perceived quality of service, repeated observations are used in this research. In reporting the results, especially the tstatistics, these repeated observations are assumed to be statistically independent from either other. In reality, the repeated observations from the same person are likely to be correlated. This correlation results from certain characteristic of the person that influences his reported level of difficulty but is unobserved. Without accounting for such correlation would inflate t-statistics and overstate the statistical significance of individual variables.

One ad hoc but conservative adjustment for such correlation is to divide the reported tstatistics by the square root of the average number of repeated observations per participant (Louviere and Woodworth, 1983). Table 8 shows both the unadjusted and conservatively adjusted t-statistics for the basic model reported earlier. In this case, the adjustment factor is 2.83 or the square root of the average number of responses per participant. Of the 15 variables in the model, 13 are significant without adjustment but only 6 are with adjustment. Similarly, the adjustment factor would be 4.58 or the square root of 21 for the study reported by Landis et al. (2001). With this adjustment, only lateral separation elements would be significant; neither motor vehicle volume nor traffic running speed would be significant. 
Table 8. Adjustment of t-statistics for Repeated Observations

\begin{tabular}{|l|c|c|c|}
\hline \multirow{2}{*}{ Variables } & \multirow{2}{*}{ Unadjusted } & \multicolumn{2}{|c|}{ Adjusted } \\
\cline { 3 - 4 } & & Conservative & Alternative \\
\hline Constant & -3.21 & -1.14 & -2.68 \\
\hline 65 Years Or Older Dummy (0-1) & 3.11 & 1.10 & 2.59 \\
\hline NS Total Volume (1000 vehicles / hour) & -4.19 & -1.48 & -3.49 \\
\hline FS Total Volume (1000 vehicles / hour) & 6.83 & $2.41^{\mathrm{c}}$ & 5.69 \\
\hline NS Turning Movements (vehicles / hour) & 3.54 & 1.25 & 2.95 \\
\hline FS Turning Movements (vehicles / hour) & 2.56 & 0.91 & 2.13 \\
\hline Average Speed (miles / hour) & $0.76^{\mathrm{u}}$ & $0.27^{\mathrm{u}}$ & $0.63^{\mathrm{a}}$ \\
\hline NS Crossing Width (feet) & -4.39 & -1.55 & -3.66 \\
\hline FS Crossing Width (feet) & 6.17 & $2.18^{\mathrm{c}}$ & 5.14 \\
\hline Width Of Restricted Median (feet) & -5.57 & $-1.97^{\mathrm{c}}$ & -4.64 \\
\hline Width Of Painted Median (feet) & 7.20 & $2.55^{\mathrm{c}}$ & 6.00 \\
\hline Crosswalk Dummy (0-1) & $-1.56^{\mathrm{u}}$ & -0.55 & $-1.30^{\mathrm{a}}$ \\
\hline Pedestrian-Signal Dummy (0-1) & -3.16 & -1.12 & -2.63 \\
\hline NS Cycle Length (seconds) & -3.40 & -1.20 & -2.83 \\
\hline FS Cycle Length In (seconds) & 5.48 & $1.94^{\mathrm{c}}$ & 4.57 \\
\hline Signal Spacing (feet) & 7.63 & $2.70^{\mathrm{c}}$ & 6.36 \\
\hline Not cul for the undusted t-stistcs
\end{tabular}

Notes: "u" for the unadjusted t-statistics indicates variables that are statistically insignificant at the 95 percent confidence level before the adjustment. "c" for the conservatively adjusted t-statistics indicates variables that are statistically significant after the adjustment. "a" for the alternatively adjusted t-statistics indicates variables that are statistically significant after the adjustment.

Alternative methods have been developed to deal with the issue of repeated observations (Ouwersloot and Rietveld, 1996; and Revelt and Train, 1998). The advantage of these two methods is that they directly take into account the repeated observations. However, both were developed in the context of estimating discrete choice models. Both require customized programming. Neither was tried in this context because of these reasons.

Evidence, though limited, from applying these two methods shows that the degree of inflation in the t-statistics is small. Using the method by Revelt and Train and stated preference data on people's scheduling choices for commuting trips, the results from Noland et al. (1997) show an adjustment factor of no larger than 1.1. The number of repeated observations was 9 in their case. Using stated preference data on people's professional networking choices, the results from Ouwersloot and Rietveld show an adjustment factor of no larger than 1.2. The number of repeated observations was 4 in this case. Using the larger of these two adjustment factors, the statistical significance of individual explanatory variables changes little as shown in the last column of Table 8.

All t-statistics outside Table 8 are reported without any adjustment. 


\section{Reasonableness}

To examine the reasonableness of the model predictions, the predicted level of crossing difficulty and the corresponding level of service designation are compared to the observed level of service for each site in the sample. Two comparisons are done below. One comparison treats the predicted level of crossing difficulty and the resulting level of service as certain. The other takes into account potential prediction errors.

\section{Without Prediction Errors}

The observed difficulty is average across all responses for a given site. The number of responses ranges from 24 to 26 . The predicted difficulty is based on average values of the explanatory variables across all responses for a given site. The corresponding levelof-service designations are based on the same breakpoints as used in the spreadsheet for examining model sensitivity. Table 9 shows the observed and predicted results for each site. Among the 31 sites included in the sample, the predicted LOS is the same with the observed LOS for 13 sites (42 percent), lower for 14 sites (45 percent), and higher for 4 sites (13 percent).

Table 9. Comparing Predicted and Observed Difficulty and LOS

\begin{tabular}{|c|c|c|c|c|}
\hline \multirow{2}{*}{ Site ID } & \multicolumn{2}{|c|}{ Predicted } & \multicolumn{2}{|c|}{ Observed } \\
\hline & Difficulty & LOS & Difficulty & LOS \\
\hline 1 & 4.2 & $\mathrm{D}$ & 4.15 & $\mathrm{D}$ \\
\hline 2 & 2.4 & B & 1.42 & A \\
\hline 3 & 4.1 & $\mathrm{D}$ & 3.54 & $\mathrm{D}$ \\
\hline 4 & 4.4 & $\mathrm{D}$ & 5.38 & E \\
\hline 5 & 4.0 & $\mathrm{D}$ & 4.16 & $\mathrm{D}$ \\
\hline 6 & 3.2 & $\mathrm{C}$ & 3.24 & $\mathrm{C}$ \\
\hline 7 & 2.0 & B & 2.16 & B \\
\hline 8 & 3.7 & $\mathrm{D}$ & 2.96 & $\mathrm{C}$ \\
\hline 9 & 2.6 & $\mathrm{C}$ & 2.15 & B \\
\hline 10 & 3.5 & $\mathrm{C}$ & 2.92 & $\mathrm{C}$ \\
\hline 11 & 2.9 & $\mathrm{C}$ & 1.77 & B \\
\hline 12 & 1.9 & B & 2.92 & $\mathrm{C}$ \\
\hline 13 & 1.7 & $\mathrm{~B}$ & 1.73 & $\mathrm{~B}$ \\
\hline 15 & 5.0 & E & 4.87 & E \\
\hline 16 & 2.0 & B & 1.62 & B \\
\hline 17 & 3.1 & $\mathrm{C}$ & 3.92 & $\mathrm{D}$ \\
\hline 18 & 2.7 & $\mathrm{C}$ & 2.21 & B \\
\hline 19 & 4.7 & $E$ & 4.04 & $\mathrm{D}$ \\
\hline 20 & 3.4 & $\mathrm{C}$ & 3.75 & $\mathrm{D}$ \\
\hline 21 & 3.2 & $\mathrm{C}$ & 2.63 & $\mathrm{C}$ \\
\hline 22 & 2.5 & B & 2.33 & B \\
\hline 23 & 1.1 & $\mathrm{~A}$ & 1.83 & $\mathrm{~B}$ \\
\hline 24 & 2.6 & $\mathrm{C}$ & 2.42 & B \\
\hline 25 & 2.9 & $\mathrm{C}$ & 1.75 & $\mathrm{~B}$ \\
\hline 26 & 2.0 & B & 1.17 & A \\
\hline 27 & 2.6 & $\mathrm{C}$ & 1.33 & A \\
\hline 29 & 2.7 & $\mathrm{C}$ & 3.83 & $\mathrm{D}$ \\
\hline 30 & 4.6 & E & 5.12 & $\mathrm{E}$ \\
\hline 31 & 3.7 & D & 4.33 & D \\
\hline 32 & 3.6 & $\mathrm{D}$ & 3.46 & $\mathrm{C}$ \\
\hline 33 & 2.9 & $\mathrm{C}$ & 1.62 & B \\
\hline
\end{tabular}


With Prediction Errors

The above comparison assumes that the predicted difficulty levels and the corresponding LOS involve no errors. A better comparison needs to take into account prediction errors. This can be done in several steps. The first step would be to determine the average standard error of the predicted difficulty levels for each site. The average error ranges from 0.167 to 0.308 across these sites. The second step would be to determine the two ends of the confidence interval for each site. They are given by the point prediction plus or minus 1.96 times the average standard error. The third step would be to determine the appropriate LOS for each of the two ends of the interval. The last step would then be to see if this LOS interval contains the observed LOS. With this approach, the predicted LOS is statistically the same with the observed LOS for 21 sites (68 percent), lower for 7 sites (23 percent), and higher for 4 sites (13 percent).

Taking into account prediction errors also affects the degree of such differences. Without considering prediction errors, for example, the predicted LOS for site 27 is lower by two levels than the observed LOS (C versus $\mathrm{A}$ ). The confidence interval, however, includes both $\mathrm{C}$ and $\mathrm{B}$. As a result, the predicted LOS is statistically low by one level than the observed LOS (B versus A).

\section{Alternative Models}

Four alternative models were considered and reported below. These include considering non-linear forms of explanatory variables, normalizing traffic volume with roadway width, combining directional measurement, and using a partial data set.

\section{Non-linear Form}

The rationale for considering non-linear forms of variables is that the rate of change in the level of crossing difficulty in response to changes in individual variables may not be constant. The question is: how would one-model non-linear relationships between an explanatory variable and the dependent variable? The answer depends partially on whether the rate of changes in the dependent variable is an increasing or decreasing function of the explanatory variable in question. It was hypothesized, for example, that both the level of crossing difficulty itself and its rate of change in response to changes in crossing distance is an increasing function of crossing distance. The commonly used square function may be used for any occasion. However, the commonly used log function may be only appropriate if the rate is a decreasing function.

For the purpose of testing, the commonly used square function is used in this research for all continuously measured characteristics. To allow flexibility, both the linear term and the square term are included initially. Table 10 reports the results after those square terms with insignificant coefficients are deleted and the model is re-estimated. Those deleted square terms include those for nearside turning movements, far-side crossing width, widths of medians, and nearside signal cycle. 
Table 10. Considering Non-linear Functions

\begin{tabular}{|l|c|c|c|}
\hline Variables & Coefficients & $\begin{array}{c}\text { Standardized } \\
\text { Coefficients }\end{array}$ & t-statistics \\
\hline Constant & -2.23649 & & -0.8422 \\
\hline 65 Years or Older (0-1) & 0.47452 & 0.0897 & 3.2643 \\
\hline NS Total Volume (1000 Vehicles / Hour) & 0.49255 & 1.1404 & 5.1425 \\
\hline Ns Total Volume Squared & -0.04262 & -1.4489 & -6.3940 \\
\hline FS Total Volume (1000 Vehicles / Hour) & -0.21890 & -0.3238 & -2.1928 \\
\hline Fs Total Volume Squared & 0.03858 & 0.5547 & 3.8540 \\
\hline NS Turning Movements (Vehicles / Hour) & 0.00394 & 0.4408 & 7.1276 \\
\hline FS Turning Movements (Vehicles / Hour) & 0.00798 & 0.7302 & 5.8165 \\
\hline FS Turning Movements Squared & -0.00001 & -0.6282 & -4.4474 \\
\hline Average Speed (Miles / Hour) & 0.33249 & 1.0680 & 2.9238 \\
\hline Average Speed Squared & -0.00444 & -0.9528 & -2.6514 \\
\hline NS Crossing Width (Feet) & 0.13457 & 0.6071 & 2.9995 \\
\hline NS Crossing Width Squared & -0.00231 & -0.6861 & -3.3030 \\
\hline FS Crossing Width (Feet) & 0.05850 & 0.3306 & 2.9753 \\
\hline Width of Restricted Median (Feet) & -0.04343 & -0.3480 & -3.7187 \\
\hline Width of Painted Median (Feet) & 0.02121 & 0.0754 & 2.0063 \\
\hline Crosswalk Dummy (0-1) & -0.48705 & -0.1489 & -2.8321 \\
\hline Pedestrian-Signal Dummy (0-1) & 0.08211 & 0.0211 & 0.5110 \\
\hline NS Cycle Length (Seconds) & -0.05434 & -1.6370 & -5.9854 \\
\hline FS Cycle Length (Seconds) & -0.10147 & -2.8500 & -2.8232 \\
\hline FS Cycle Length Squared & 0.00102 & 3.4974 & 4.8759 \\
\hline Signal Spacing (Feet) & -0.00106 & -1.0451 & -3.0519 \\
\hline Adjusted R Square & & 0.455 & \\
\hline Std. Error of the Regression & & 1.208 & \\
\hline Sample Size & & 767 & \\
\hline & & & \\
\hline
\end{tabular}

The inclusion of these square terms has at least two apparent advantages. Both the adjusted R-square and the standard error of the regression are improved by a good margin. Also traffic running speed becomes statistically significant in this specification. If these were the only criteria for selecting models for predictive purposes, this model would be chosen over the basic model. However, relying only on these criteria would be misguided for selecting a predictive model.

The inclusion of these square terms has its disadvantages as well. They add further complexity to a model that is already crowded with variables. Since one variable and its squared term are often highly correlated, adding these square terms worsens the problem of multicollinearity in the data. More important, though, one needs to take a detailed look at how the dependent variable responds to changes in those explanatory variables with square terms and whether these responses are consistent with hypotheses.

For illustrative purposes, Table 11 shows qualitatively how the predicted level of crossing difficulty responds to changes in selected explanatory variables that have a 
square term included. With higher running speed, for example, the model would predict that the level of crossing difficulty would first increase at a declining rate until speed reaches about $37 \mathrm{mph}$ and then decrease afterwards at an increasing rate. Neither the declining rate before the turning point nor the decreasing direction after the turning point makes intuitive sense. Except maybe FS signal cycle, the non-linear effects of the other selected explanatory variables do not make good intuitive sense either. As a result, this alternative does not appear to be better suited the basic model.

Table 11. Non-Linear Effects of Selected Explanatory Variables on Crossing Difficulty

\begin{tabular}{|l|c|c|c|c|c|}
\hline \multirow{2}{*}{ Variables } & \multirow{2}{*}{$\begin{array}{c}\text { Turning } \\
\text { Point }\end{array}$} & \multicolumn{2}{|c|}{$\begin{array}{c}\text { Changes } \\
\text { before Turning Point }\end{array}$} & \multicolumn{2}{c|}{$\begin{array}{c}\text { Changes } \\
\text { after Turning Point }\end{array}$} \\
\cline { 3 - 6 } & & Direction & Rate & Direction & Rate \\
\hline NS Total Volume (1000 vehs / hour) & 5.78 & Increase & Declining & Decrease & Increasing \\
\hline FS Total Volume (1000 vehs / hour) & 2.84 & Decrease & Declining & Increase & Increasing \\
\hline FS Turning Movements (vehs / hour) & 307 & Increase & Declining & Decrease & Increasing \\
\hline Running Speed (mph) & 37 & Increase & Declining & Decrease & Increasing \\
\hline NS Crossing Width (feet) & 29 & Increase & Declining & Decrease & Increasing \\
\hline FS Signal Cycle (seconds) & 50 & Decrease & Declining & Increase & Increasing \\
\hline
\end{tabular}

Notes: Both the turning points and the non-linear effects are derived from the coefficients of both the linear and squared terms of the same explanatory variable.

\section{Normalized Total Volume}

Another natural variation in model specification is to normalize total volume by crossing width. This is done separately for the two directions with everything else specified as in the basic model. The results are shown in Table 12. For ease of comparison, the basic model is also shown. One positive observation from this model is that the results on the other variables are extremely stable both in the magnitude and sign of the coefficients. However, normalizing total volume with crossing width does not appear to improve upon the basic model. For example, the adjusted R-square is smaller and the standard error of the regression is larger. As a result, this alternative does not appear to be better suited than the basic model. 
Table 12. Considering Normalized Total Volume

\begin{tabular}{|l|r|r|r|r|}
\hline \multirow{2}{*}{ Variables } & \multicolumn{2}{|c|}{ Alternative Model } & \multicolumn{2}{c|}{ Basic Model } \\
\cline { 2 - 5 } & Coefficients & t-statistics & Coefficients & t-statistics \\
\hline Constant & -2.7309 & -3.5785 & -2.4778 & -3.2120 \\
\hline 65 Years Or Older Dummy (0-1) & 0.4918 & 3.0909 & 0.4937 & 3.1133 \\
\hline NS Total Volume (1000 vehicles / hour) & & & -0.1159 & -4.1854 \\
\hline FS Total Volume (1000 vehicles / hour) & & & 0.2674 & 6.8259 \\
\hline Ratio of NS Total Volume to NS Crossing Width & -2.8274 & -3.3291 & & \\
\hline Ratio of FS Total Volume to FS Crossing Width & 7.3290 & 6.2181 & & \\
\hline NS Turning Movements (vehicles / hour) & 0.0015 & 2.9016 & 0.0018 & 3.5434 \\
\hline FS Turning Movements (vehicles / hour) & 0.0013 & 2.4027 & 0.0013 & 2.5595 \\
\hline Average Speed (miles / hour) & 0.0096 & 0.6819 & 0.0107 & 0.7618 \\
\hline NS Crossing Width (feet) & -0.1089 & -5.4970 & -0.0852 & -4.3901 \\
\hline FS Crossing Width (feet) & 0.1599 & 7.7265 & 0.1241 & 6.1663 \\
\hline Width Of Restricted Median (feet) & -0.0669 & -5.5385 & -0.0661 & -5.5726 \\
\hline Width Of Painted Median (feet) & 0.0703 & 7.0446 & 0.0712 & 7.2010 \\
\hline Crosswalk Dummy (0-1) & -0.2984 & -1.6923 & -0.2762 & -1.5645 \\
\hline Pedestrian-Signal Dummy (0-1) & -0.5086 & -3.3084 & -0.4930 & -3.1598 \\
\hline NS Cycle Length (seconds) & -0.0287 & -2.9779 & -0.0326 & -3.3957 \\
\hline FS Cycle Length In (seconds) & 0.0571 & 5.1217 & 0.0610 & 5.4797 \\
\hline Signal Spacing (feet) & 0.0006 & 7.5070 & 0.0007 & 7.6269 \\
\hline Adjusted R Square & 0.337 & & 0.341 \\
\hline Std. Error of the Regression & 1.332 & & 1.328 \\
\hline Sample & 767 & & 767 \\
\hline
\end{tabular}

\section{No Directional Measurement}

Another alternative model form is to combine the directional measures for each of the four directionally measured characteristics. The results reported in Table 13 are disappointing on several fronts. First, turning movements, crossing width, and width of restricted median are no longer statistically significant. Second, the adjusted R-square is much lower while the standard error of the regression is larger. Third, both speed and width of restricted median have the incorrect signs. Overall, it is not an improvement over the basic model. 
Table 13. Considering Non-Directional Measurement

\begin{tabular}{|l|c|c|c|}
\hline Variables & Coefficients & $\begin{array}{c}\text { Standardized } \\
\text { Coefficients }\end{array}$ & t-statistics \\
\hline Constant & 0.9693 & & 1.3621 \\
\hline 65 Years Or Older (0-1) & 0.5648 & 0.1067 & 3.3869 \\
\hline Total Volume (1000 Vehicles / Hour) & 0.0606 & 0.2164 & 4.5431 \\
\hline Total Turning Movements (Vehicles / Hour) & 0.0001 & 0.0117 & 0.2758 \\
\hline Average Speed (Miles Per Hour) & -0.0058 & -0.0185 & -0.3994 \\
\hline Crossing Width (Feet) & 0.0063 & 0.0614 & 0.9291 \\
\hline Width of Restricted Median (Feet) & 0.0046 & 0.0365 & 0.5432 \\
\hline Width of Painted Median (Feet) & 0.0863 & 0.3068 & 8.3935 \\
\hline Crosswalk Dummy (0-1) & -0.4186 & -0.1280 & -2.3264 \\
\hline Pedestrian-Signal Dummy (0-1) & -0.5131 & -0.1317 & -3.1971 \\
\hline Signal Cycle (Seconds) & 0.0095 & 0.2747 & 3.1514 \\
\hline Signal Spacing (Feet) & 0.0002 & 0.2354 & 3.1736 \\
\hline Adjusted R Square & \multicolumn{3}{|l|}{0.26} \\
\hline Std. Error Of The Regression & 1.407 \\
\hline Sample & \multicolumn{3}{|l}{} \\
\hline
\end{tabular}

\section{Partial Data Set}

The final alternative considered is to re-estimate the basic model with a partial data set. For one reason or another, the full sample includes data collected from one site that was controlled by stop sign and two sites that were one-way. Because the major differences between these sites from the others are not controlled in the model, it is a good practice to examine the sensitivity of the basic model to excluding observations from these three sites. The results are reported in Table 14. The coefficients for most of the variables change little from those with the full sample. The adjusted R-square is slightly higher and the standard error of the regression is slightly lower. However, speed has the wrong sign, indicating potential problems with the model. 
Table 14. Considering Partial Data Set

\begin{tabular}{|l|c|c|c|c|}
\hline \multirow{2}{*}{ Variables } & \multicolumn{2}{|c|}{ Alternative Model } & \multicolumn{2}{c|}{ Basic Model } \\
\cline { 2 - 5 } & Coefficients & t-statistics & Coefficients & t-statistics \\
\hline Constant & -2.2714 & -2.6870 & -2.4778 & -3.2120 \\
\hline$(+)$ 65 Years Or Older Dummy (0-1) & 0.5354 & 3.1665 & 0.4937 & 3.1133 \\
\hline$(+)$ NS Total Volume (1000 vehicles / hour) & -0.1807 & -5.6424 & -0.1159 & -4.1854 \\
\hline$(+)$ FS Total Volume (1000 vehicles / hour) & 0.4224 & 8.3268 & 0.2674 & 6.8259 \\
\hline$(+)$ NS Turning Movements (vehicles / hour) & 0.0028 & 5.1278 & 0.0018 & 3.5434 \\
\hline$(+)$ FS Turning Movements (vehicles / hour) & 0.0021 & 3.8200 & 0.0013 & 2.5595 \\
\hline$(+)$ Average Speed (miles / hour) & -0.0017 & -0.1120 & 0.0107 & 0.7618 \\
\hline$(+)$ NS Crossing Width (feet) & -0.1115 & -5.6030 & -0.0852 & -4.3901 \\
\hline$(+)$ FS Crossing Width (feet) & 0.1180 & 5.7502 & 0.1241 & 6.1663 \\
\hline$(-)$ Width Of Restricted Median (feet) & -0.0707 & -5.8850 & -0.0661 & -5.5726 \\
\hline$(-)$ Width Of Painted Median (feet) & 0.0636 & 6.1918 & 0.0712 & 7.2010 \\
\hline$(-)$ Crosswalk Dummy (0-1) & -0.5953 & -2.9909 & -0.2762 & -1.5645 \\
\hline$( \pm)$ Pedestrian-Signal Dummy (0-1) & -0.4238 & -2.5467 & -0.4930 & -3.1598 \\
\hline$( \pm)$ NS Cycle Length (seconds) & -0.0324 & -3.3363 & -0.0326 & -3.3957 \\
\hline$( \pm)$ FS Cycle Length In (seconds) & 0.0621 & 5.5694 & 0.0610 & 5.4797 \\
\hline$( \pm)$ Signal Spacing (feet) & 0.0008 & 8.5714 & 0.0007 & 7.6269 \\
\hline Adjusted R Square & \multicolumn{2}{|c|}{0.354} & & \\
\hline Std. Error of the Regression & \multicolumn{2}{|c|}{1.325} & & 7.341 \\
\hline Sample & \multicolumn{2}{|c|}{767} \\
\hline
\end{tabular}




\section{Chapter Six: LESSONS LEARNED}

The research team learned a number of lessons from this overall research project. The lessons have been divided into four categories for discussion: those related to procedures that were modified after the initial research design from the first phase, those related to procedures that worked well, those related to procedures that could be improved, those related to issues that need further discussion, and areas for further research. Some of these lessons are unique to this particular project, while others are more general. The Department could potentially use the general lessons in its future research efforts to expand and improve its multi-modal level of service methodologies.

\section{What Worked Well}

A number of elements of both phases of the research project worked extremely well given the circumstances:

- The Model

- The Issue Paper

- Field Survey Method

- Temp Workers

- Logistics

\section{The Model}

The preferred model as shown in Table 5 behaves well. It is stable to changes in the presence or absence of some of its determinants. Its predictions are sensitive to changes in individual or combinations of individual determinants. It out-performs many alternative model forms. The various determinants behave as expected.

\section{The Issue Paper}

The issue paper greatly facilitated the successful completion of this overall research project. The two most significant contributions are discussed here: selecting the determinants and exploring alternative approaches to issues.

\section{Selecting Determinants}

The issue paper used a balanced approach to the process of selecting potential determinants for level of service measurement. This balanced approach takes both theoretical and practical considerations. It involves two steps. The first step selects a set of potential determinants through a theoretical analysis of pedestrian behavior for street crossing. The theoretical consideration ensures that these potential determinants have a sound behavioral foundation. The second step narrows down this set through a practical consideration by an Advisory Committee. This practical analysis ensures that the final set of potential determinants meets planning needs and data availability. This two-step 
approach proved to be highly effective as indicated by the fact that these potential determinants largely behave as expected in the preferred model.

\section{Exploring Alternative Approaches}

The issue paper raised a variety of issues involved in developing a pedestrian level of service methodology. More importantly, it explored alternative approaches to dealing with these issues. For those issues that are unique to this project, this exploration allowed the research team to select the best possible approach. For the other issues that are general, this exploration found approaches that are potentially better than what had been used in previous research efforts. Some examples include whether to solicit perceived level of service directly or perceived quality of service from participants; whether to measure stated perception or revealed perception; whether to model perception scale as continuous or ordered; or whether to determine breakpoints for level of service conversion arbitrarily or through statistical estimation. Some of the alternative approaches to critical issues are further discussed later as future research topics.

\section{Field Survey Method}

As already described, the survey method adopted placed participants in actual field conditions and solicited their perception on these conditions without their behavioral involvement. Our experience both in the field and with the statistical analysis suggests that it is an effective method to collect user perception of operational conditions. In the field, participants appeared to be serious, observing, and knowing how to order their perception of the observed conditions. From the statistical analysis, the best indicator of whether the survey method works is again whether the estimated model from the data is reasonable compared to expectations.

\section{Temp Workers}

Given the amount of efforts on the part of the participants, drawing a random sample of the general public would not work. The research team was left with several ad hoc approaches of selecting participants. These include recruiting through a multi-media campaign, recruiting through organizations, or recruiting temp workers through a temp agency. While all three approaches could result in bias because none of them would result in a representative sample of the general population, the bias from using temp workers is not likely to be any larger than those of the other two approaches.

The use of temp workers, however, has two significant advantages. First, it was more certain before the survey how many participants would actually show up for surveys. This was important because one month or two can easily be consumed to conduct another round of recruiting if the first round proved to be not enough. Second, it is more flexible for scheduling the surveys. With either of the other two ad hoc recruiting approaches, only weekend days would be open for surveys. However, significant variation in traffic is critically important in getting a full range of perceptions. Conducting surveys on weekdays can greatly facilitate such an effort. 


\section{Logistics}

The use of buses, the clustering of sites, the use of multiple days, and the use of multigroups on each day all proved to be good logistic strategies.

Use of Buses

The use of bus transportation had potential disadvantages. One is the amount of participant-time spent waiting on the bus for their turns when the bus is at a given location. If a bus were at a given location for 30 minutes, for example, each participant would only spend 5 minutes surveying and the rest on waiting. The other is potential cost of the bus transportation. A total of about 40 bus hours, for example, was involved in the field surveys of this project. The research team was fortunate enough that the two transit agencies in the study area, HARTline and PSTA, provided the bus transportation at no cost to the project.

The use of bus transportation, however, greatly simplified the logistics of moving individual groups of participants around the sites assigned to them. There were two important benefits of this simplification. One is the reduced risk of involvement in crashes by the participants. The other is the increased certainty of participant presence at individual sites when they are needed.

\section{Clustering of Sites}

The clustering of sites refers to the selection of sites for different survey events from different geographic areas that are relatively compact. For this project, sites were clustered in three areas: the University of South Florida, South Tampa, and the City of St Petersburg. This clustering reduces the amount of driving involved on any given day. This reduced driving is particularly significant to this project because reduced driving means less time for which the buses are tied up and the temp workers are compensated.

\section{Multi-day Surveys}

The only disadvantage of conducting the surveys on different days is that certain activities are repeated. One example is the briefing of participants about the surveys. However, dividing the surveys into different days has several advantages. First, it allows the use of only two buses on any given day. Since HARTline and PSTA provided the buses at no cost to the project, it would be much harder to ask for six such buses on a single day. Second, it allows one to more likely to capture a variety of traffic conditions across multiple days than a single day. Third, it also allows one to take advantage of the clustering of sites across geographic areas by conducting surveys for different clusters on different days. 


\section{Multiple Groups}

Dividing the participants on each day into relatively small groups has several advantages. First, it allows the use of relatively small buses. It is much easier to maneuver and park a smaller bus in many places. Second, it also reduces the number of sites that each group has to go through for a given number of total survey days. For this project, the average number of sites per group was 5 sites. It took an average of 5 hours for a group to finish these 5 sites.

\section{What was Modified}

As discussed earlier, an initial research design was developed from the first phase. This design was modified at the beginning of the second phase after a pilot test and the first field survey. Reported here are three elements of the initial design that were modified: approaches to site selection and collecting dynamic data, including turning movements, traffic volume, and running speed.

\section{Approach to Site Selection}

The initial research design calls for assembling a database of roadway blocks and using it for site selection. The research team made request to District Seven of the Department for such a database. Several computer files from the Roadway Characteristics Inventory (RCI) for the Hillsborough and Pinellas Counties were sent to the research team. The research team was unable to use these files for sampling sites for two reasons. First, no single file contains all the information for sampling. Merging of these files to create a separate file that would have the major characteristics of individual roadway blocks proved to be extremely difficult. Second, these files do not appear to contain all roadways in these two counties that have a local or higher classification.

\section{Approach to Collecting Dynamic Data}

\section{Turning Movements}

The procedure to record turning movements in the field was modified from videotaping to manual forms. Turning movements are measured by direction. For a given direction, there are a number of sources of turning movements that could affect traffic patterns created by the traffic signals. These include right turns from upstream driveways, right turns from the upstream intersection, left turns from the upstream intersection, left turns from upstream median openings, and u-turns from upstream median openings. With the multiple sources, it was thought during the initial design phase that videotaping would be an appropriate tool for recording these movements. One video camera would be used for each direction. The cameras would be placed on the ground when the bus arrives at a site and would be supervised during the whole survey duration of this site. 
It turned out that videotaping was not an effective approach to collecting turning movements. First, it would take more time to get the information from the videotape and enter into a compute database than from a manually recorded sheet. Second, a camera placed on the ground proved to be incapable of capturing all the turning movements for a given direction. This problem is made worse when vehicles taller than automobiles are present in the traffic stream. Had the cameras been pre-placed in a relatively high position, this issue would not have been a problem. Given the limited number of cameras and supervisors available, this placement was not an option. Third, turning movements appeared to be hard to see when the distance between the camera and the source of turning movements is relatively long.

\section{Traffic Volume and Speed}

The procedure for collecting data on total traffic volume and running speed at mid-block locations was modified from videotaping only to using traffic counters with videotaping as a backup. This change of approach was made right after the initial design was finalized in the issue paper. The motivation was the potential savings in both accuracy and cost of data-reduction.

Without automated equipment, traffic volume and speed would have to be manually extracted from the videotape while it is being played. Traffic volume would have to be counted. Such manual counting becomes problematic when speed is high and multiple lanes are involved, especially with big trucks present in the traffic stream. To determine the running speed, the actual distance shown in the video frame and the amount of time vehicles took to go through the frame would need to be measured. One problem with measuring the actual distance shown was that the video frame changed. One problem with measuring the amount of time becomes extremely difficult when the speed is high.

However, the use of videotaping as a backup turned out to be a good strategy. Because of miscommunications as discussed earlier, traffic counters were either located at a wrong place or were taken away before the survey was complete. In such cases, the backup videos allowed the research team to determine both traffic volume and running speed.

\section{What Could be Improved}

A number of areas of the research project could have been done better. For some of these lessons, solutions are offered for improvement. For others, solutions are not offered because there are not any obvious ones.

\section{Missed Issues}

While the issue paper was a great contribution to the research project, it still missed a number of important issues. As a result, the research design had a number of holes that 
should be avoided in the future. Many of these missed issues are discussed below as separate areas for improvement.

One strategy to avoid such missed issues at the beginning of the project was the creation of an Advisory Committee. The committee, especially Dr. Crider of the University of Florida and FDOT members, contributed significantly to the development of the issue paper. Despite that, however, these issues were still missed.

One potential solution may be to broaden the role of the Advisory Committee somewhat. With a few exceptions, the role of the committee was to comment on issues that had already been raised. That role was not by design but probably chosen unconsciously by individual members. In future efforts, members of such committees may be asked to also suggest the addition or deletion of issues to be considered. Another potential solution may be to financially compensate committee members who are not state employees.

\section{Mismatch of Traffic Volumes}

The issue here is the mismatch between the traffic volumes observed when sites were being examined for selection and the traffic volumes observed when the field surveys were being conducted. One consequence is that a large number of these sites had relatively low volumes. This problem was exacerbated by the fact that only mid-day traffic conditions were captured on all three survey-days.

One solution to avoid such a mismatch would be to first determine the timing of surveying for each survey-days and to then examine the sites targeted for that survey day during the same time frame. If surveys for sites in Clearwater are to be scheduled to capture afternoon peak conditions on a Monday, for example, the field work for selecting sites there would be scheduled to include the peak conditions on a Monday too.

\section{Timing of Daily Surveys}

The timing of the daily surveys was never considered to be an issue. On each of the three survey days, the participants were asked to come to a central location for briefing at around 8:30 AM, slightly later than most work start times in the morning. Actual field surveys started around 9:30 AM to 10:00 AM. The surveys ended only when all sites were completed for that day, typically around 2:30 PM. One consequence was that only mid-day traffic conditions were reflected.

The solution is to conduct surveys on multiple days as in this project and to vary the day of week and the starting time on each day. If surveys in the future are to be conducted on four days, for example, one day would be a weekend day and all others would be weekdays. Among the weekdays, one would start early in the morning to capture the traffic conditions of the morning peak; one would start mid-afternoon to capture the traffic conditions of the afternoon peak; one would start late morning to capture the conditions of the mid-day. 


\section{Repeating Participants}

In requesting the participation of temp workers through the temp agency, the research team specified the number of persons desired on each of the three days. As a result, some participants showed up on multiple days. While this multi-day appearance by the same person is not necessarily a bad thing, it does make the research team to lose control over the number of repeated responses from the same person. For most of the participants, they provided 5 responses because they only showed up on one day. For those who showed up on all three days, they provided 15 responses. The number of repeated responses has important implications to statistical inferences.

The solution to this problem would be to ask the temp agency not to send people who have already participated in the study on a previous day.

\section{Synchronizing Collection of Dynamic Data}

The various elements of the process for collecting dynamic data were not fully synchronized. Dynamic data, including traffic volume, running speed, and turning movements, can change significantly over a short duration. It is highly desirable to match what the participants observed in responding the survey question with what were actually measured from the field. To successfully match these observations and measurements, the various elements of the process for collecting dynamic data need to be fully synchronized. These elements include the clock time on the counters, the clock time on the video camera, and the watch time of the field workers who control timing of the three-minute observations. Another element is the time intervals for which traffic volume and speed are recorded by the traffic counters. This is separately discussed below.

\section{Specification of Traffic Counters}

The research team is grateful to District Seven of the Department and the City of St. Petersburg for help with the traffic counters at no additional cost to the project. Two problems were encountered with the traffic counters due to miscommunications between the research team and the two agencies. One problem was that some counters were pulled from the field before the surveys were complete. Fortunately this problem was rare and backup videos were available for these sites. The second problem was that the traffic counters were programmed to record volumes and speed at either 15-minute intervals or one-hour intervals. The desired interval was one minute so that they can be combined to create volumes and speed for three-minute intervals. Three minutes was the duration for which the participants observed traffic conditions before response. This problem was widespread though few sites had data at one-hour intervals.

If the District offices and other local agencies continue to cooperate with research efforts, one solution to the problem would be to communicate with these agencies in advance 
through written forms about the desired recording intervals. Also important would be to directly check with those engineers who actually program and install the traffic counters.

\section{Confusion over Survey Forms}

For a given group and day, the survey form for collecting their perception of the level of crossing difficulty showed the range of possible levels of difficulty in columns and the different sites in rows. The levels of difficulty were identified with letters from A on the left through F on the right. A was indicated as "no difficulty" and F as "extreme difficulty." The sites were identified with site Ids that are not necessarily in consecutive orders. The sites were being visited in the order from the top row to the bottom row. The participants were briefed about these arrangements.

Two types of confusion were observed among the participants in filling out the form with their responses. One confusion was over whether A or F indicates the most difficulty conditions. The other was over the order in which the sites were being visited. The research team discovered such confusion when a few participants asked about theses whether only old persons were confused or only older persons were willing to ask the questions. It is unclear what was the extent of such confusion either. There is no obvious approach to identifying those who were confused.

One potential solution to this problem would be to emphasize these orders in the briefing stage, re-emphasize them on the way to the first site, and re-enforce the participants' understanding of these orders before the participants start their observations and responses. Changing the IDs of the sites on the form so that they are in an ascending order would likely to be helpful too. Finally, instead of indicating the levels of difficulty with letters A through F, they may be described with phrases: not difficult, slightly difficult, acceptably difficult, difficult, very difficult, and extremely difficult.

\section{Advisory Committee}

At the very beginning of the project, FDOT suggested that an Advisory Committee be formed and proposed individual members selected from the Department's Multi-modal LOS steering committee. The members had a range of background and individual strengths. It was a great idea, especially for this project that was exploring new grounds in terms of survey methods and survey logistics. Due to its arrangements, however, the influence of the committee was limited largely because most of the members were not responsive to requests for inputs.

One potential solution to this problem appears to find ways to financially tie members, especially those from non-government organizations, to the research efforts in question. 


\section{What Needs Further Discussion}

Several issues were missed in the issue paper but do not belong to any of the other categories in this chapter. The research team feels that they are not settled issues. Further thoughts are required. Two are discussed here.

\section{Time Allowed for Field Observation}

After the pilot test, it was realized that instructions needed to be given to the participants on how long they should observe the sites and traffic conditions in responding to the survey question. The first choice was between an instant response upon reaching the curb and a delayed response once an observation for a given duration is made. The second choice was the amount of time given to the participants for their observation. One consideration was that the time should be long enough for participants to observe a full signal cycle for most sites. The duration was somewhat arbitrarily set for 3 minutes.

The remaining aspects of this issue are two. Is 3 minutes too long or too short? Should it be based on some measurement of the distribution of all signal cycles such as the $85^{\text {th }}$ percentile? Should it vary with individual sites, depending on actual signal cycle length?

\section{Field Treatment of Pedestrian Signals}

An issue was raised half way through the surveys about pedestrian signals: should the signal be pushed right before individual participants start their 3-minute observation? It was unclear at that time what should be done. The first few pedestrian signals encountered were not pushed but some were toward the end of the surveys. With more time to think through the issue now, it seems that a case may be made to not push these buttons. Pedestrian signals can differ in terms of what happens when a button is pushed. They can also differ in terms of the green duration. Unless these differences are specifically measured and included in the statistical modeling, it is better to not reveal these differences to the participants.

\section{What Needs Further Research}

Individual issues of further research are grouped into several categories for ease of discussion.

\section{Mid-block Crossing Difficulty}

Is Running Speed Really Unimportant?

The preferred model suggests that mid-block running speed does not play an important role in how people perceive the level of difficulty for mid-block crossing. The importance of being able to answer this question cannot be over-emphasized. If running speed does play an important role in mid-block crossing difficulty, this result has 
important implications to pedestrian safety. This result means that people judge traffic gaps by distance rather than by time. This result, however, does not tell why people behave like that. It is either because they prefer judging gaps through distance or because they are unable to perceive time gaps reasonably well. Regardless the reason, this behavior can be dangerous.

Do Wider Painted Medians Make Crossing More Difficult?

The preferred model also suggests that roads with wider painted medians make people think it is more difficult to cross at mid-block locations than roads with narrower painted medians. The width of painted medians is a direct policy variable.

Is the Preferred Model Transferable?

While the other two issues are also related to the transferability of the results, they are limited to two specific variables. The issue here refers to the geographical transferability of the preferred model as a whole.

Are Interactions between Variables Important?

Alternative model forms that include interactions between variables were considered but not estimated. It is reasonable to hypothesize that certain site characteristics become important only if some of the other site characteristics reach certain levels. For example, the presence of pedestrian signals may start to reduce the perceived difficulty for midblock crossing once traffic volume is very high. Such interactions are not included for several reasons. First, there are potentially a large number of interactions. Second, it is unknown where the breakpoints are for each interaction. Determining these breakpoints for the large number of potential interactions would mean almost endless mining of the data. Third, the range of variation, particularly traffic volume, is very limited in the sample due largely to the fact that the field surveys occurred mostly during the mid-day period.

\section{Improving LOS Methodologies}

We collectively do not know how some of the alternative approaches to dealing with a number of critical issues would affect the ultimate models and LOS determinations.

\section{Asking for Perceived LOS and Perceived QOS}

In an effort to collect user perception for developing LOS methodologies, typically research participants have been asked for their perceived level of service rather than their perceived operational conditions. This perceived level of service is conceptually qualitative but would be used as quantitative in correlating it with a set of the determinants of quality of service. The predicted quantitative level of service value would finally be used in designating qualitative levels of service. A conceptually more sound approach would be to ask the participants for their perceived quality of service. 
This perceived quality of service is a quantitative measure of the operational conditions. Data collected on this perceived quality of service are used to develop a model relating perceived quality of service to a set of its determinants. The determined value of perceived quality of service from this model is viewed as the measure of effectiveness for designating levels of service. This method of collecting data on the dependent variable and the subsequent use of the data is consistent with the traditional concept of transportation level of service. As a result, the second approach could simplify crossmodal comparisons.

\section{Differences Between Stated and Revealed Perception}

Typically one derives the perceived quality of service by directly asking the participants of a research project about how they perceive the quality of service as a pedestrian or a bicyclist for a particular site. An alternative would be to take a revealed-perception approach, under which one would derive the perceived quality of service from estimating a behavioral model that is based on pedestrian choices of some kind. One example of such choices is whether a pedestrian would cross a street at certain locations under certain conditions. Variables used to characterize these conditions will be part of the behavioral model. The estimated utility functions from the model would be used as a measure of effectiveness. The measure of effectiveness captures the overall satisfaction a pedestrian would receive from crossing a street. By basing the model on hypothetical pedestrian choices rather than actually observed ones, this alternative approach would also take into account potential latent demand for street crossing.

\section{Continuous and Ordered-Response Modeling}

There is the issue of selecting a statistical model that is most appropriate for the nature of the data collected. Data collected on perceived pedestrian quality of service are typically ratings on a scale from 1 through 6 , for example. Such ratings are not continuous but discrete and ordinal. Typically, including this project, reported ratings have been treated as continuous and standard linear regressions are carried out. The main disadvantage is that it is inappropriate for the nature of data. It implicitly treats the discrete and ordinal dependent variable as a continuous and cardinal one. As a result, for example, they treat the difference between ratings 1 and 2 the same as the difference between 4 and 5. An ordered response would avoid these problems and takes advantage of the discrete nature of the data. In addition, such a model would also estimate the breakpoints necessary for LOS designations.

\section{LOS Conversion With Arbitrary Versus Estimated Ranges}

Once a model is estimated, it can be used to estimate the quality of service of any site for which data are available for the variables included in the model. In order to determine the level of service for this site, however, one would need a conversion mechanism that translates the estimated quality of service to one of the level of service designations. The key is how to select the breakpoints for such designation. Typically, the following breakpoints have been used: $1.5,2.5,3.5,4.5$, and 5.5 when the scale is 1 through 6 . A 
more objective approach is to directly estimate the breakpoints. The main advantage is its objectiveness. Another advantage is that the designation of level of service will be based on the true quality of service rather than ratings.

\section{Differences in Survey Methods}

Alternative survey methods are available that can be potentially be used to collect user perceptions for developing LOS methodologies. We have little evidence on the effect of alternative methods on the resulting methodologies. A solid knowledge of these differences would potentially save the Department research dollars.

\section{Complexity of Multi-Dimensions}

For some facilities or services, the most appropriate measure of effectiveness is one that characterizes the operational conditions in multiple dimensions, including some or all of the following: speed and travel time, freedom to maneuver, traffic interruptions, comfort and convenience, and safety. A number of research questions emerge with multidimensional measurement. Are people really capable of perceiving quality of service that has multiple dimensions? Is it better to solicit their perceptions on individual dimensions first and then to combine them into a single measure? What is the best approach to communicating with participants about what it is that you would like to get their perception? Is it better simply to use "quality of service?" Or is it better to use terms such as "comfort," "difficulty," "image," etc. It is unclear how many of the dimensions would be considered by participants when a single abstract term such as these is used. It is unclear either how individual participants would interpret each such term differently. Both of these unknowns can significantly affect the data collected and ultimately the level of service methodology developed.

\section{Integration}

For a given roadway block, there are potentially up to six measurements of pedestrian quality of service. Up to two of them would be related to walking along each side of the block. Up to two would be related to mid-block crossing, and up to two would be related to intersection crossing. The issue is this: how to best combine these components of pedestrian quality of service measures into a single measure? This is necessary to determine pedestrian level of service for an entire roadway segment. This is also necessary to incorporate pedestrian quality of service into the Transit Level of Service Methodology, which is measured at the roadway segment level and requires a single measurement of pedestrian quality of service. 


\section{Chapter Seven: Model Application}

This short chapter shows two alternative forms of the preferred model in an equation format and illustrates their usage through an example.

\section{Equation Format}

To apply the preferred model for planning studies, it may take one of two forms.

\section{Side-Specific}

If a planning study calls for levels of crossing difficulty that are side specific, especially because the four directionally-measured characteristics are asymmetric between the two sides, the original form of the basic model would be used as shown in Table 5. It would be applied twice for each street block. In an equation format, the model looks as follows:

Directional Level of Crossing Difficulty $=$

$-2.4778$

$+0.4937 *$ Share 65 Years or Older

$-0.1159 *$ Nearside Total Volume (1000 vehicles / hour)

$+0.2674 *$ Far-side Total Volume (1000 vehicles / hour)

$+0.0018 *$ Nearside Turning Movements (vehicles / hour)

$+0.0013 *$ Far-side Turning Movements (vehicles / hour)

$+0.0107 *$ Running Speed (miles / hour)

$-0.0852 *$ Nearside Crossing Width (feet)

$+0.1241 *$ Far-side Crossing Width (feet)

$-0.0661 *$ Width of Restricted Median (feet)

$+0.0712 *$ Width of Painted Median (feet)

$-0.2762 *$ Crosswalk ( 1 if present; 0 otherwise)

$-0.4930 *$ Pedestrian-Signal (1 if present; 0 otherwise)

$-0.0326 *$ Nearside Cycle Length (seconds)

$+0.0610 *$ Far-side Cycle Length (seconds)

$+0.0007 *$ Signal Spacing (feet)

\section{Combined}

If the street block is largely symmetric in the four directionally measured characteristics, however, there is no need to estimate side-specific levels of crossing difficulty. In that case, the two directional measures for each of the four directionally measure characteristics may be combined and a simplified model format may be used as follows in an equation format: 
Combined Level of Crossing Difficulty $=$

\author{
$-2.4778$ \\ $+0.4937 *$ Share 65 Years or Older \\ $+0.0758 *$ Combined Total Volume (1000 vehicles / hour) \\ $+0.0016 *$ Combined Turning Movements (vehicles / hour) \\ $+0.0107 *$ Running Speed (miles / hour) \\ $+0.0195 *$ Combined Crossing Width (feet, excluding medians) \\ $-0.0661 *$ Width of Restricted Median (feet) \\ $+0.0712 *$ Width of Painted Median (feet) \\ $-0.2762 *$ Crosswalk ( 1 if present; 0 otherwise) \\ $-0.4930 *$ Pedestrian-Signal (1 if present; 0 otherwise) \\ $+0.0284 *$ Average Cycle Length (seconds) \\ $+0.0007 *$ Signal Spacing (feet)
}

\title{
Example Calculations
}

One example is used below to illustrate how the predicted level of crossing difficulty may be calculated from the preferred model and how the corresponding level of service may be determined from the predicted difficulty. This is done separately for the side-specific model form and the combined model form.

\section{Side-Specific}

Table 15 illustrates how the side-specific model may be used in planning studies to predict crossing difficulty and determine the corresponding level of service. The variables in the model are shown in the first column. The values of the variables for this sample site are shown in the next column. Please note that the value for Constant is 1 and the value for 65 Years or Older Dummy is percentage. The conversion column is there to put the values in units appropriate for the model. In this case, only the percent of pedestrians who are 65 years or older is converted to get a share value. In real applications, some of these variables may be measured on a daily basis. If that is the case, these variables also need to be converted appropriately. If total volume is measured as average annual daily traffic, for example, an appropriate conversion factor is required to get a particular hourly rate. The last column is the product of the Coefficients and Conversion columns. 
Table 15. Illustration of Side-Specific Model

\begin{tabular}{|c|c|c|c|c|}
\hline Variables & Coefficients & Values & Conversion & Difficulty \\
\hline Constant & -2.4778 & 1 & 1 & -2.48 \\
\hline Share 65 Years Or Older & 0.4937 & 25 & 0.25 & 0.12 \\
\hline Nearside Total Volume (1000 vehicles / hour) & -0.1159 & 6.0 & 6.0 & -0.70 \\
\hline Farside Total Volume (1000 vehicles / hour) & 0.2674 & 6.0 & 6.0 & 1.60 \\
\hline Nearside Turning Movements (vehicles / hour) & 0.0018 & 180 & 180 & 0.32 \\
\hline Farside Turning Movements (vehicles / hour) & 0.0013 & 180 & 180 & 0.23 \\
\hline Average Speed (miles / hour) & 0.0107 & 55 & 55 & 0.59 \\
\hline Nearside Crossing Width (feet) & -0.0852 & 36 & 36 & -3.07 \\
\hline Farside Crossing Width (feet) & 0.1241 & 36 & 36 & 4.47 \\
\hline Width Of Restricted Median (feet) & -0.0661 & 0 & 0 & 0.00 \\
\hline Width Of Painted Median (feet) & 0.0712 & 0 & 0 & 0.00 \\
\hline Crosswalk Dummy $(0-1)$ & -0.2762 & 0 & 0 & 0.00 \\
\hline Pedestrian-Signal Dummy (0-1) & -0.4930 & 0 & 0 & 0.00 \\
\hline Nearside Cycle Length (seconds) & -0.0326 & 150 & 150 & -4.89 \\
\hline Farside Cycle Length In (seconds) & 0.0610 & 150 & 150 & 9.15 \\
\hline Signal Spacing (feet) & 0.0007 & 1,000 & 1,000 & 0.70 \\
\hline Predicted Difficulty for Sample Site & \multicolumn{4}{|c|}{6.06} \\
\hline 95 Percent Confidence Interval & \multicolumn{4}{|c|}{$5.69-6.43$} \\
\hline Predicted Level of Service & \multicolumn{4}{|c|}{$\mathrm{F}$} \\
\hline
\end{tabular}

To get the predicted level of difficulty for this site, one simply needs to add the last column up. It is 6.06 in this case. Each row in the last column may be interpreted as the contribution of each variable to the overall level of difficulty.

To determine the predicted level of service for this site, one needs a mechanism to convert this predicted level of difficulty into a particular level of service designation. Following previous practices and the breakpoints used in the sensitivity analysis, the level of service is F since the predicted level of difficulty is in the range of at least 5.5.

Taking into account prediction errors would not change the predicted level of service in this case because the entire confidence interval is located above 5.5, the breakpoint for level of service F. Using an average standard error of predictions of 0.188 and a 95 percent confidence level, the lower bound of the confidence interval would be 5.7, which is still higher than the breakpoint for level of service F.

\section{Combined}

Table 16 shows a similar illustration for the combined model. In terms of calculation, the difference is in the four characteristics that were measured by direction. For cycle length, the value is the average of the two directions. For the other three, the value is the sum of the two directions. The result is the same in this case because the directions are assumed to be symmetrical in terms of these four characteristics. 
Table 16. Illustration of Combined Model

\begin{tabular}{|l|r|r|r|r|}
\hline Variables & Coefficients & Values & Conversion & Difficulty \\
\hline Constant & -2.4778 & 1 & 1 & -2.48 \\
\hline Share 65 Years Or Older (0-1) & 0.4937 & 25 & 0.25 & 0.12 \\
\hline Total Volume (1000 vehicles / hour) & 0.0758 & 12.0 & 12 & 0.91 \\
\hline Turning Movements (vehicles / hour) & 0.0016 & 360 & 360 & 0.56 \\
\hline Average Speed (miles / hour) & 0.0107 & 55 & 55 & 0.59 \\
\hline Crossing Width (feet) & 0.0195 & 72 & 72 & 1.40 \\
\hline Width Of Restricted Median (feet) & -0.0661 & 0 & 0 & 0 \\
\hline Width Of Painted Median (feet) & 0.0712 & 0 & 0 & 0 \\
\hline Crosswalk Dummy (0-1) & -0.2762 & 0 & 0 & 0 \\
\hline Pedestrian-Signal Dummy (0-1) & -0.4930 & 0 & 0 & 0 \\
\hline Average Cycle Length (seconds) & 0.0284 & 150 & 150 & 4.26 \\
\hline Signal Spacing (feet) & 0.0007 & 1,000 & 1,000 & 0.70 \\
\hline Predicted Difficulty for Sample Site & \multicolumn{5}{|c|}{6.06} \\
\hline 95 Percent Confidence Interval & \multicolumn{5}{|c|}{ F } & $0.69-63$ \\
\hline Predicted Level of Service & \multicolumn{5}{|c|}{} \\
\hline
\end{tabular}




\section{REFERENCES}

Black, John, Michael Dunne, and Xiao-Ping Guo (1998), Effects of Urban Bunched Traffic Flow on Pedestrian Delay, Traffic and Transportation Studies: Proceedings Of ICTTS '98, 598-607.

Bowman, Brian L., and Robert L. Vecellio (1994), Pedestrian Walking Speeds and Conflicts at Urban Median Locations, Transportation Research Record 1438: 67-73.

Center for Urban Transportation Research (CUTR) (2001). Pedestrian Quality of Service for Mid-block Crossing: An Issue Paper. University of South Florida, Tampa, Florida.

City of Auburn (1998). Auburn 2020: Imaging a Better Community. Auburn, Alabama.

Coffin, A and J. Morrall (1995), Walking Speeds of Elderly Pedestrians at Crosswalks, Transportation Research Record 1487: 63-67.

Dipletro, C.M., and L.E. King (1970), Pedestrian Gap Acceptance, Highway Research Record 308: 80-91.

Dixon, Linda B. (1996), Bicycle and Pedestrian Level-of-service Performance Measures and Standards for Congestion Management Systems, Transportation Research Record 1538: $1-9$.

Dunn, R.C.M., and R.L. Pretty (1984), Mid-block Pedestrian Crossings: An Examination of Delay, ARRB Proceedings 12: 118-127.

Federal Highway Administration (FHWA) (1988), Manual on Uniform Traffic Control Devices, Department of Transportation, Washington, D.C.

FHWA (2000), Hazard Index for Assessing Pedestrian and Bicyclist Safety at Intersections, Solicitation No. DTFH61-00-R-00071.

Florida Department of Transportation (FDOT) (2000), 1998 Level of Service Handbook, http://www.dot.state.fl.us/planning/Systems/sm/los/los_sw2.htm.

FDOT (1999), Florida Pedestrian Facilities Planning and Design Handbook, http://www.dot.state.fl.us/safety/ped bike/ped bike_standards.htm.

Gallin, N. (2001), Quantifying Pedestrian Friendliness: Guidelines for Assessing Pedestrian Level of Service, Road and Transport Research 10: 47-55.

Goldschmid, J. (1977), Pedestrian Delay and Traffic Management, TRRL Supplementary Report SR 356, Transport and Road Research Laboratory, Crowthorne, UK. 
Greene, William H. (1990). Econometric Analysis, Macmillan Publishing Company, New York, NY.

Guttenplan, Martin, Bruce W. Landis, Linda Carter, and Douglas S. McLeod (2001). Multi-Modal Level of Service (LOS) Analysis at a Planning Level, TRB Paper No. 013084.

Harkey, David L., Donald W. Reinfurt, Matthew Knuiman, J. Richard Stewart, and Alex Sorton (1998), Development of the Bicycle Comparability Index: A Level of Service Concept, FHWA-RD-98-072, http://www.hsrc.unc.edu/oldhsrc/research/pedbike/98072.

Harrell, W.A., and Tami Bereska (1992), Gap Acceptance by Pedestrians, Perceptual and Motor Skills 75: 432-434.

Hensher, David A. (1991), Hierarchical Stated Response Designs - An Application to Bus User Preferences, The Logistics and Transportation Review 26: 299-323.

Highway Research Board (HRB) (1966). Highway Capacity Manual 1965, Special Report 87, National Research Council, Washington, D.C.

Hine, Julian; and John Russell (1993), Traffic Barriers and Pedestrian Crossing Behavior. Journal of Transport Geography 1: 230-239.

Homburger, Wolfgang S., Jerome W. Hall, Boy C. Loutzenheiser, and William R. Reilly (1996). Fundamentals of Traffic Engineering, $14^{\text {th }}$ Edition, Institute of Transportation Studies, University of California, Berkeley.

Hoxie, R.E., and L.Z. Rubenstein (1994), Are Older Pedestrians Allowed Enough Time to Cross Intersections Safely? Journal of the American Geriatrics Society 42: 241-244.

Hunt, J.G., and S.L. Williams (1982), Delays to Pedestrians Crossing the Road at a Random Point, Traffic Engineering and Control 23: 216-221.

Hunt, John, and Jalal Abduljabbar (1993), Crossing the Road: A Method of Assessing Pedestrian Crossing Difficulty, Traffic Engineering and Control 34: 526-532.

Hunt, J.G., and J.D. Griffiths (1991), Pedestrian Crossing Criteria Research: Random Crossing Model. TRRL Contract Report CR 248, Transport and Road Research laboratory, Crowthorne, UK.

Hunt, J. (2000), Developments in the Layout and Operation Of Mid-block Pedestrian Crossings in the United Kingdom, In 2nd International Symposium on Highway Geometric Design, ed. by Brilon, W and Krammes, R, pp. 586-597.

Jaskiewicz, Frank (2000), Pedestrian Level of Service Based on Trip Quality, Transportation Research Circular E-C019: G-1/1-14. 
Kennedy, Peter (1985). A Guide to Econometrics, $2^{\text {nd }}$ Ed., MIT Press, Cambridge, Massachusetts.

Khisty, J. C. (1994), Evaluation of Pedestrian Facilities: Beyond the Level-of-Service Concept, Transportation Research Record 1438: 45-50.

Karachepone, John (2000), Multi-modal Level of Service: Concepts/Approach to Transit Quality of Service Methodology, Technical Memorandum, Kittleson and Associates, Inc.

Kita, Hideyuki (2000), Level-of-Service Measure of Road Traffic Based on Driver's Perception, Transportation Research E-Circular E-C018: 53-62.

Kittelson, Wayne K. (2000), Historical Overview of the Committee on Highway Capacity and Quality of Service, Transportation Research Circular E-C018: 5-16.

Landis, Bruce W., Venkat R. Vattikuti, and Michael T. Brannick (1997), Real-time Human Perceptions: Toward a Bicycle Level of Service, Transportation Research Record 1538: 119-126.

Landis, Bruce W., Russell M. Ottenberg, and Venkat R. Vattikuti (1999), The Roadside Pedestrian Environment: Toward a Comprehensive Level of Service, Transportation Research Board Paper No. 990570.

Landis, Bruce W., Venkat R. Vattikuti, Russell M. Ottenberg, Douglas S. McLeod, and Martin Guttenplan (2001), Modeling the Roadside Walking Environment: A Pedestrian Level of Service.

Louviere, Jordan J., and George Woodworth (1983), Design and Analysis of Simulated Consumer Choice or Allocation Experiments: An Approach Based on Aggregate Data, Journal of Marketing Research 20: 350-367.

Madanat, S.M, M.J. Cassidy, and W.H. Wan Ibrahim (1994), A Methodology for Determining Level of Service Categories Using Attitudinal Data, Transportation Research Board Preprint 940093.

McLeod, Douglas S. (1999), Concepts for Multimodal Quality of Service Analysis, Florida Department of Transportation.

McLeod, Douglas S. (2000), Multimodal Arterial Level of Service, Florida Department of Transportation.

Momer, KF, and Khan, AM. (1988), Airport Landside Level of Service Estimation: Utility Theoretical Approach, Transportation Research Record 1199: 33-40.

Ndoh, Ngoe N., and Norman J. Ashford (1994), Evaluation of Transportation Level of Service Using Fuzzy Sets, Transportation Research Board 1461: 31-37. 
Noland, Robert B., Kenneth A. Small, Pia Maria Koskenoja, and Xuehao Chu (1997), Simulating Travel Reliability, Regional Science and Urban Economics 28: 535-564.

Oudejans, Raoul R.D., Claire F. Michaels, Bertina van Dort, and Erik J.P. Frissen (1996), To Cross or Not to Cross: The Effect of Locomotion on Street Crossing Behavior, Ecological Psychology 8: 259-267.

Ouwersloot, Hans, and Piet Rietveld (1996), Stated Choice Experiments with Repeated Observations, Journal of Transport Economics and Policy 30: 203-212.

Palamarthy, Srinivas, Hani S. Mahmassani, and Randy B. Machemehl (1994), Models of Pedestrian Crossing Behavior at Signalized Intersections, Research Report 1296-1, Center for Transportation Research, University of Texas at Austin.

Pecheux, Kelly Klaver, Martin T. Pietrucha, and Paul P. Jovanis (2000), User Perception of Level of Service at Signalized Intersections: Methodological Issues, Transportation Research E-Circular E-C018: 322-335.

Pushkarev, B., and J. Zupan (1975), Urban Space for Pedestrians, MIT Press, Cambridge, Mass.

Revelt, David, and Kenneth Train (1998), Mixed Logit with Repeated Choices: Households' Choices of Appliance Efficiency Level, The Review of Economics and Statistics 80: 647-657.

Roess, Roger P., and William R. McShane (1987), Changing Concepts of Level of Service in the 1985 Highway Capacity Manual: Some Examples, ITE Journal, May, 2731.

Rouphail, Nagu M., Joseph E. Hummer, Joseph S. Milazzo II, and D. Patrick Allen (1998), Recommended Procedures for Chapter 13, "Pedestrians, " of the HCM, FHWARD-98-107.

Russell, John, and Julian Hine (1996), The Impact of Traffic on Pedestrian Behavior, Traffic Engineering and Control 37: 16-18.

Transportation Research Board (TRB) (1998), Highway Capacity Manual, Special Report 209, $3^{\text {rd }}$ Edition, National Research Council, Washington, D.C.

Wellar, Barry (1998), Walking Security Index-Final Report, Department of Geography, University of Ottawa, Canada. 